NUREG/CR-6251

BMI-2180

\title{
Stainless Steel Submerged Arc Weld Fusion Line Toughness
}

Manuscript Completed: November 1994

Date Published: April 1995

Prepared by

A. R. Rosenfield, P. R. Held, G. M. Wilkowski

\section{DISCLAIMER}

Battelle

505 King Avenue

Columbus, $\mathrm{OH} 43201$

\section{Prepared for}

Division of Engineering Technology

Office of Nuclear Regulatory Research

U.S. Nuclear Regulatory Commission

Washington, DC 20555-0001

NRC Job Code B5702
This report was prepared as an account of work sponsored by an agency of the United States Government. Neither the United States Government nor any agency thereof, nor any of their employees, makes any warranty, express or implied, or assumes any legal liability or responsibility for the accuracy, completeness, or usefulness of any information, apparatus, product, or process disclosed, or represents that its use would not infringe privately owned rights. Reference herein to any specific commercial product, process, or service by trade name, trademark, manufacturer, or otherwise does not necessarily constitute or imply its endorsement, recommendation, or favoring by the United States Government or any agency thereof. The views and opinions of authors expressed herein do not necessarily state or reflect those of the United States Government or any agency thereof. 


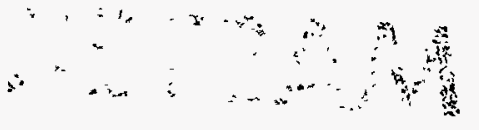




\section{DISCLAIMER}

Portions of this document may be illegible in electronic image products. Images are produced from the best available original document. 
Abstract

\section{ABSTRACT}

This effort evaluated the fracture toughness of austenitic steel submerged-arc weld (SAW) fusion lines. The incentive was to explain why cracks grow into the fusion line in many pipe tests conducted with cracks initially centered in SAWs. The concern was that the fusion line may have a lower toughness than the SAW.

It was found that the fusion line, $\mathrm{J}_{\mathrm{Ic}}$ was greater than the SAW toughness but much less than the base metal. Of greater importance may be that the crack growth resistance $\left(J_{D}-R\right)$ of the fusion line appeared to reach a steady-state value, while the SAW had a continually increasing $J_{D}-R$ curve. This explains why the cracks eventually turn to the fusion line in the pipe experiments. A method of incorporating these results would be to use the weld metal J-R curve up to the fusion-line steady-state $\mathrm{J}$ value. These results may be more important to LBB analyses than the ASME flaw evaluation procedures, since there is more crack growth with through-wall cracks in LBB analyses than for surface cracks in pipe flaw evaluations. 


\section{CONTENTS}

Page

EXECUTIVE SUMMARY $\ldots \ldots \ldots \ldots \ldots \ldots \ldots \ldots \ldots \ldots \ldots \ldots \ldots$

ACKNOWLEDGMENTS $\ldots \ldots \ldots \ldots \ldots \ldots \ldots \ldots \ldots \ldots \ldots \ldots \ldots \ldots \ldots$

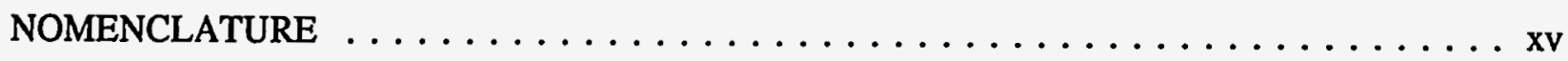

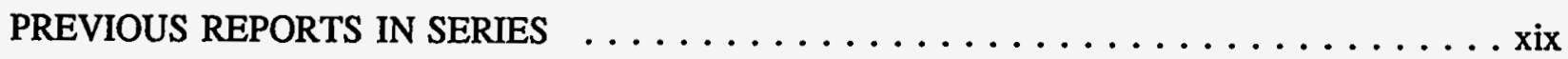

1.0 INTRODUCTION $\ldots \ldots \ldots \ldots \ldots \ldots \ldots \ldots \ldots \ldots \ldots \ldots \ldots \ldots \ldots \ldots$

1.1 Background and Incentives for the Project $\ldots \ldots \ldots \ldots \ldots \ldots \ldots \ldots \ldots$

1.2 Report Outline ............................ 1-8

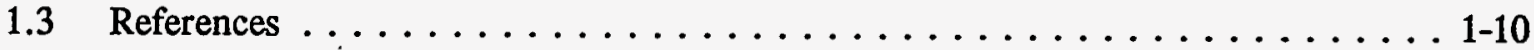

2.0 EXPERIMENTAL PROGRAM $\ldots \ldots \ldots \ldots \ldots \ldots \ldots \ldots \ldots \ldots \ldots \ldots$

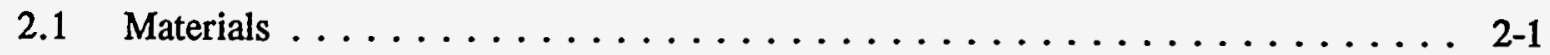

2.1.1 Preliminary Base Metal Experiments (Steel DP2-F33-4) . . . . . . . . 2-1

2.1.2 Flat-Notch Fusion-Line Experiments (Weld DP2-A53W) . . . . . . . . 2-1

2.1.3 Slant-Notch Fusion-Line Experiments (Weld DP2-A8W4) . . . . . . . . 2-4

2.2 Charpy Tests $\ldots \ldots \ldots \ldots \ldots \ldots \ldots \ldots \ldots \ldots \ldots \ldots \ldots \ldots \ldots$

2.3 Fracture Toughness Tests $\ldots \ldots \ldots \ldots \ldots \ldots \ldots \ldots \ldots \ldots \ldots \ldots$

2.3.1 Background on Slant-Notch Specimen Testing $\ldots \ldots \ldots \ldots \ldots \ldots$. . . .

2.3 .2 Procedures . . . . . . . . . . . . . . . . . . . 2-11

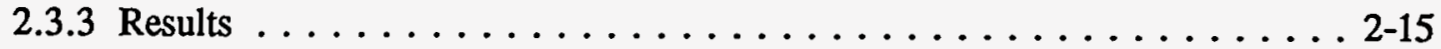

2.3.3.1 TP304 Base Metal Experiments (Steel DP2-F33-4) . . . . . . . . 2-15

2.3.3.2 Flat-Notch Fusion-Line Experiments (Weld DP2-A53W1) . . . . 2-17

2.3.3.3 Slant-Notch Fusion-Line Experiments (Weld DP2-A8W4) . . . . 2-20

2.4 Discussion on Integration of Specimen Test Results

with Past Results ......................... 2-20

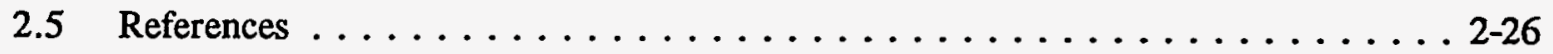

3.0 SUMMARY AND CONCLUSIONS $\ldots \ldots \ldots \ldots \ldots \ldots \ldots \ldots \ldots \ldots \ldots$

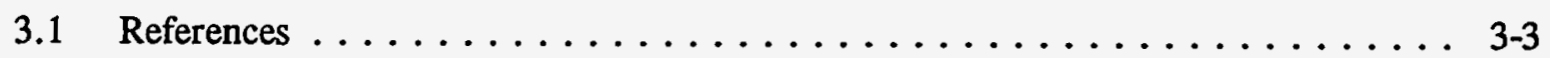

APPENDIX A - Detailed Data from $C(T)$ Tests $\ldots \ldots \ldots \ldots \ldots \ldots \ldots \ldots$ 


\section{LIST OF FIGURES}

Figure

Page

1.1 IGSCC in 102-mm (4-inch) diameter BWR recirculation bypass line

(Loop B of the Quad Cities II reactor) . . . . . . . . . . . . . . . . . . 1-1

1.2 IGSCC in Nine-Mile Point Plant; 711-mm (28-inch) diameter main recirculation

line with a crack growing into the weld metal . . . . . . . . . . . . . . 1-2

1.3 IGSCC in Nine Mile Point Plant; 711-mm (28-inch) diameter main recirculation

line with cracks growing along the fusion line $\ldots \ldots \ldots \ldots \ldots \ldots \ldots \ldots \ldots$

1.4 Stainless steel base metal and weld J-R curve data from DTRC, Ref. $1.6 \ldots \ldots$. . . . 1-4

1.5 Comparison of TP304 base metal and SAW J-R curves at $288 \mathrm{C}$

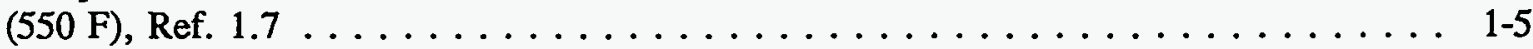

1.6 Crack propagation in base metal, HAZ remote from fusion line, and weld

metal in single-edge notch tension specimens at $288 \mathrm{C}(550 \mathrm{~F})$, Ref. $1.7 \ldots \ldots \ldots$

1.7 Crack propagation behavior at $288 \mathrm{C}(550 \mathrm{~F})$ in 152-mm (6-inch) and 406-mm

(16-inch) diameter TP304 pipe experiments with a circumferential through-wall

crack initially in the center of a SAW, Ref. $1.7 \ldots \ldots \ldots \ldots \ldots \ldots \ldots \ldots$

1.8 Crack propagation at $288 \mathrm{C}(550 \mathrm{~F})$ along fusion line of a TP316 SAW

from a 711-mm (28-inch) diameter pipe test, Ref. 1.10 (weld

crown ground off prior to test) $\ldots \ldots \ldots \ldots \ldots \ldots \ldots \ldots \ldots \ldots \ldots$

1.9 Crack propagation at $288 \mathrm{C}(550 \mathrm{~F})$ along fusion line of $406-\mathrm{mm}$ (16-inch)

diameter pipe with initial circumferential surface crack in center of a SAW $\ldots . . . .1-9$

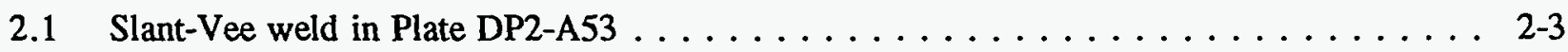

2.2 Example of K-weld preparation with out-of-plane bulging of the

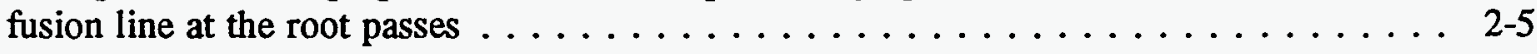

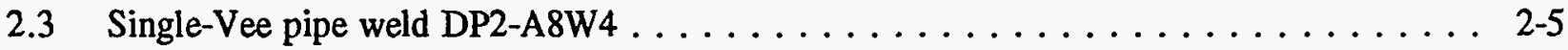

2.4 Orientation of Charpy specimens $\ldots \ldots \ldots \ldots \ldots \ldots \ldots \ldots \ldots \ldots \ldots$

2.5 Schematic diagram of compact specimen test geometry $\ldots \ldots \ldots \ldots \ldots \ldots \ldots$

2.6 Initiation data for a variety of steels containing inclined precracks $\ldots \ldots \ldots \ldots$

2.7 Relation between opening-mode and shear-mode toughness $\ldots \ldots \ldots \ldots \ldots \ldots$. . . . . . .

2.8 Effect of angle of crack plane on nominal fracture toughness $\ldots \ldots \ldots \ldots \ldots \ldots$ 


\section{LIST OF FIGURES}

Figure

2.9 Comparison of toughness parameters for the slant-notch specimens $\ldots \ldots \ldots \ldots$. . . . . 2-14

$2.10 \mathrm{~J}$-resistance curves for flat- and slant-notch specimens

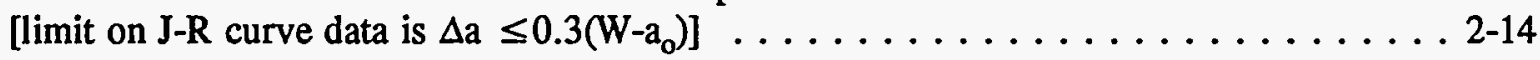

2.11 Mixed-mode failure envelope for stainless steel safe end DP2-F33 $\ldots \ldots \ldots \ldots$. . . 2-17

2.12 Load-displacement curves for flat-notch, fusion-line specimens $\ldots \ldots \ldots \ldots \ldots$. . . . .

$2.13 \mathrm{~J}$-resistance curves for flat-notch, fusion-line specimens from DP2-A53W

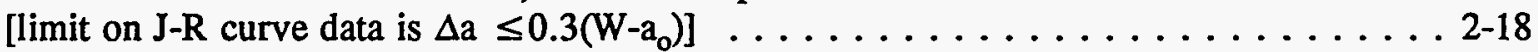

2.14 Fracture surfaces of flat-notch specimens $\ldots \ldots \ldots \ldots \ldots \ldots \ldots \ldots \ldots$

2.15 Low-magnification profiles of centerlines of flat-notch, fusion-line specimens to illustrate importance of precise crack-tip location on initiation toughness $\ldots \ldots \ldots 2-21$

2.16 Load-displacement curves of slant-notch, fusion-line specimens $\ldots \ldots \ldots \ldots \ldots$. . . . . 22

$2.17 \mathrm{~J}$-resistance curves of slant-notch, fusion-line specimens

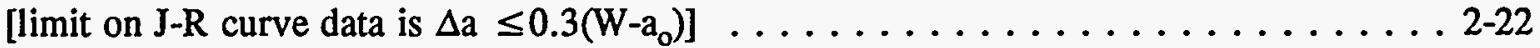

2.18 High-magnification (100X) profile of slant-notch fusion-line specimen DP2-A8W-1 $\ldots$ 2-23

2.19 Comparison of $\mathrm{J}_{\text {nom }}$ resistance curves for base metal, weld, and fusion line $\ldots \ldots \ldots 2-23$

$2.20 J_{D}-R$ curves for austenitic SAW C(T) specimens of various planform sizes (Ref. 2.14) . 2-24 


\section{LIST OF TABLES}

$\underline{\text { Table }}$

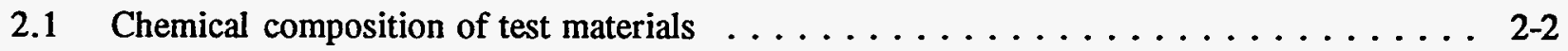

2.2 Quasi-static mechanical properties at $288 \mathrm{C}(550 \mathrm{~F}) \ldots \ldots \ldots \ldots \ldots$

2.3 Typical self-shielded flux-cored arc-welding procedures for stainless steels

using stainless steel electrodes (from AWS Welding Handbook - Volume 2) . . . . . 2-3

2.4 Charpy data for weld fusion lines $\ldots \ldots \ldots \ldots \ldots \ldots \ldots \ldots$

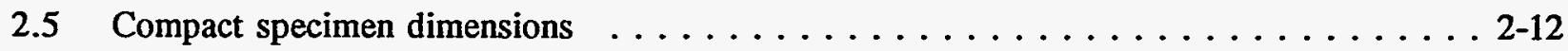

2.6 Summary of compact specimen data $\ldots \ldots \ldots \ldots \ldots \ldots \ldots \ldots \ldots$

3.1 Crack growth resistance parameters $\ldots \ldots \ldots \ldots \ldots \ldots \ldots \ldots \ldots \ldots \ldots$

A.1a J-resistance test data for Compact Specimen A53W1-FL-1 tested at $288 \mathrm{C}(550 \mathrm{~F})$;

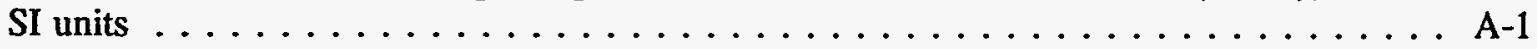

A.1b J-resistance test data for Compact Specimen A53W1-FL-1 tested at $288 \mathrm{C}(550 \mathrm{~F})$;

English units . ......................... A-2

A.2a J-resistance test data for Compact Specimen A53W1-FL-2 tested at $288 \mathrm{C}(550 \mathrm{~F})$;

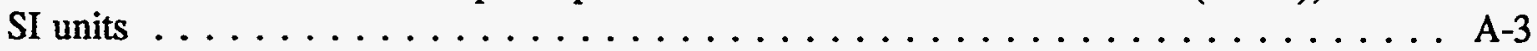

A.2b J-resistance test data for Compact Specimen A53W1-FL-2 tested at $288 \mathrm{C}(550 \mathrm{~F})$;

English units . . . . . . . . . . . . . . . . . A $\ldots \ldots$

A.3a J-resistance test data for Compact Specimen A53W1-FL-3 tested at $288 \mathrm{C}(550 \mathrm{~F})$;

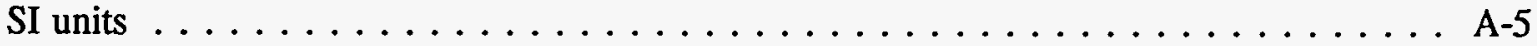

A.3b J-resistance test data for Compact Specimen A53W1-FL-3 tested at $288 \mathrm{C}(550 \mathrm{~F})$;

English units . .......................... A 6

A.4a J-resistance test data for Compact Specimen A53W1-FL-4 tested at $288 \mathrm{C}$ (550 F);

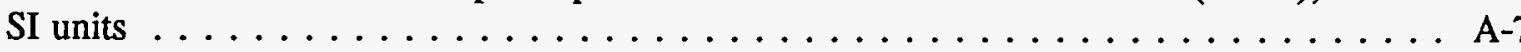

A.4b J-resistance test data for Compact Specimen A53W1-FL-4 tested at $288 \mathrm{C}$ (550 F);

English units . . . . . . . . . . . . . . . . . . .

A.5a J-resistance test data for Compact Specimen A53W1-FL-5 tested at $288 \mathrm{C}$ (550 F);

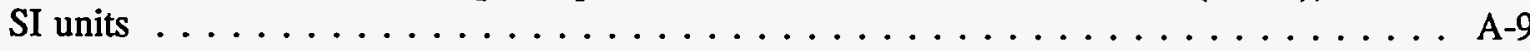




\section{LIST OF TABLES}

Table

$\underline{\text { Page }}$

A.5b J-resistance test data for Compact Specimen A53W1-FL-5 tested at $288 \mathrm{C}(550 \mathrm{~F})$;

English units

A.6a Test data from C(T) Specimen A8W4-FL-1 (Slant-notch with angle of 55 degrees from specimen face to follow fusion-line, test at $288 \mathrm{C}$; SI units)

A.6b Test data from C(T) Specimen A8W4-FL-1 (Slant-notch with angle of 55 degrees from specimen face to follow fusion-line, test at $288 \mathrm{C}$; English units) $\ldots \ldots \ldots \ldots$ A-12

A.7a Test data from C(T) Specimen A8W4-FL-2 (Slant-notch with angle of 55 degrees from specimen face to follow fusion-line, test at $288 \mathrm{C}$; SI units) $\ldots \ldots \ldots \ldots \ldots$ A-13

A.7b Test data from C(T) Specimen A8W4-FL-2 (Slant-notch with angle of 55 degrees from specimen face to follow fusion-line, test at $288 \mathrm{C}$; English units) $\ldots \ldots \ldots \ldots$ A-14

A.8a Test data from C(T) Specimen A8W4-FL-3 (Slant-notch with angle of 55 degrees from specimen face to follow fusion-line, test at $288 \mathrm{C}$; SI units) . . . . . . . A A-15

A.8b Test data from C(T) Specimen A8W4-FL-3 (Slant-notch with angle of 55 degrees from specimen face to follow fusion-line, test at $288 \mathrm{C}$; English units) $\ldots \ldots \ldots \ldots$ A-16

A.9a Test data from C(T) Specimen A8W4-FL-5 (Slant-notch with angle of 55 degrees from specimen face to follow fusion-line, test at $288 \mathrm{C}$; SI units) $\ldots \ldots \ldots \ldots \ldots$ A-17

A.9b Test data from C(T) Specimen A8W4-FL-5 (Slant-notch with angle of 55 degrees from specimen face to follow fusion-line, test at $288 \mathrm{C}$; English units) $\ldots \ldots \ldots \ldots$ A-18

A.10a J-resistance test data for Compact Specimen F33-4-SS-1 tested at $288 \mathrm{C}$ (550 F); SI units . . . . . . . . . . . . . . . . . . . . . . . A-19

A.10b J-resistance test data for Compact Specimen F33-4-SS-1 tested at 288 C (550 F); English units .

A.11a J-resistance test data for Compact Specimen F33-4-SS-2 tested at $288 \mathrm{C}$ (550 F); SI units

A.11b J-resistance test data for Compact Specimen F33-4-SS-2 tested at $288 \mathrm{C}(550 \mathrm{~F})$; English units

A.12a Test data from C(T) Specimen F33-4-SSS-1 (Slant-notch with angle of 55 degrees from specimen face, test at $288 \mathrm{C}$; SI units) 


\section{LIST OF TABLES}

Table

Page

A.12b Test data from C(T) Specimen F33-4-SSS-1 (Slant-notch with angle of 55 degrees from specimen face, test at $288 \mathrm{C}$; English units $\ldots \ldots \ldots \ldots \ldots \ldots \ldots$. . . . . . . . .

A.13a Test data from C(T) Specimen F33-4-SSS-2 (Slant-notch with angle of 55 degrees from specimen face, test at $288 \mathrm{C}$; SI units) $\ldots \ldots \ldots \ldots \ldots \ldots \ldots \ldots$

A.13b Test data from C(T) Specimen F33-4-SSS-2 (Slant-notch with angle of 55 degrees from specimen face, test at $288 \mathrm{C}$; English units) $\ldots \ldots \ldots \ldots \ldots \ldots \ldots$ A-26 


\section{EXECUTIVE SUMMARY}

The objective of this effort was to evaluate the fracture toughness of the fusion line of austenitic steel submerged arc welds. The incentive was to explain why the cracks grew into the fusion line in many of the pipe tests which were conducted with cracks initially in the center of the weld. The concern is that the fusion line may have a much lower toughness than the submerged arc weld metal. Since the submerged arc weld metal toughness is considered the lowest toughness for pipe flaw evaluation in the ASME Section XI austenitic pipe flaw evaluation criteria, and would typically be used in LBB evaluations, the implication of this work is significant.

To conduct this evaluation, Charpy V-notch and compact tension [C(T)] specimens were fabricated from two different welds. One weld was a standard single-Vee weld from a girth-welded pipe, and the other was a slant-Vee weld from a plate weld that had one of the fusion lines perpendicular to the plate surface. The standard single-Vee weld $C(T)$ specimens had the notch machined along the fusion line, i.e., they had a slant notch. The slant-Vee weld $C(T)$ specimens had standard (flat) notches machined along the fusion line, which was perpendicular to the plate face. The $C(T)$ specimens were tested at $288 \mathrm{C}(550 \mathrm{~F})$ at quasi-static monotonic loading rates. Charpy specimens were tested at room temperature and $288 \mathrm{C}(550 \mathrm{~F})$. Data for cracks in the center of the weld and in the base metal were available from previous work for comparison with results in this program.

The results showed that:

(1) The value of toughness determined at the fusion line using a sharp crack specimen is highly sensitive to the crack tip location relative to the fusion line. This result was expected.

(2) The $J_{1 \mathrm{~mm}}$ values calculated from the Charpy energy data using the ASME Section XI Appendix $H$ correlation were less than the $C(T)$ specimen $J_{I c}$ values. Hence, the ASME Charpy energy correlation can be used, but it may be very conservative, e.g., by a factor of 9 in one case.

(3) From the data developed in this report, the initiation toughness of the stainless steel base metal is much higher than determined from either the SAW or the fusion line. The fusion-line initiation toughness $J_{I c}$ was greater than that at the SAW centerline.

(4) The crack growth resistance at the fusion line appeared to reach a steady state value, while the SAW J-R curve had an increasing $J_{D}-R$ curve. This result may explain why in the pipe experiments, the cracks eventually turn and grow along the fusion line. Also, this result implies that the weld metal J-R curve should be used up to the fusion-line steady state J value for stainless steel welds. A large $C(T)$ specimen test with the initial crack in the fusion line would help to confirm this conclusion. 
(5) If the crack tip is slightly off the fusion line in the base metal, the initiation toughness may be high, but the crack can quickly grow into the lower toughness fusion line and produce a decreasing J-R curve. Such a decreasing toughness curve has not been observed when testing homogeneous specimens.

(6) The most important conclusion is that the fusion-line J-R curve results can have an impact on the ASME Section XI austenitic pipe flaw evaluation criteria and LBB analyses for wrought and probably cast stainless steels. In the past, the weld metal toughness has been the limiting toughness; whereas the fusion line and heat-affected-zone toughness have been given little attention.

Other factors that could also force the crack to follow the fusion line are: the center of the weld in most of the pipe experiments was thicker than the pipe due to the weld crown being left on. The crack may want to turn to the root of the weld where the pipe wall is thinner. Furthermore, there is a slight stress concentration at the toe of the weld crown. It has also been observed that on the inside of the pipe, the crack will go to either the toe of the weld or to the counterbore. The toe of the weld and counterbore are slight stress risers, which would help to guide the crack, like using side grooves in a laboratory specimen. However, in one pipe experiment the weld crown was removed, and the crack still followed the fusion line. Hence, the presence of a weld crown may help to make the crack turn to the fusion line, but it is not a sufficient condition to cause crack extension in the fusion line. Therefore, the fusion-line toughness aspect is relevant to all austenitic piping welds, whether the weld crown is ground off or not. Finally, as noted in prior work, the effect of residual stresses on ductile fracture in stainless steel pipe welds is not significant.

A final relative comparison involved comparing results from this program with those from experiments from the Degraded Piping Program. The implication from the comparison of the weld metal and fusion line crack-tip-opening angle data from single-edge notched tension, SEN(T), specimens was that the fusion-line toughness was a factor of 3 less than that of the weld even at small amounts of crack growth. The lower toughness of the fusion line at small amounts of crack growth was not observed in the work performed in this effort. A contributing factor may be the direction of crack growth in the SEN(T) versus $C(T)$ specimens. In the $C(T)$ tests performed in this effort, the crack is growing as a through-wall crack parallel to the weld; whereas, for the past SEN(T) specimens, the crack was growing as a surface crack. Conducting tests in the through-thickness or radial direction with $\mathrm{SEN}(\mathrm{T})$ or bend-bar specimens might help to clarify this discrepancy. 


\section{ACKNOWLEDGMENTS}

This work was supported by the U.S. Nuclear Regulatory Commission through the Materials Engineering Branch of the Office of Nuclear Regulatory Research as part of the Short Cracks in Piping and Piping Welds program under Contract No. NRC-04-90-069. Mr. A. Hiser was the NRC program manager during most of this work. Mr. Michael Mayfield is the current program manager.

We would like to thank others at Battelle who have helped in these efforts. Technicians who have contributed to the efforts are: Mr. G. Wall, Mr. P. Mincer, and Mr. R. Pratt. Other contributing researchers were Dr. C. Marschall and Mr. R. Tenaglia. We thank Ms. Carolyn Pepper and Mrs. V. Kreachbaum for typing this report, Dr. A. Hopper, Mr. Keith Dufrane, and Mr. R. Mesloh for editorial review comments, and Mr. D. Hayes for drafting assistance. 

$\cdots$ 


\section{NOMENCLATURE}

\section{SYMBOLS}

Crack length

$a_{o} \quad$ Initial crack length

CVN Charpy V-notch

J Path-independent J integral

$J_{D} \quad$ Deformation theory J-integral

$\mathrm{J}_{1 \mathrm{~mm}} \quad \mathrm{~J}$-integral value at $1 \mathrm{~mm}$ of crack growth

$\mathrm{J}_{\text {Ic }} \quad \mathrm{J}$ integral at onset of crack growth for pure Mode-I loading

$\mathrm{J}_{\text {IIIc }} \quad \mathrm{J}$ integral at onset of crack growth for pure Mode-III loading

$\mathrm{J}_{\mathrm{M}} \quad$ Modified J-integral

$\mathbf{J}_{\mathbf{i}} \quad$ Mode-I component of $\mathrm{J}$ integral under mixed-mode loading

$\mathrm{J}_{\mathrm{ic}} \quad$ Value of $\mathrm{J}_{\mathrm{i}}$ at onset of crack growth for mixed-mode loading

$\mathrm{J}_{\mathrm{iii}} \quad$ Mode-III component of J integral under mixed-mode loading

$J_{\text {iiic }} \quad$ Value of $J_{i i i}$ at onset of crack growth for mixed-mode loading

$J_{\text {nom }} \quad$ For a slant-notch specimen, the value of $\mathrm{J}$ calculated using the measured load/displacement/crack-growth history and assuming a flat crack whose width is equal to the specimen thickness

$\mathrm{J}_{\mathrm{ss}} \quad$ Steady-state or constant $\mathrm{J}$ value reached in a J-R curve

$\mathrm{J}_{\text {tot }} \quad$ Sum of Mode-I and Mode-III components of $\mathrm{J}$ integral

$\mathrm{k} \quad$ Parameter in mixed-mode failure criterion in Equation 2.2

U Electric potential

$\mathrm{U}_{\mathrm{o}} \quad$ Electric potential at crack initiation

W Specimen width 


\section{Nomenclature}

$\theta \quad$ Angle between specimen face and crack plane

$\sigma_{\mathrm{y}} \quad$ Yield strength

\section{ACRONYMS AND INITIALISMS}

ASME American Society of Mechanical Engineers

ASTM American Society for Testing and Materials

AWS American Welding Society

BWR Boiling Water Reactor

$\mathrm{C}(\mathrm{T}) \quad$ Compact (tension) specimen

CTOA Crack tip opening angle

DTRC David Taylor Research Center

EPRI Electric Power Research Institute, USA

GE General Electric

HAZ Heat-affected zone

IGSCC Intergranular stress corrosion cracking

IPIRG-1 First International Piping Integrity Research Group

J-R J-resistance (curve)

$J_{D}-R \quad$ Deformation theory $\mathrm{J}$-resistance (curve)

LBB Leak before break

L-C Orientation that indicates crack plane is normal to longitudinal axis $(\mathrm{L})$ and crack growth direction is circumferential $(C)$, corresponding to a circumferential through-wall crack in a pipe

L-R Orientation that indicates crack plane is normal to longitudinal axis $(\mathrm{L})$ and crack growth direction is radial ( $R)$, corresponding to a circumferential surface crack in a pipe

NDE Non-destructive evaluation 
NRC Nuclear Regulatory Commission

SAW Submerged-arc weld

SMAW Shielded-metal-arc weld

SEN(T) Single-edge notched (tension) specimen 



\section{PREVIOUS REPORTS IN SERIES}

Previous Reports from Short Cracks in Piping and Piping Welds Program

"Short Cracks in Piping and Piping Welds," First Semiannual Report, NUREG/CR-4599, Vol. 1, No. 1, March 1991.

"Short Cracks in Piping and Piping Welds," Second Semiannual Report, NUREG/CR-4599, Vol. 1, No. 2, April 1992.

"Short Cracks in Piping and Piping Welds," Third Semiannual Report, NUREG/CR-4599, Vol. 2, No. 1, September 1992.

"Short Cracks in Piping and Piping Welds," Fourth Semiannual Report, NUREG/CR-4599, Vol. 2, No. 2, February 1993.

"Short Cracks in Piping and Piping Welds," Fifth Semiannual Report, NUREG/CR-4599, Vol. 3, No. 1, October 1993.

"Short Cracks in Piping and Piping Welds," Sixth Semiannual Report, NUREG/CR-4599, Vol. 3, No. 2, March 1994.

"Effect of Dynamic Strain Aging on the Strength and Toughness of Nuclear Ferritic Piping at LWR Temperatures," NUREG/CR-6226, October 1994.

\section{Previous Related Documents from NRC's Degraded Piping Program}

"Degraded Piping Program - Phase II," Semiannual Report, NUREG/CR-4082, Vol. 1, October 1984.

"Degraded Piping Program - Phase II," Semiannual Report, NUREG/CR-4082, Vol. 2, June 1985.

"Degraded Piping Program - Phase II," Semiannual Report, NUREG/CR-4082, Vol. 3, March 1986.

"Degraded Piping Program - Phase II," Semiannual Report, NUREG/CR-4082, Vol. 4, July 1986.

"Degraded Piping Program - Phase II," Semiannual Report, NUREG/CR-4082, Vol. 5, December 1986.

"Degraded Piping Program - Phase II," Semiannual Report, NUREG/CR-4082, Vol. 6, April 1988.

"Degraded Piping Program - Phase II," Semiannual Report, NUREG/CR-4082, Vol. 7, March 1989.

"Degraded Piping Program - Phase II," Semiannual Report, NUREG/CR-4082, Vol. 8, March 1989.

"NRC Leak-Before-Break (LBB.NRC) Analysis Method for Circumferentially Through-Wall Cracked Pipes Under Axial Plus Bending Loads," Topical Report, NUREG/CR-4572, March 1986. 
Previous Reports in Series

"Elastic-Plastic Finite Element Analysis of Crack Growth in Large Compact Tension and Circumferentially Through-Wall-Cracked Pipe Specimen--Results of the First Battelle/NRC Analysis Round Robin," Topical Report, NUREG/CR-4573 September 1986.

"An Experimental and Analytical Assessment of Circumferential Through-Wall Cracked Pipes Under Pure Bending," Topical Report, NUREG/CR-4574, June 1986.

"Predictions of J-R Curves With Large Crack Growth From Small Specimen Data," Topical Report, NUREG/CR-4575, August 1986.

"An Assessment of Circumferentially Complex-Cracked Pipe Subjected to Bending," Topical Report, NUREG/CR-4687, September 1986.

"Analysis of Cracks in Stainless Steel TIG Welds," Topical Report, NUREG/CR4806, November 1986.

"Approximate Methods for Fracture Analyses of Through-Wall Cracked Pipes," Topical Report, NUREG/CR-4853, January 1987.

"Assessment of Design Basis for Load-Carrying Capacity of Weld-Overlay Repair," Topical Report, NUREG/CR-4877, February 1987.

"Analysis of Experiments on Stainless Steel Flux Welds," Topical Report, NUREG/CR-4878, February 1987.

"Experimental and Analytical Assessment of Circumferentially Surface-Cracked Pipes Under Bending," Topical Report, NUREG/CR-4872, April 1987.

Previous Related Documents from NRC's International Piping Integrity Research Group (IPIRG) Program

"Evaluation and Refinement of Leak-Rate Estimation Models," NUREG/CR-5128 Revision 1, June 1994.

"Loading Rate Effects on Strength and Fracture Toughness of Pipe Steels Used in Task 1 of the IPIRG Program," Topical Report, NUREG/CR-6098, October 1993.

"Stability of Cracked Pipe Under Inertial Stresses - Subtask 1.1 Final Report," NUREG/CR-6233, August 1994.

Previous Reports from Other NRC Programs

"Validation of Analysis Methods for Assessing Flawed Piping Subjected to Dynamic Loading," NUREG/CR-6234, August 1994. 


\subsection{INTRODUCTION}

\subsection{Background and Incentives for the Project}

The initial concern for intergranular stress corrosion cracks (IGSCC) in BWRs occurred in 1974, Refs. 1.1 and 1.2, and was for small pipe, [i.e., 102-mm (4-inch) diameter by $8.9-\mathrm{mm}$ (0.35-inch) thick]. The work in References 1.1 and 1.2 showed that cracks occurred in the HAZ in stainless steel pipe typically at a distance of 2.5 to $6.35 \mathrm{~mm}$ ( 0.1 to 0.25 inch) from the weld fusion line, see Figure 1.1. Fracture toughness evaluations of sensitized TP304 stainless steel, Refs. 1.3 and 1.4, showed that sensitized stainless steel at these distances from the fusion line had a toughness equivalent to that of unsensitized wrought stainless steel, which has very high toughness.

Around 1982, cracks were found in larger diameter recirculation line BWR piping. In particular, the 711-mm (28-inch) diameter by 30.2-mm (1.19-inch) thick pipe in the Nine Mile Point plant main recirculation line showed cracks that occasionally grew from the base metal into the weld metal, see Figure 1.2 from Reference 1.5. However, more often the cracks grew along the fusion line of the weld, see Figure 1.3.

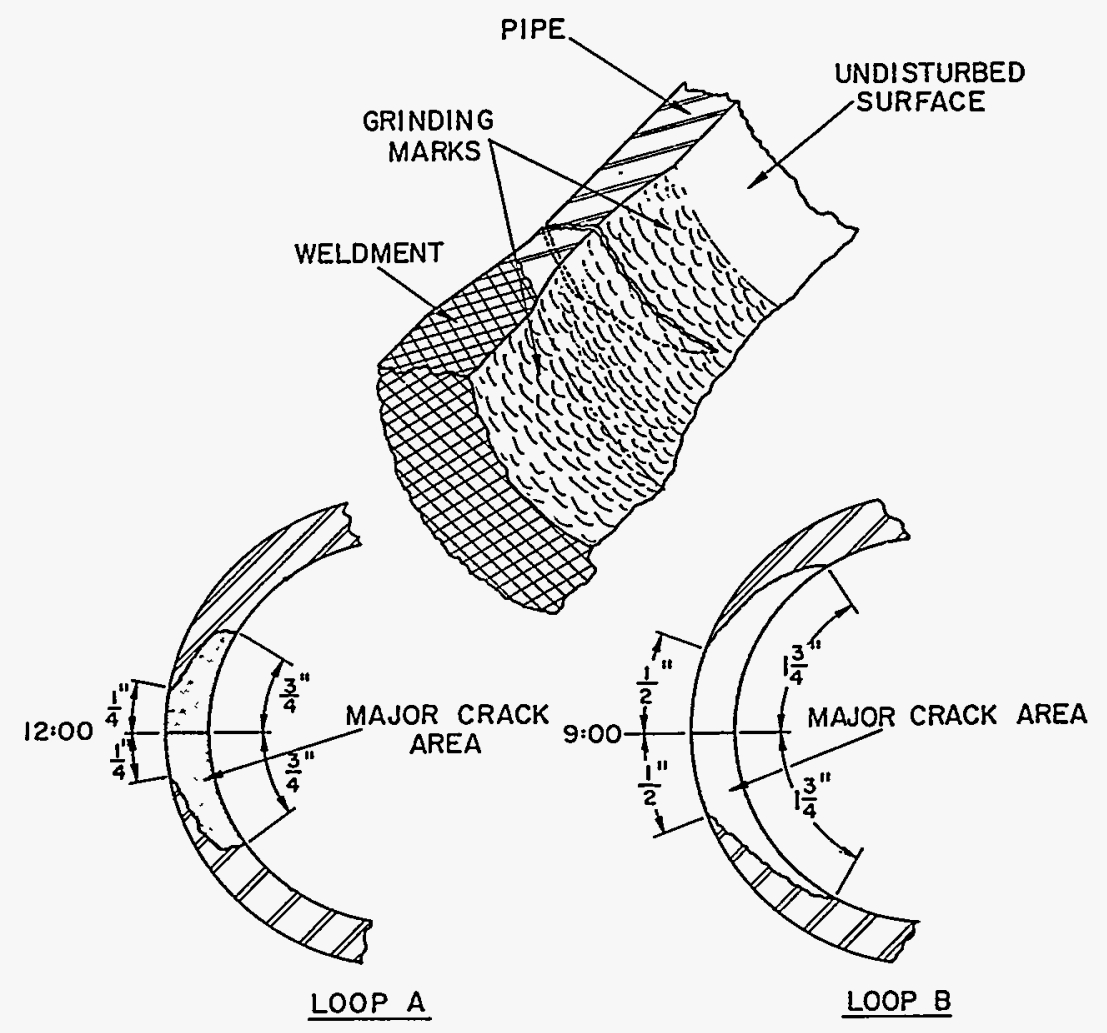

Figure 1.1 IGSCC in 102-mm (4-inch) diameter BWR recirculation bypass line (Loop B of the Quad Cities II reactor) 

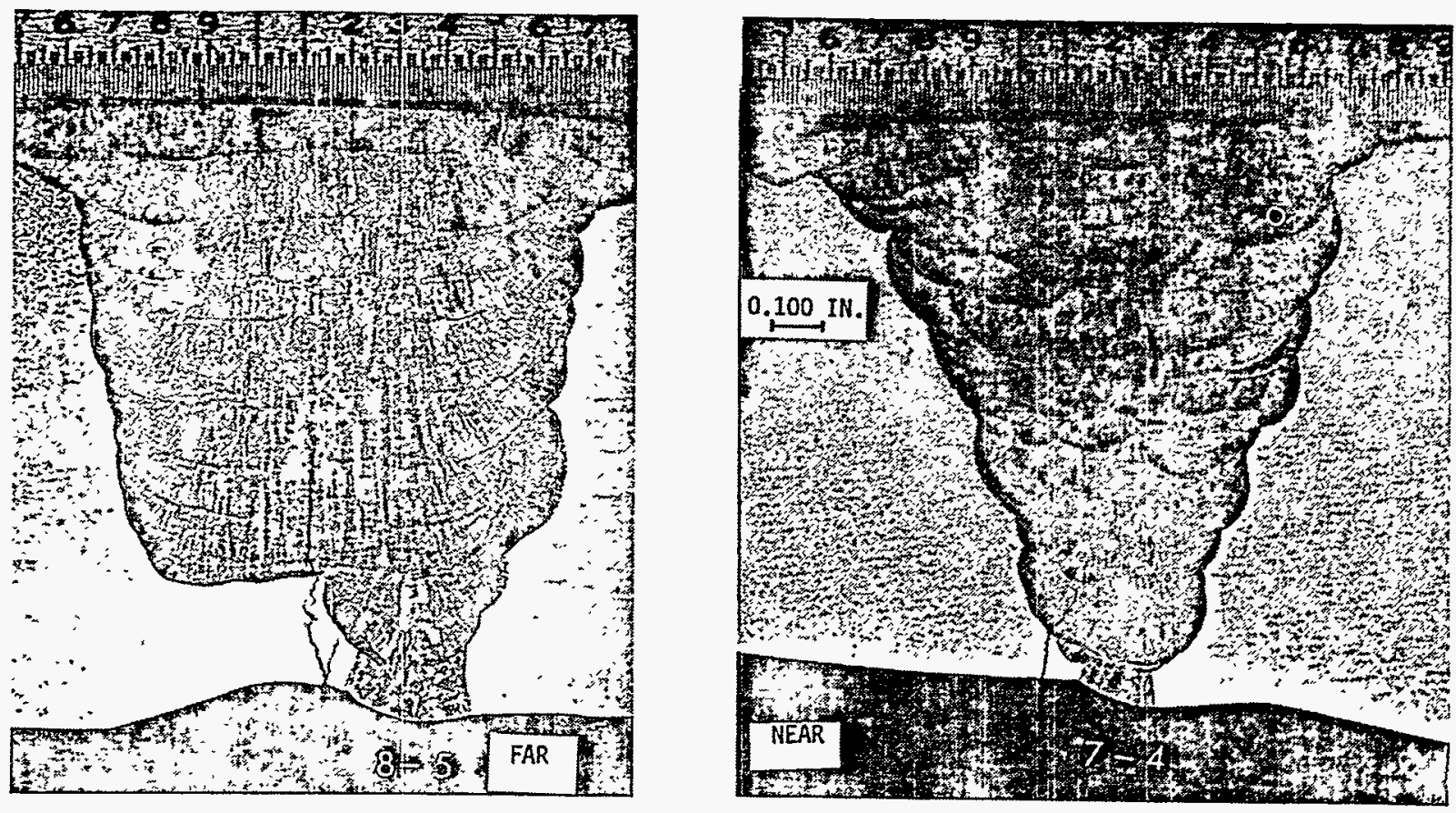

Figure 1.2 IGSCC in Nine Mile Point Plant; 711-mm (28-inch) diameter main recirculation line with a crack growing into the weld metal

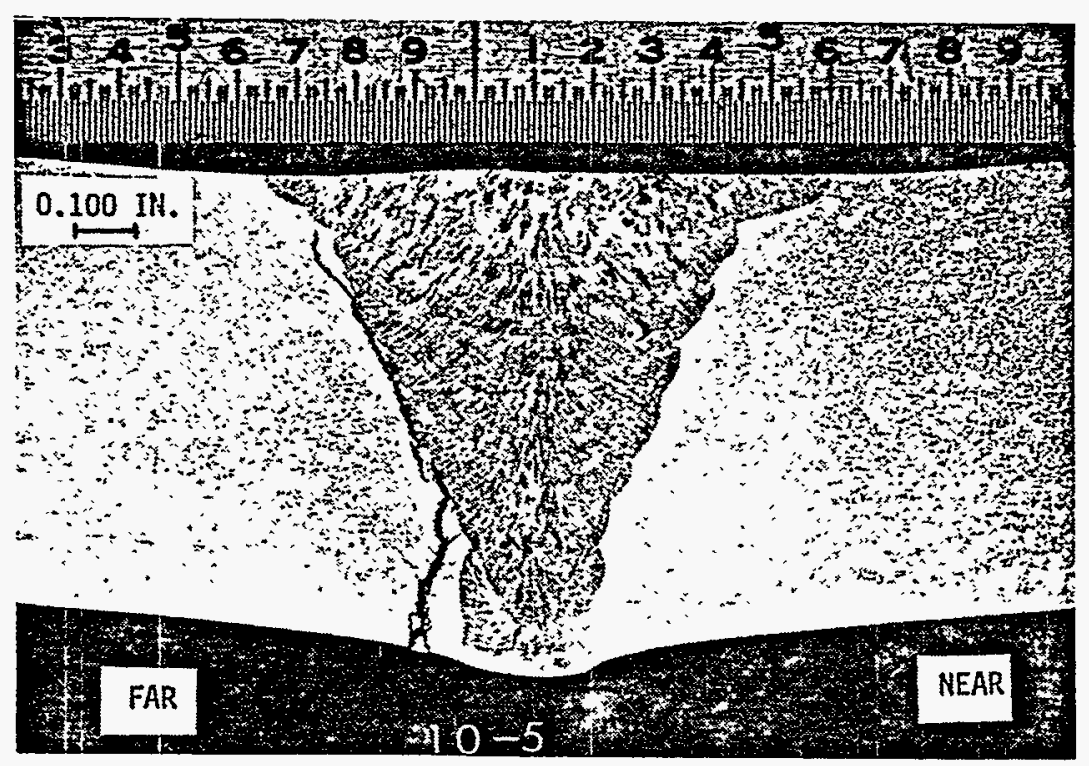

Figure 1.3 IGSCC in Nine Mile Point Plant; 711-mm (28-inch) diameter main recirculation line with cracks growing along the fusion line 
The occurrence of the cracks in the weld metal raised considerable concern about the fracture behavior of BWR pipes, particularly those fabricated with low toughness flux (SAW and SMAW) welds. In particular, the question arose as to whether IGSCC was occurring in an unusually low toughness region of the pipe, which could lead to premature rupture. DTRC in 1981 first showed that stainless steel flux welds can have significantly lower toughness than the base metal, see Figure 1.4 from Reference 1.6. The DTRC results from Reference 1.6 were subsequently verified by work in the NRC's Degraded Piping program, Figure 1.5 from Reference 1.7, and EPRI funded work at GE and Westinghouse, Refs. 1.8 and 1.9. The Westinghouse data were subsequently used in the ASME Section XI IWB-3640 austenitic pipe flaw evaluation procedures, where the lower toughness of flux weld metal was accounted for by an approximate elastic-plastic correction to the limit-load analysis. This correction factor, called a Z-factor, was a correction on the allowable stress.

During the course of the NRC's Degraded Piping Program, Ref. 1.7, an initial scoping study was conducted to evaluate the toughness of cracks in the HAZ and weld metal in the L-R orientation, which corresponds to a circumferential surface-crack growing through the thickness. In contrast, References 1.6, 1.8, and 1.9 involved C(T) specimens in the L-C orientation, which corresponds to growth of a circumferential through-wall crack in a pipe. The L-R orientation toughness study in Reference 1.7 involved single-edge notched tension, SEN(T), fracture tests. The results showed that the base metal had a high toughness, as is evident by the large crack-tip-opening angle (CTOA) of about 25 degrees in Figure 1.6, and the shielded metal arc weld (SMAW) had a lower toughness with a CTOA of about 12 degrees. For the HAZ specimens, if the crack stayed in the sensitized base metal, the CTOA was similar to that of the base metal, which confirmed the prior studies in References 1.3 and 1.4. However, in one specimen the crack grew along the fusion line with a significantly lower CTOA of about 4 degrees. The implication of this finding was that the fusion line toughness could possibly be much lower than that of the SMAW. Unfortunately, the SEN(T) specimen thickness was very large, about $76 \mathrm{~mm}(3 \mathrm{inch})$, and the crack grew into the fusion line only along one half of the specimen, which made a J-R curve analysis impossible. Since a J-R curve for the fusion line could not be calculated from this specimen, only CTOA observations could be reported.

Additional interesting results came from several pipe fracture experiments in other NRC-funded programs. These pipe experiments consistently showed that with the initial crack in the center of a low toughness SAW, the crack frequently grew out of the center of the weld and followed the fusion line. Several examples are cited below.

- $\quad$ Figure 1.7 shows a schematic of the crack growth paths from two Degraded Piping program experiments. Frequently, the crack followed the fusion line. This occurred in 406-mm (16-inch) and 152-mm (6-inch) diameter TP304 stainless steel pipe experiments at $288 \mathrm{C}$, Ref. 1.7.

- This same behavior occurred in Pipe Experiment 1.1.1.23 in the Short Cracks in Piping and Piping Welds program, Ref. 1.10. This test was conducted at $288 \mathrm{C}(550 \mathrm{~F})$ on a 711-mm (28-inch) diameter TP316 pipe from the Nine Mile Point plant. Figure 1.8 shows metallographic sections of the initial notch location and the crack growth paths. 


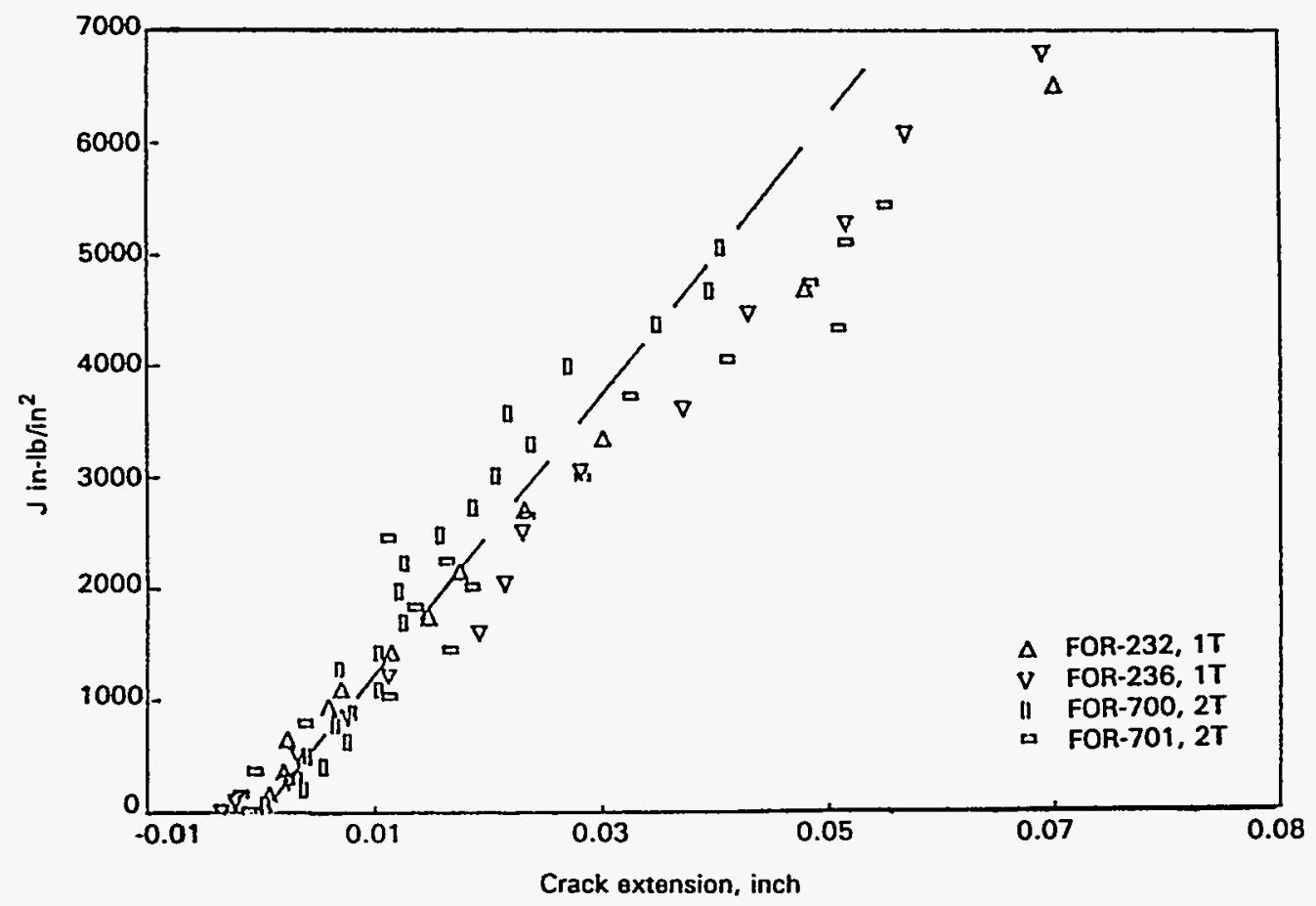

(a) Base metal data

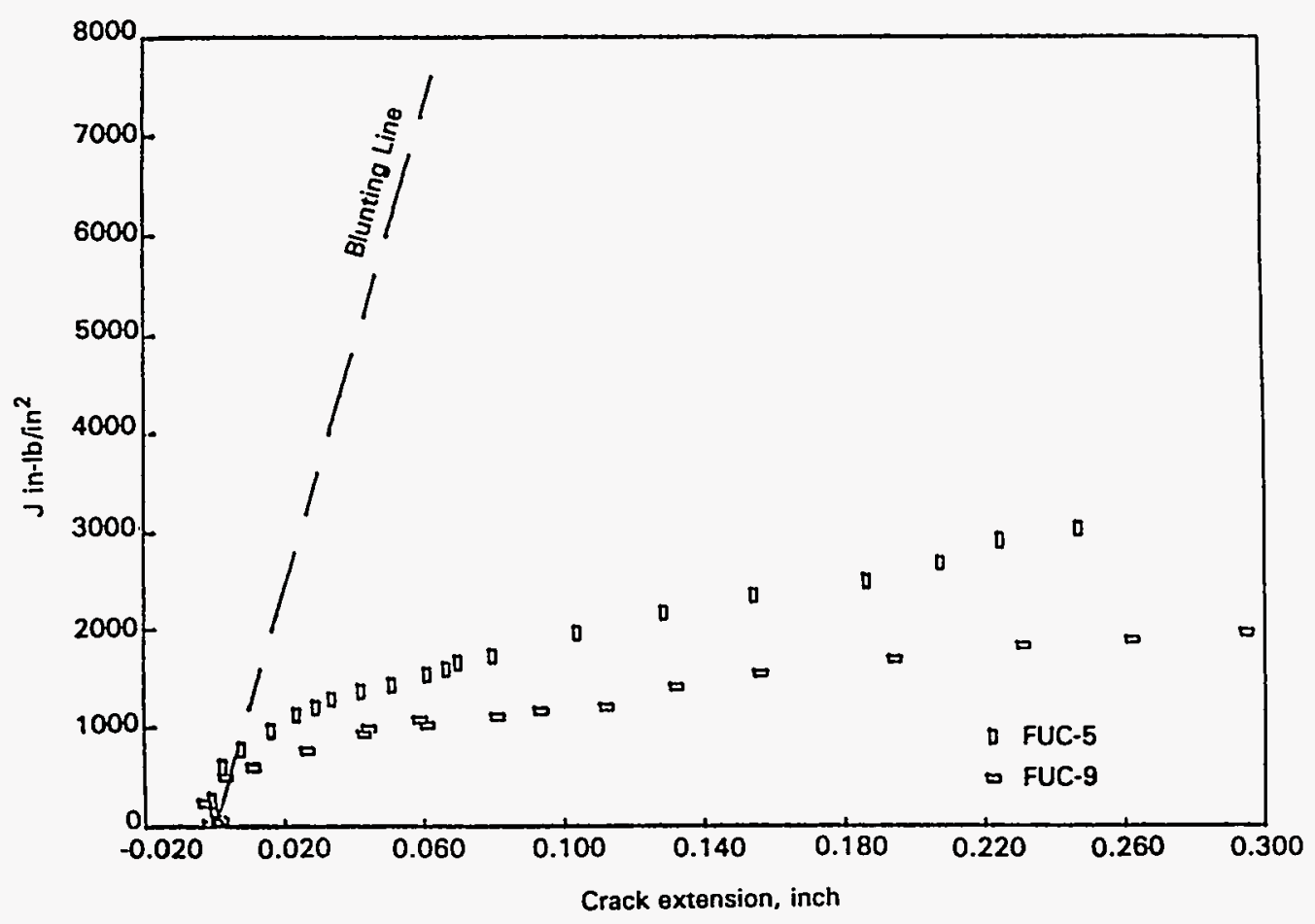

(b) Weld metal data

Figure 1.4 Stainless steel base metal and weld J-R curve data from DTRC, Ref. 1.6 


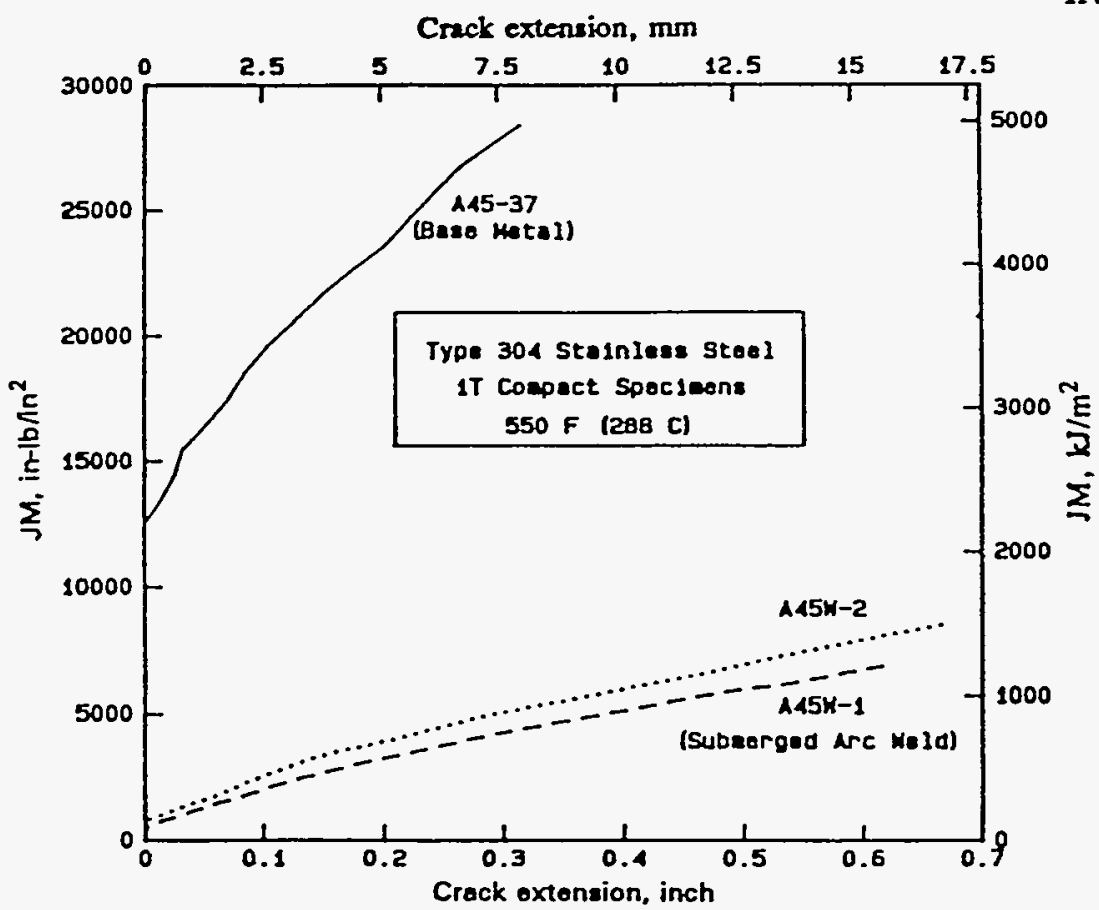

Figure 1.5 Comparison of TP304 base metal and SAW J-R curves at 288 C (550 F), Ref. 1.7

Type 304

Stainless Steel

Base Metal

$\mathrm{CTOA}=25^{\circ}$

Heat Affected $\quad \mathrm{CTOA}=25^{\circ}$

Zone

$\mathrm{CTOA}=25^{\circ}$

Fusion Line

$\mathrm{CTOA}=4^{\circ}$

Weld Metal

CTOA $=12^{\circ}$
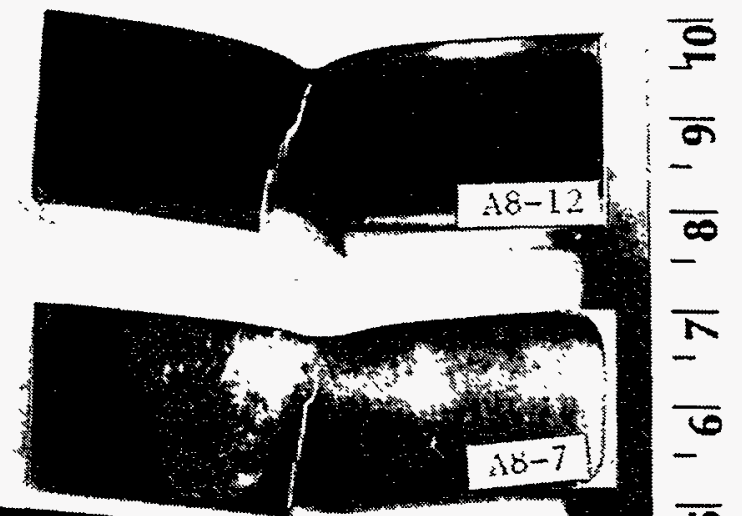

$\bar{T}$

$\underline{-}$

6

-

\section{ऊ}

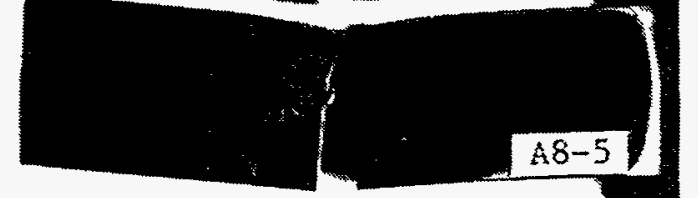

$\overline{-}$

$\bar{m}$

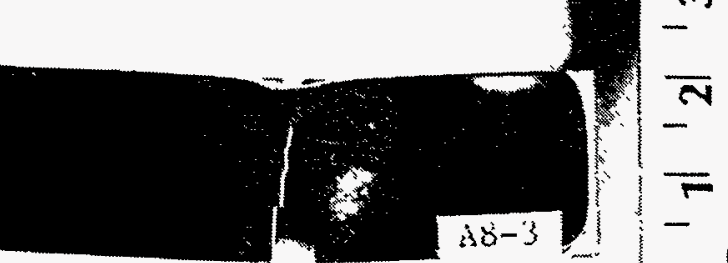

Figure 1.6 Crack propagation in base metal, HAZ remote from fusion line, and weld metal in single-edge notch tension specimens at $288 \mathrm{C}$ (550 F), Ref. 1.7 


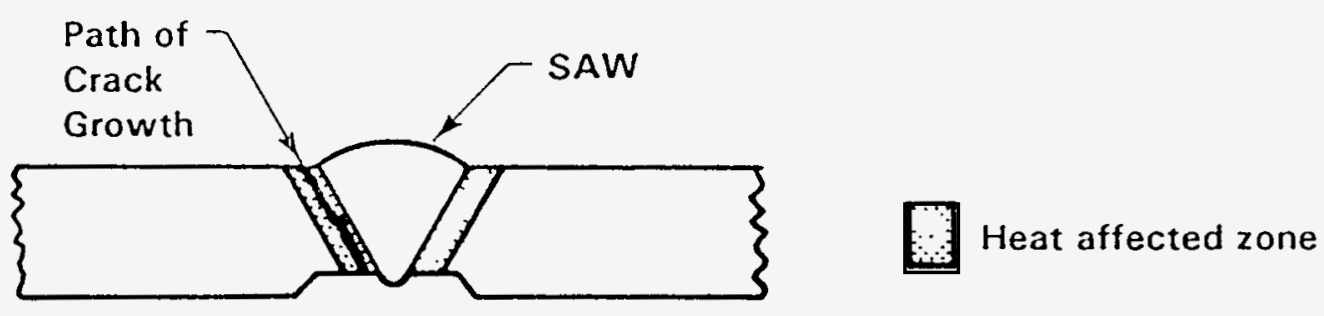

(a) Crack growth in $\mathrm{HAZ}$ as seen at one crack tip in Experiment 4141-1

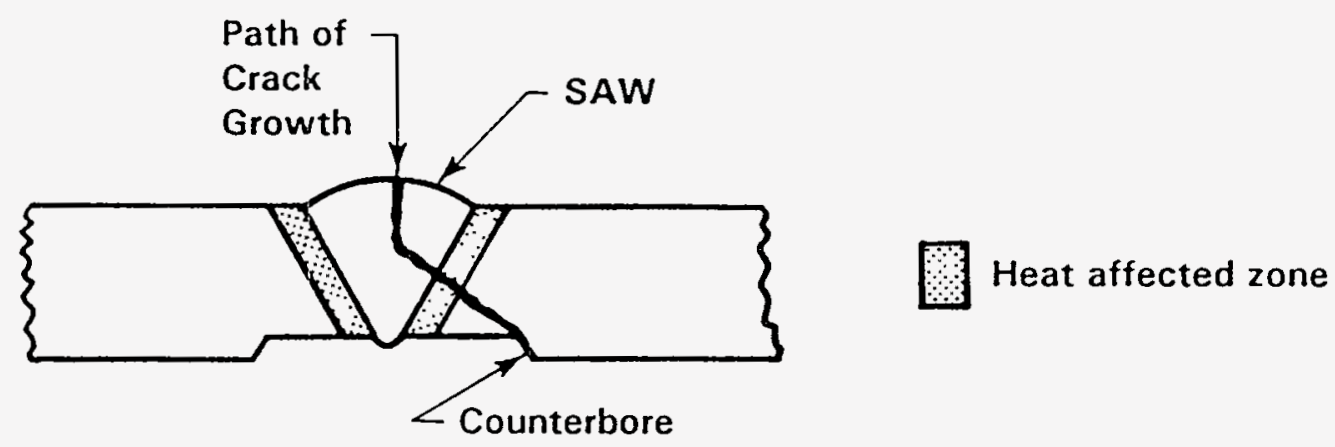

(b) Crack growth in SAW extending out to internal counterbore as seen at one crack tip in Experiment $4141-1$ and at both crack tips in Experiment 4141-3

Figure 1.7 Crack propagation behavior at $288 \mathrm{C}(550 \mathrm{~F})$ in $152-\mathrm{mm}$ (6-inch) and 406-mm (16-inch) diameter TP304 pipe experiments with a circumferential through-wall crack initially in the center of a SAW, Ref. 1.7 

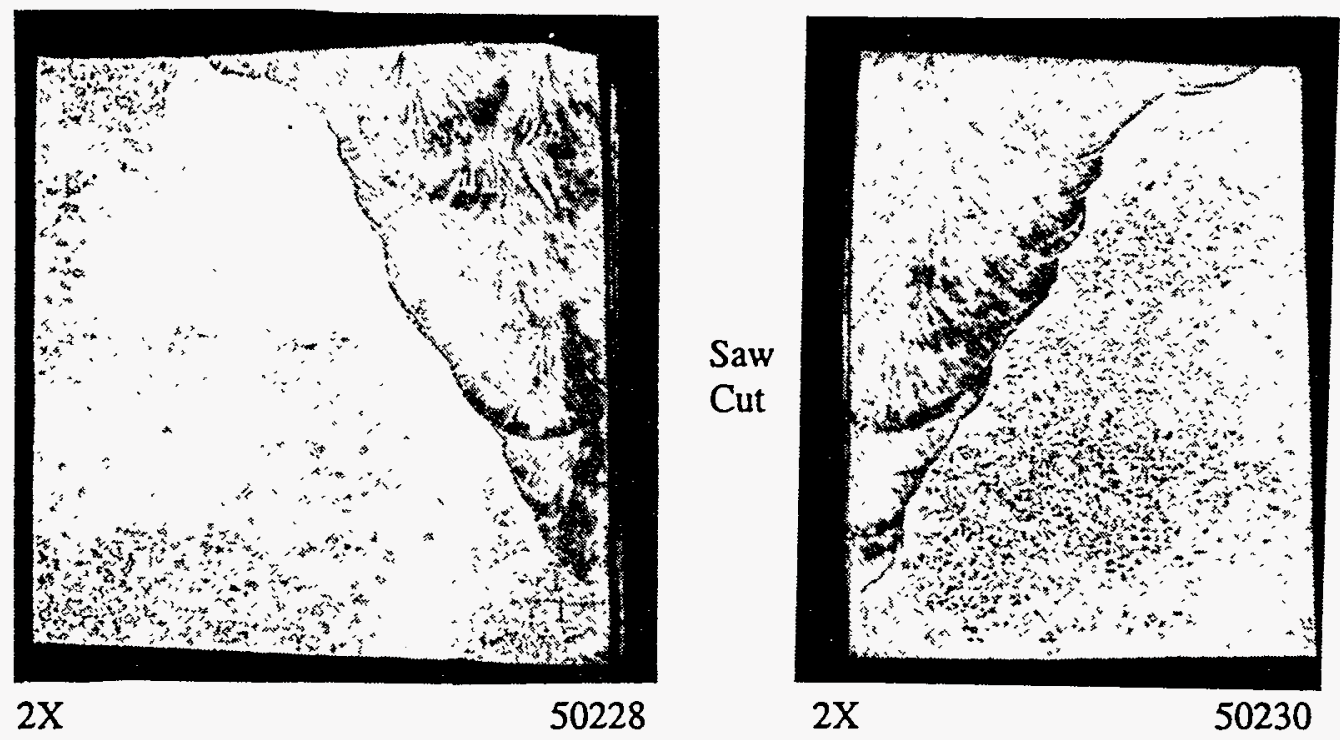

(a) Initial crack tip location in center of weld

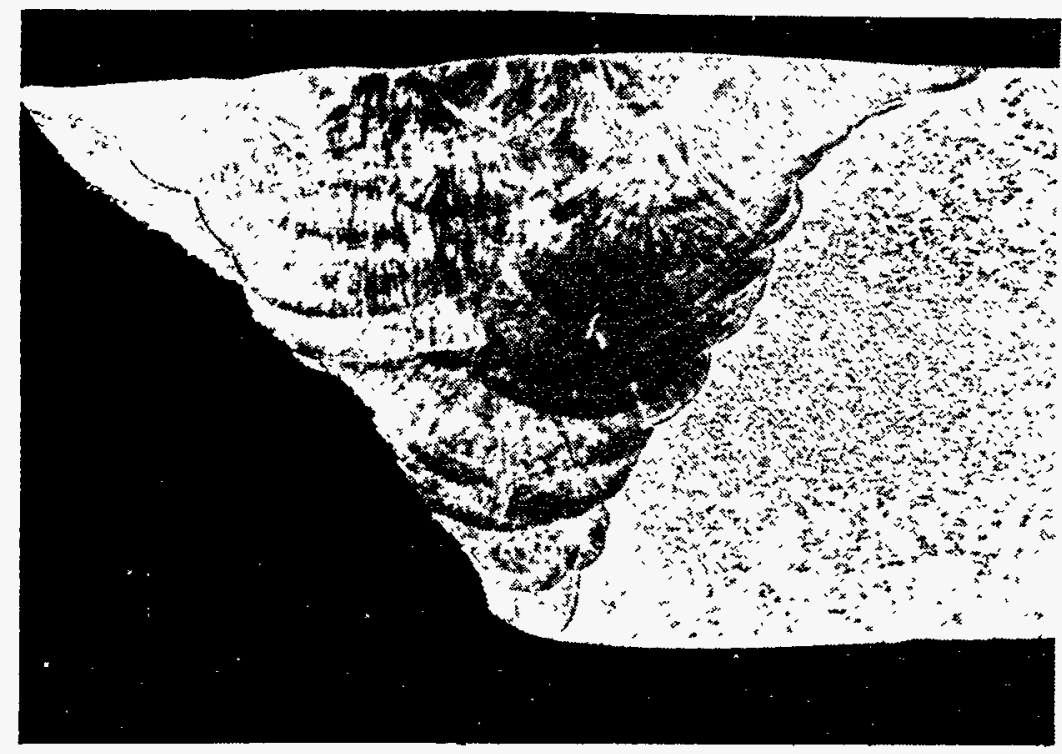

$2 \mathrm{X}$
50229

Section A2

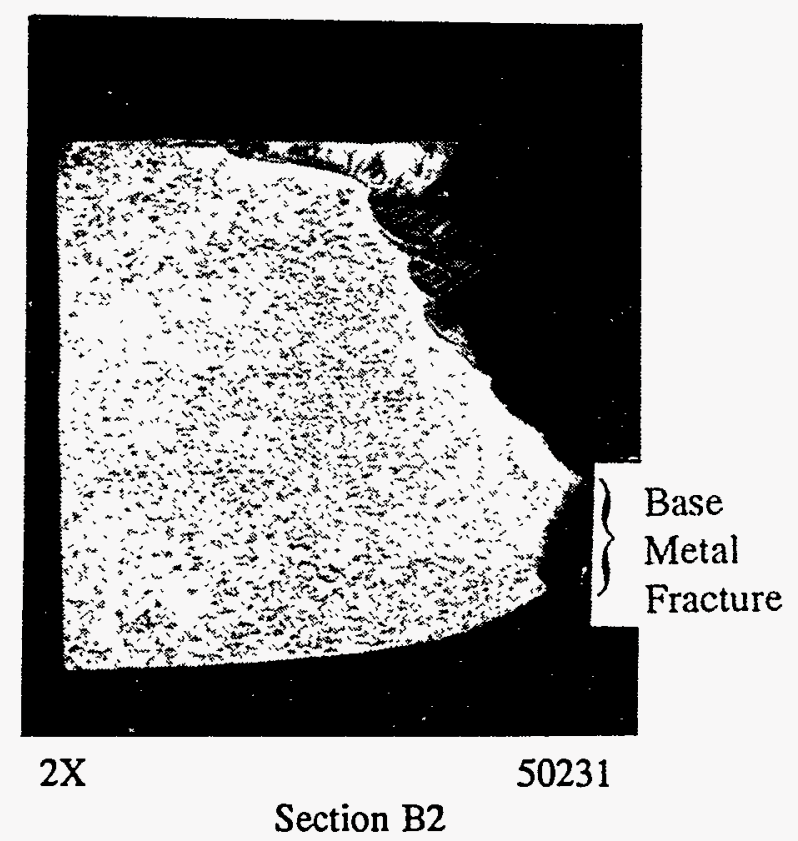

(b) Crack propagation paths

Figure 1.8 Crack propagation at $288 \mathrm{C}(550 \mathrm{~F})$ along fusion line of a TP316 SAW from a 711-mm (28-inch) diameter pipe test, Ref. 1.10 (Weld crown ground off prior to test) 
- From the IPIRG-2 program currently on-going at Battelle, an experiment was conducted on a 406-mm (16-inch) diameter pipe with a surface crack initially in the center of the SAW. The crack followed the fusion line once the crack grew past the initial surface flaw location. Figure 1.9 shows the fracture surface from that experiment. The weld beads along the fusion line can easily be seen in this figure.

Therefore, incentives for conducting this program on fusion line toughness were:

(a) IGSCC in thicker wall piping tended to grow more often along the fusion line than in the weld metal.

(b) A low CTOA value was observed in the SEN(T) fusion line specimen.

(c) Many of the pipe experiments resulted in cracks tending to follow the fusion line rather than staying in the low toughness SAW.

\subsection{Report Outline}

This report integrates the results from past programs and describes an experimental program involving laboratory tests, i.e., Charpy and $C(T)$ specimens, to evaluate the toughness of the fusion line of typical TP304 stainless steel SAWs.

The experimental program is described in Section 2. Both flat-notch and slant-notch $C(T)$ specimens were tested, the latter to simulate a circumferential crack growing along the fusion line of a girth weld in pipe experiments. Questions raised about the combined Mode I and Mode III loading imposed on the crack in the slant-notch specimens are addressed in Section 2, along with prior work on slant-notch $\mathrm{C}(\mathrm{T})$ testing.

Section 3 provides a summary and conclusions. 


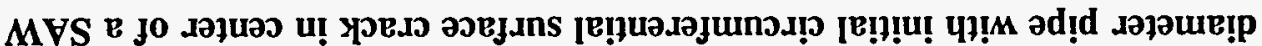

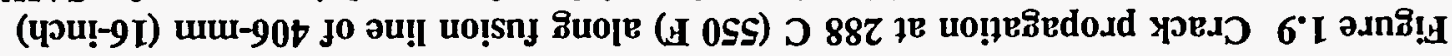
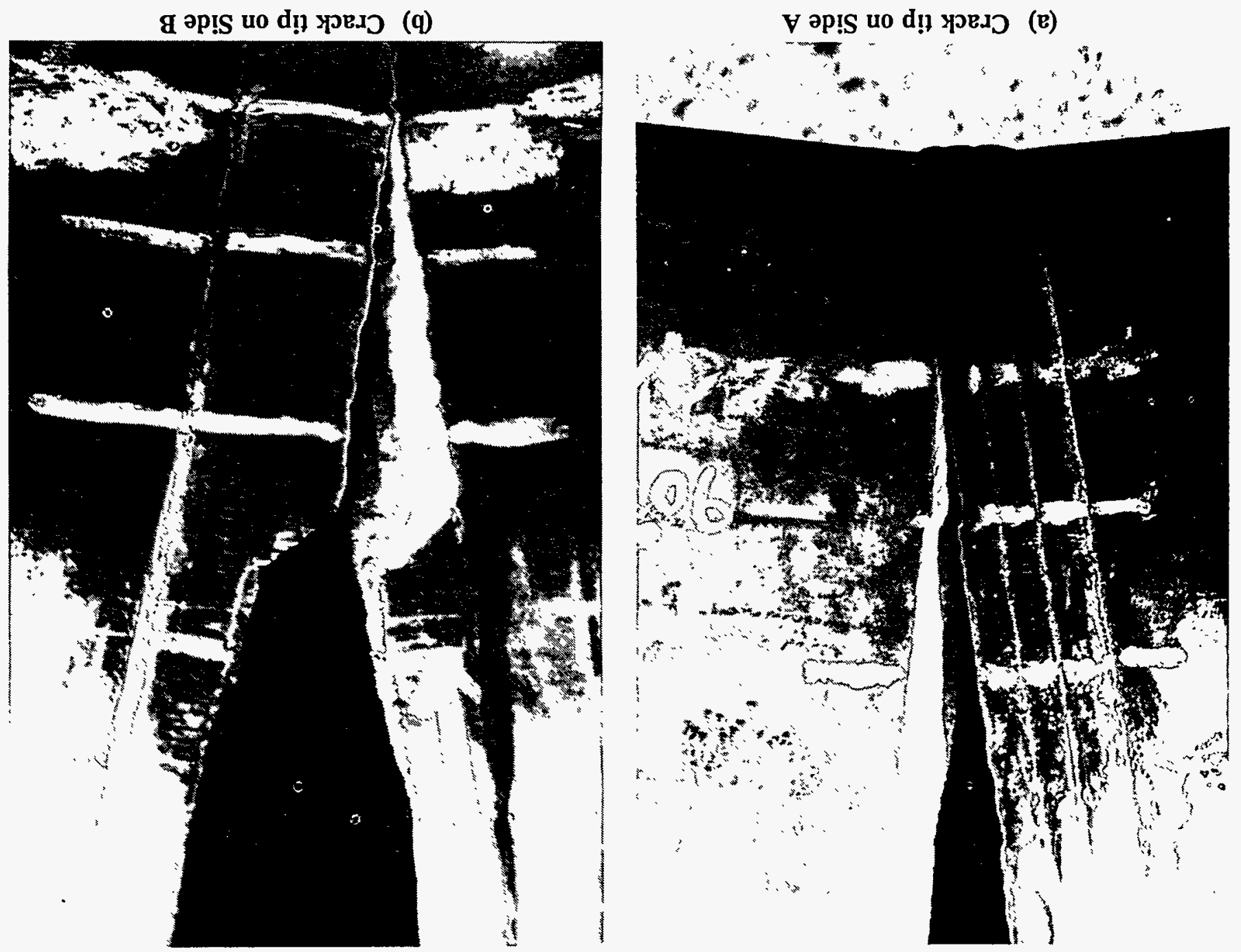


\subsection{References}

1.1 "Investigation and Evaluation of Cracking in Austenitic Stainless-Steel Piping of Boiling Water Reactor Plants," NUREG-75/067, October 1975.

1.2 "Proceedings: Seminar on Countermeasures for Pipe Cracking in BWR's," EPRI WS-79-174 Volumes 1-4, May 1980.

1.3 Kanninen, M. F., and others, "Mechanical Fracture Predictions for Sensitized Stainless Steel Piping with Circumferential Cracks," Final Report, EPRI NP-192, September 1976.

1.4 Kanninen, M. F., and others, "Instability Predictions for Circumferentially Cracked Type 304 Stainless Steel Pipes Under Dynamic Loadings," Final Report on EPRI Project T118-2, by Battelle Columbus Laboratories, EPRI Report Number NP-2347, April 1982.

1.5 "Ultrasonic Sizing Capability of IGSCC and Its Relation to Flaw Evaluation Procedures," Interim Report on EPRI Research Project 1570-2, prepared by EPRI NDE Center and EPRI Staff, August 4, 1983.

1.6 Gudas, J. P. and Anderson, D. R., "J-R Characterization of Piping Materials and Welds," U.S. NRC 9th Water Reactor Safety Research Information Meeting, Washington, D. C., October 1981.

1.7 Wilkowski, G. M., and others, "Analysis of Experiments on Stainless Steel Flux Welds," NUREG/CR-4878, April 1987.

1.8 Horn, R. M., and others, "Evaluation of the Toughness of Austenitic Stainless Steel Pipe Weldments," EPRI report NP-4668, June 1986.

1.9 Landes, J. D., and McCabe, D. E., "Toughness of Austenitic Stainless Steel Pipe Welds," EPRI NP-4768, October 1986.

1.10 Wilkowski, G. M. and others, "Short Cracks in Piping and Piping Welds," NUREG/CR-4599, Vol. 2, No. 1, September 1992. 


\subsection{EXPERIMENTAL PROGRAM}

The experimental program consisted of conducting Charpy and J-R curve tests with the cracks in the fusion line of stainless steel submerged arc welds. Since typical single-Vee welds would have the fusion line at an angle through the thickness, a special slant-Vee weld was made to allow fabrication of flat-notch C(T) specimens. This weld was made in TP304 stainless steel plate material.

Additionally, there was a standard single-Vee girth weld made in the past in a 406-mm (16-inch) diameter pipe using the same weld procedures. The pipe and plate were approximately the same thickness, i.e., $25.4 \mathrm{~mm}(1.0 \mathrm{inch})$. The standard pipe weld required the $\mathrm{C}(\mathrm{T})$ specimens to have a slant notch. A technical background section on past slant notch tests and analyses is given in Section 2.3.1. In addition, some base metal stainless steel flat and slant notch $C(T)$ specimens were fabricated with the notch in the same plane.

\subsection{Materials}

The chemical compositions of the materials evaluated as part of this effort are provided in Table 2.1 and their mechanical properties are in Table 2.2. Note that the strength of both welds exceeded that of the base plates; that is, the welds were overmatched.

\subsubsection{Preliminary Base Metal Experiments (Steel DP2-F33-4)}

These $C(T)$ tests were conducted using steel from a Type 316 stainless steel safe end, which had a diameter of approximately $914 \mathrm{~mm}$ (36 inches) and a wall thickness of $81 \mathrm{~mm}$ (3.2 inches). The objective of the preliminary slant-notch experiments was to ensure that the room temperature test procedures could be extended to $288 \mathrm{C}(550 \mathrm{~F})$ and to assess the $\mathrm{J}_{\mathrm{i}}$ and $\mathrm{J}_{\mathrm{iii}}$ components in conducting tests where material anisotropy effects are not a factor.

\subsubsection{Flat-Notch Fusion-Line Experiments (Weld DP2-A53W)}

Two plates of Type 304 stainless steel, 25.4-mm (1-inch) thick, were joined by the submerged arc welding procedure given in NUREG/CR-4878, Ref. 2.1. The slant-Vee weldment cross-section profile is shown in Figure 2.1. Welding was done by the Uni-Facs Corporation of Columbus, Ohio.

The purpose of preparing such a profile is to have one of the fusion lines perpendicular to the plate surfaces to facilitate the machining of compact specimens and Charpy specimens having the notch located at the fusion line and through the thickness (denoted flat-notch in this report). We also considered a K-weld preparation. However, that procedure has the higher-heat-input root passes in the middle of the thickness. This fact may cause the fusion line to bulge out-of-plane there, which is undesirable (see Figure 2.2). The slant-Vee root passes are near one surface, and out-of-plane 
Table 2.1 Chemical composition of test materials

\begin{tabular}{|c|c|c|c|c|c|}
\hline \multirow[b]{3}{*}{ Element } & \multicolumn{5}{|c|}{ Percent by Weight } \\
\hline & \multicolumn{2}{|c|}{ DP2-A8W4 } & \multirow{2}{*}{$\frac{\text { DP2-F33-4 }}{\text { Pipe }}$} & \multicolumn{2}{|c|}{ DP2-A53W } \\
\hline & Pipe & Weld & & Plate & Weld \\
\hline C & 0.055 & 0.05 & 0.01 & 0.05 & 0.03 \\
\hline $\mathbf{M n}$ & 1.25 & 2.4 & 1.3 & 2.0 & 2.5 \\
\hline $\mathbf{P}$ & 0.019 & 0.03 & 0.03 & 0.03 & 0.02 \\
\hline $\mathbf{S}$ & 0.000 & 0.012 & $<0.01$ & 0.002 & 0.008 \\
\hline $\mathrm{Si}$ & 0.70 & 0.63 & 0.63 & 0.40 & 0.58 \\
\hline $\mathrm{Cu}$ & 0.12 & 0.21 & 0.32 & 0.17 & 0.061 \\
\hline Sn & 0.007 & 0.01 & 0.01 & 0.01 & 0.01 \\
\hline $\mathrm{Ni}$ & 7.7 & 9.8 & 12.2 & 8.6 & 9.2 \\
\hline $\mathrm{Cr}_{\mathbf{r}}$ & 17.0 & 20.0 & 16.1 & 19.0 & 20.3 \\
\hline Mo & 0.017 & 0.18 & 2.1 & 0.42 & 0.15 \\
\hline $\mathrm{Al}$ & 0.008 & 0.02 & 0.02 & 0.02 & 0.03 \\
\hline V & 0.08 & 0.09 & 0.06 & 0.09 & 0.06 \\
\hline $\mathrm{Nb}$ & 0.016 & 0.01 & 0.041 & 0.03 & 0.01 \\
\hline $\mathrm{Zr}$ & 0.002 & 0.007 & 0.001 & 0.002 & 0.009 \\
\hline $\mathrm{Ti}$ & 0.029 & 0.006 & 0.005 & 0.005 & 0.006 \\
\hline B & 0.0021 & 0.0021 & 0.0002 & 0.0002 & 0.0002 \\
\hline $\mathrm{Ca}$ & * & 0.0007 & 0.0013 & 0.0016 & 0.0007 \\
\hline Co & 0.12 & 0.14 & 0.341 & 0.13 & 0.07 \\
\hline $\mathrm{Fe}$ & Balance & 66.8 & 66.4 & 69.4 & 66.8 \\
\hline
\end{tabular}

* Not determined

Table 2.2. Quasi-static mechanical properties at $288 \mathrm{C}(550 \mathrm{~F})$

\begin{tabular}{|c|c|c|c|c|c|c|}
\hline \multirow{2}{*}{\multicolumn{2}{|c|}{ Property }} & \multicolumn{2}{|c|}{ DP2-A8W4 } & \multirow{2}{*}{$\begin{array}{c}\text { DP2-F33-4 } \\
\text { Pipe }\end{array}$} & \multicolumn{2}{|c|}{ DP2-A53W } \\
\hline & & Pipe & Weld & & Plate & Weld \\
\hline \multicolumn{2}{|c|}{ Hardness, Rockwell B } & 86 & 92 & $68-70$ & 86 & 92 \\
\hline \multicolumn{2}{|c|}{ Yield Strength, MPa (ksi) ${ }^{* *}$} & $184(26.6)$ & $258(37.4)$ & $157(22.8)$ & $* * *$ & *** \\
\hline \multicolumn{2}{|c|}{ Ultimate Tensile Strength, MPa (ksi) } & $453(65.8)$ & $469(68.0)$ & $415(60.2)$ & $* * *$ & *** \\
\hline \multicolumn{2}{|c|}{ Elongation, pct. } & $45.9^{+}$ & $26.4^{++}$ & $43.6^{+}$ & *** & *** \\
\hline \multicolumn{2}{|c|}{ Reduction in area, pct. } & *** & $* * *$ & 76 & *** & *** \\
\hline \multicolumn{2}{|c|}{$\begin{array}{l}\mathrm{J} \text { at initiation, } \\
\mathrm{kN} / \mathrm{m}(\mathrm{klb} / \mathrm{in})\end{array}$} & $729(4.16)$ & $55(0.315)$ & $2,233(12.8)^{+++}$ & $* * *$ & *** \\
\hline \multicolumn{2}{|c|}{$\mathrm{dJ} / \mathrm{da}, \mathrm{MPa}(\mathrm{ksi})$} & $538(78.1)$ & $135(19.6)$ & $187(27.1)^{+++}$ & *** & *** \\
\hline * & Room temperature data & & & & & \\
\hline ** & 0.2 percent offset & & & & & \\
\hline$* * *$ & Not determined & & & & & \\
\hline+ & $25.4 \mathrm{~mm}$ (1 inch) gage section & & & & & \\
\hline++ & $20.3 \mathrm{~mm}$ (0.8 inch) gage section & & & & & \\
\hline+++ & Reference 2.9 & & & & & \\
\hline
\end{tabular}




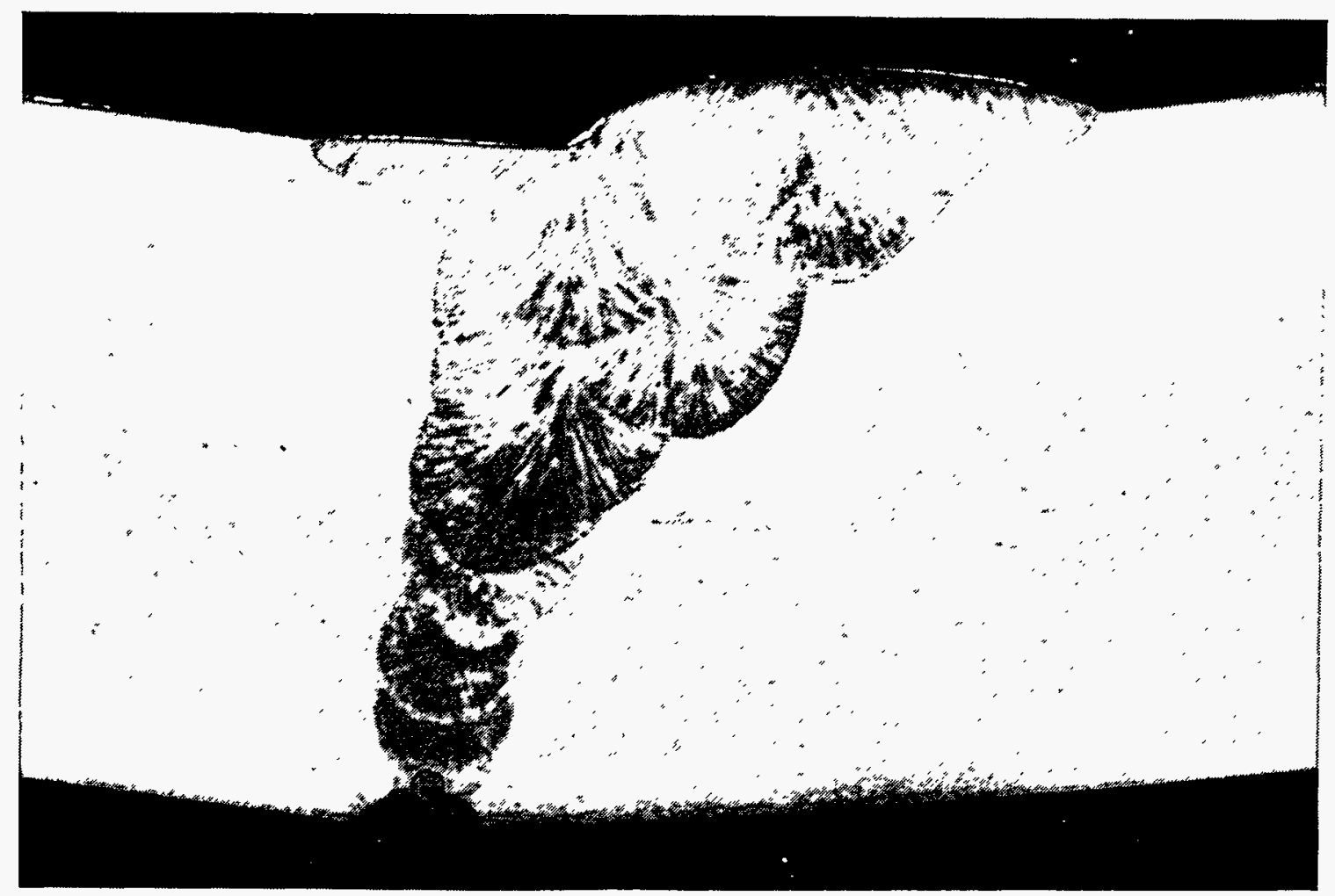

Figure 2.1. Slant-Vee weld in Plate DP2-A53

Table 2.3 Typical self-shielded flux-cored arc-welding procedures for stainless steels using stainless steel electrodes (from AWS Welding Handbook - Volume 2)

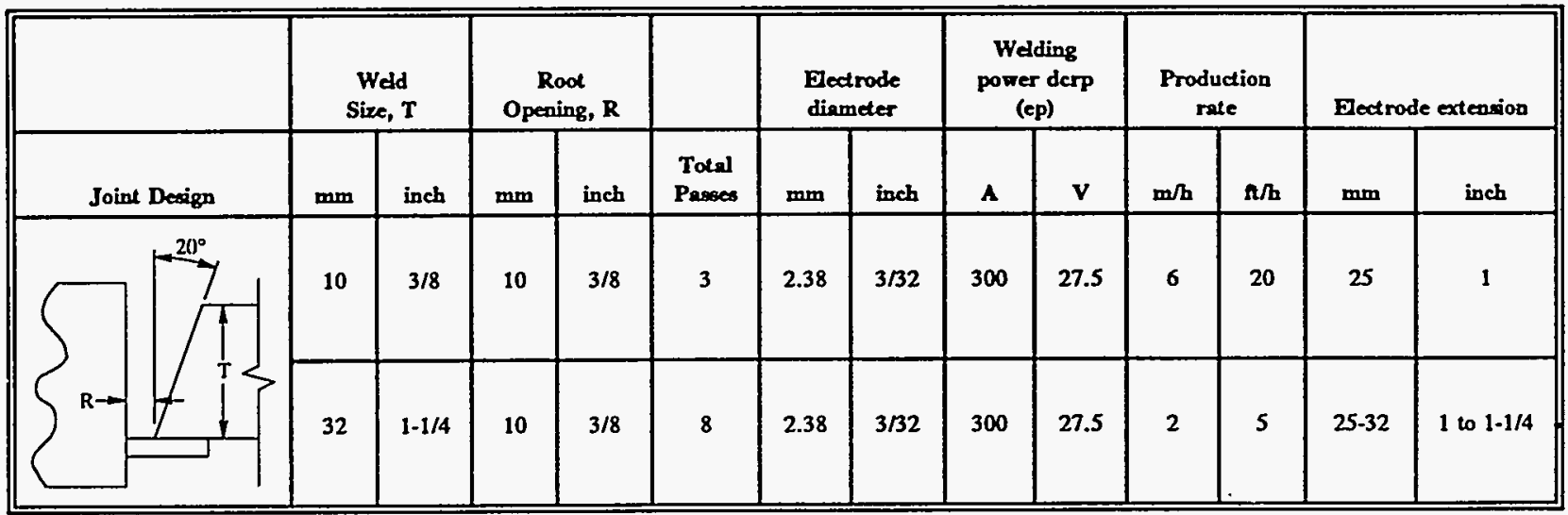


bulging of the fusion line could be machined away. Note that the slant Vee weld preparation is a standard weld preparation (see Table 2.3, which came from the AWS Welding Handbook Volume 2, Reference 2.2).

\subsubsection{Slant-Notch Fusion-Line Experiments (Weld DP2-A8W4)}

The pipe used for these experiments was seam welded, Schedule 100, ASTM A358, Type 304 stainless steel having a diameter of $406 \mathrm{~mm}$ (16 inches) and a wall thickness of $26.2 \mathrm{~mm}$ (1.032 inches). Specimens were taken from the submerged-arc girth weld, which had the profile given in Figure 2.3. Standard J-R curve data for the pipe and the center of the weld metal in that weldment had been determined previously in Reference 2.1 .

These experiments combined features of the previous two series: slant-notch geometry plus precrack positioned along the fusion line.

\subsection{Charpy Tests}

Charpy specimens were tested to determine whether Charpy V-notch impact test data could be used to determine the fusion line toughness. The specimens were machined so that the notches were along the fusion lines according to the sketches in Figure 2.4. As noted in Table 2.4, both fusion lines showed complete ductile fracture at both room temperature and $288 \mathrm{C}(550 \mathrm{~F})$. However, the slant-Vee weld, DP2-A53W, had considerably higher notch toughness than did the single-Vee weld, DP2-A8W4. 


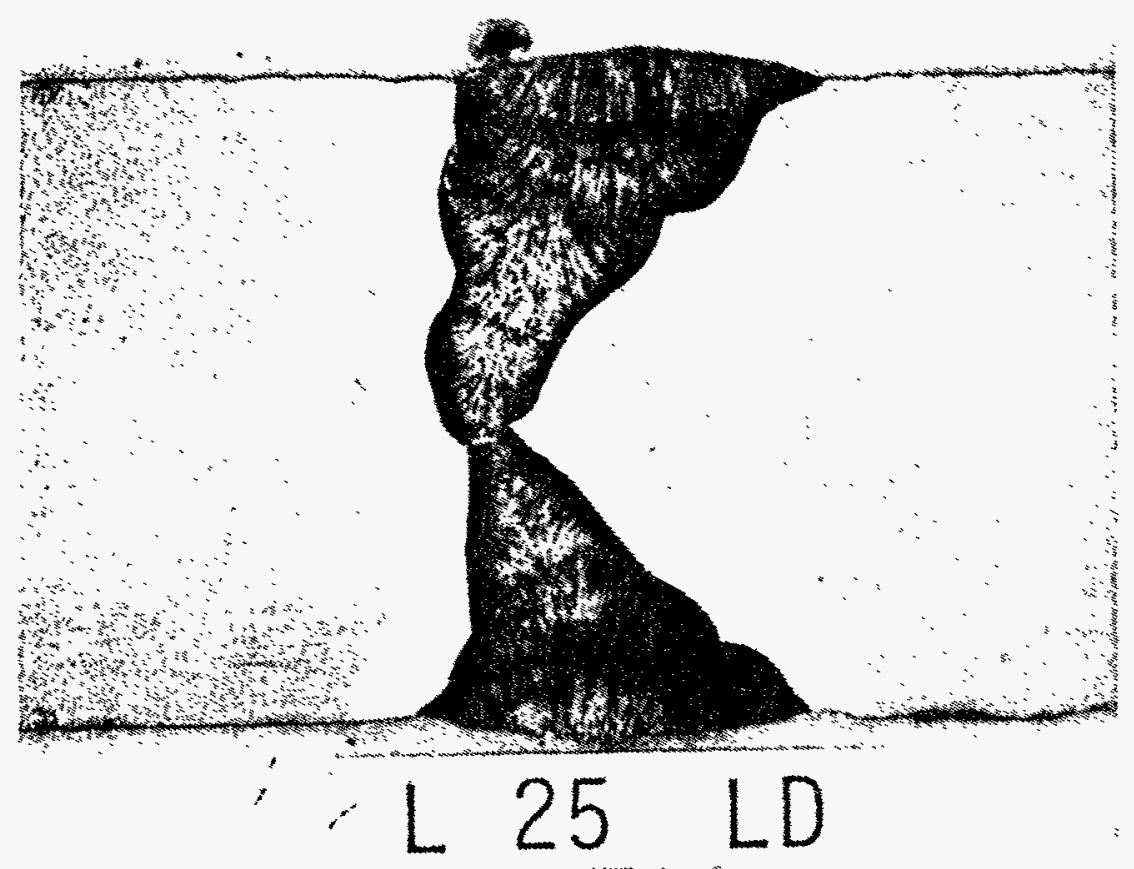

$2.5 \mathrm{X}$

Figure 2.2 Example of K-weld preparation with out-of-plane bulging of the fusion line at the root passes

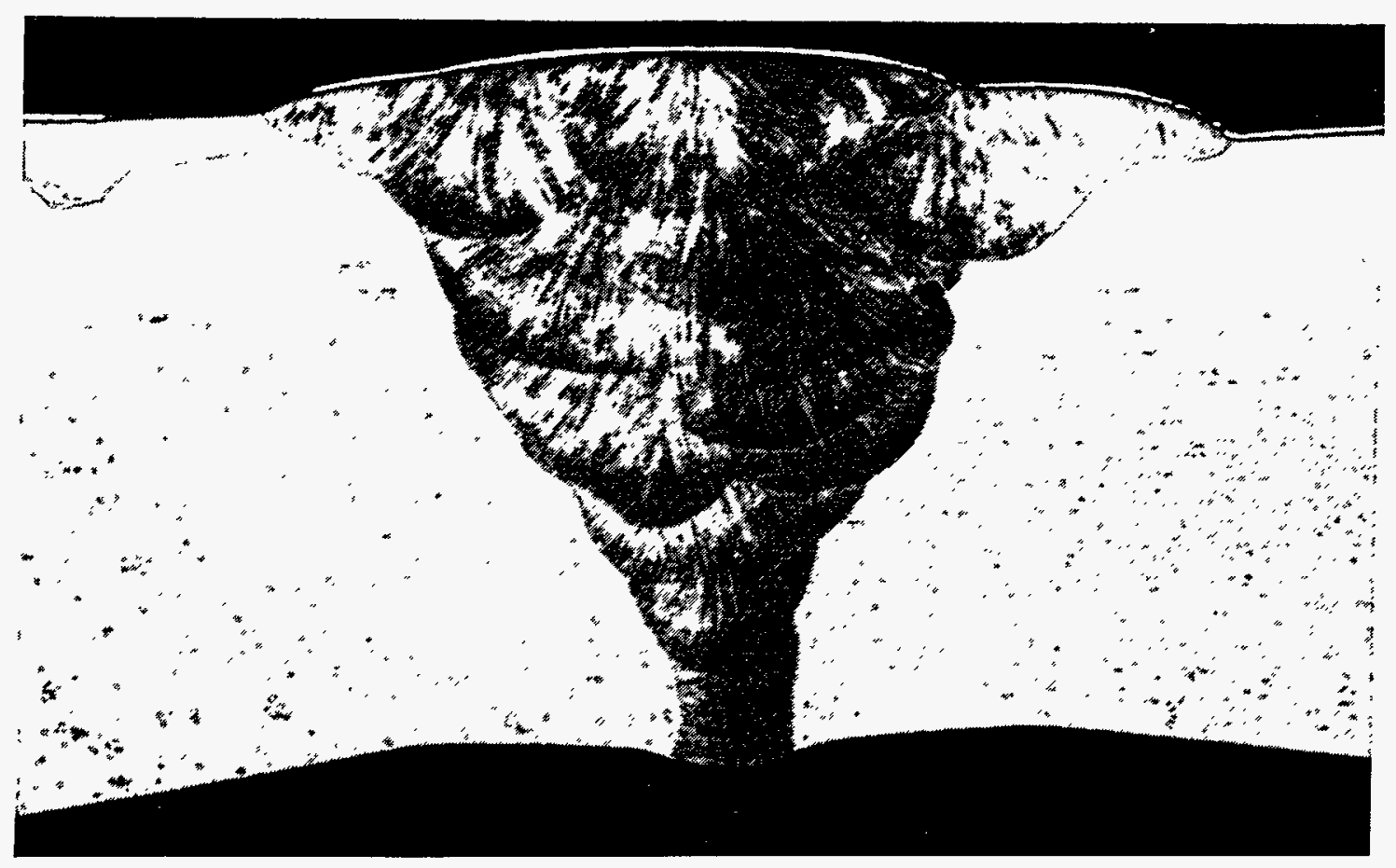

Figure 2.3 Single-Vee pipe Weld DP2-A8W4

(Slant notch put along left fusion line.) 


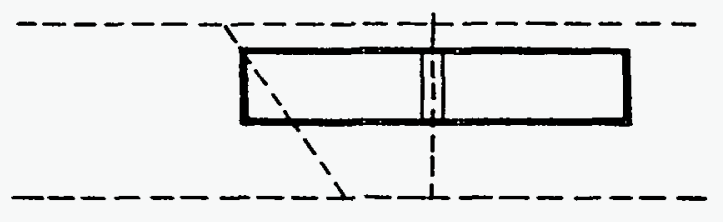

(a) Slant-vee Weld A53W1

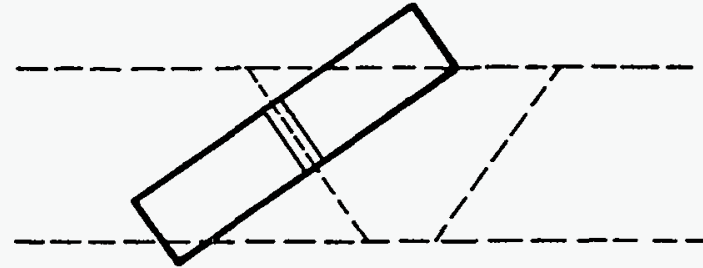

(b) Pipe Weld A8W4; Corners of Charpy specimens built up by weld deposit

Figure 2.4 Orientation of Charpy specimens

Table 2.4 Charpy data for weld fusion lines

\begin{tabular}{|c|c|c|c|c|}
\hline $\begin{array}{c}\text { Temperature, } \\
\text { C (F) }\end{array}$ & $\begin{array}{l}\text { Energy, } \\
\mathrm{J} \text { (ft-lb) }\end{array}$ & $\begin{array}{c}\text { Lateral } \\
\text { Expansion, mm } \\
\text { (mils) }\end{array}$ & $\begin{array}{l}\text { Percent } \\
\text { Shear }\end{array}$ & 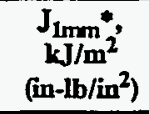 \\
\hline \multicolumn{5}{|c|}{ Single-Vee weld DP2-A8W4 } \\
\hline 23 (73) & $60(44)$ & $0.44(17.5)$ & 100 & $77.0(440)$ \\
\hline $23(73)$ & $49(36)$ & $0.42(16.5)$ & 100 & $63.0(360)$ \\
\hline $23(73)$ & $76(56)$ & $\underline{0.58(23)}$ & $\underline{100}$ & $98.1(560)$ \\
\hline Average & $61.7(45.3)$ & $8.48(19)$ & 100 & $79.3(453)$ \\
\hline $288(550)$ & $61(45)$ & $0.61(24)$ & 100 & $78.8(450)$ \\
\hline $288(550)$ & $69(51)$ & $0.64(25)$ & 100 & $89.3(510)$ \\
\hline $288(550)$ & $\underline{66(49)}$ & $0.58(23)$ & $\underline{100}$ & $85.5(490)$ \\
\hline Average & $65.3(48.3)$ & $0.61(24)$ & 100 & $84.6(483)$ \\
\hline \multicolumn{5}{|c|}{ Slant-Vee weld DP2-As3W } \\
\hline $23(73)$ & $171(126)$ & $1.07(42)$ & 100 & $221(1,260)$ \\
\hline $23(73)$ & $171(126)$ & $1.04(41)$ & 100 & $221(1,260)$ \\
\hline $23(73)$ & $193(142)$ & $\underline{1.04(41)}$ & 100 & $249(1,420)$ \\
\hline Average & $178.3(131.3)$ & $1.05(41.3)$ & 100 & $230(1,313)$ \\
\hline $288(550)$ & $349(257)$ & $1.05(41.5)$ & 100 & $450(2,570)$ \\
\hline $288(550)$ & $251(185)$ & $0.85(33.5)$ & 100 & $324(1,850)$ \\
\hline $288(550)$ & $347(256)$ & $1.09(43)$ & 100 & $448(2,560)$ \\
\hline Average & 315 (232) & $1.00(39.3)$ & 100 & $406(2,320)$ \\
\hline
\end{tabular}

- Estimated from Equation (2.1). 
The ASME Section XI Appendix H correlation between Charpy energy and J at $1 \mathrm{~mm}(0.039$ inch) of crack extension was used to calculate the $J_{1 \mathrm{~mm}}$ values given in Table 2.4. Strictly speaking this correlation was validated only for ferritic steels (including HAZ), but in past evaluations at Battelle it was found to work well for austenitic SAWs also. This equation is

$$
\mathrm{J}_{1 \mathrm{~mm}}=\mathrm{a}(\mathrm{CVN})
$$

where

$a=10$ when $J_{1 \mathrm{~mm}}$ is in units of in-lb/in ${ }^{2}$, and CVN is Charpy energy in units of $\mathrm{ft}-\mathrm{lbs}$.

and

$a=1287$ when $J_{1 \mathrm{~mm}}$ is in units of $\mathrm{N} / \mathrm{m}$, and CVN is in units of Joules.

\subsection{Fracture Toughness Tests}

As noted in the introduction, two different welds were used in the experiments. One weld had the fusion line perpendicular to a plate so that the notch was also perpendicular to the plate; the other weld was a standard single-Vee weld, which required a slant notch in the $C(T)$ test specimens. Because the slant notch specimen is non-standard, some additional technical background on this specimen geometry is given.

\subsubsection{Background on Slant-Notch Specimen Testing}

The experiments described in this section were initiated to evaluate a method for testing archival standard single-Vee weldments for plant-specific applications. As discussed in Section 1, failure of piping has been observed along fusion lines in welded pipe. In order to measure fracture toughness associated with this type of crack growth, we fabricated compact specimens from weldments and aligned the notch and precrack with the weld fusion line. Two designs were used because two fusion-line orientations were evaluated. No design modifications were needed for testing a fusion line normal to the plate surface (i.e., the broad face of the specimen). However, when the fusion line was inclined at an angle of 55 degrees to the pipe surface, modifications of the standard compact specimen design were required. The guideline was that the stress system resolved on the fusion line must reflect the stress system associated with pipe rupture. Figure 2.5 shows the geometric relations between pipe and compact specimen that were used to satisfy this requirement. The figure represents the case where the loading on the specimen simulates axial bending of the pipe. Because of the inclined nature of the crack plane, its tip is subjected to both Mode-I (opening) and Mode-III (transverse shear) loadings. 


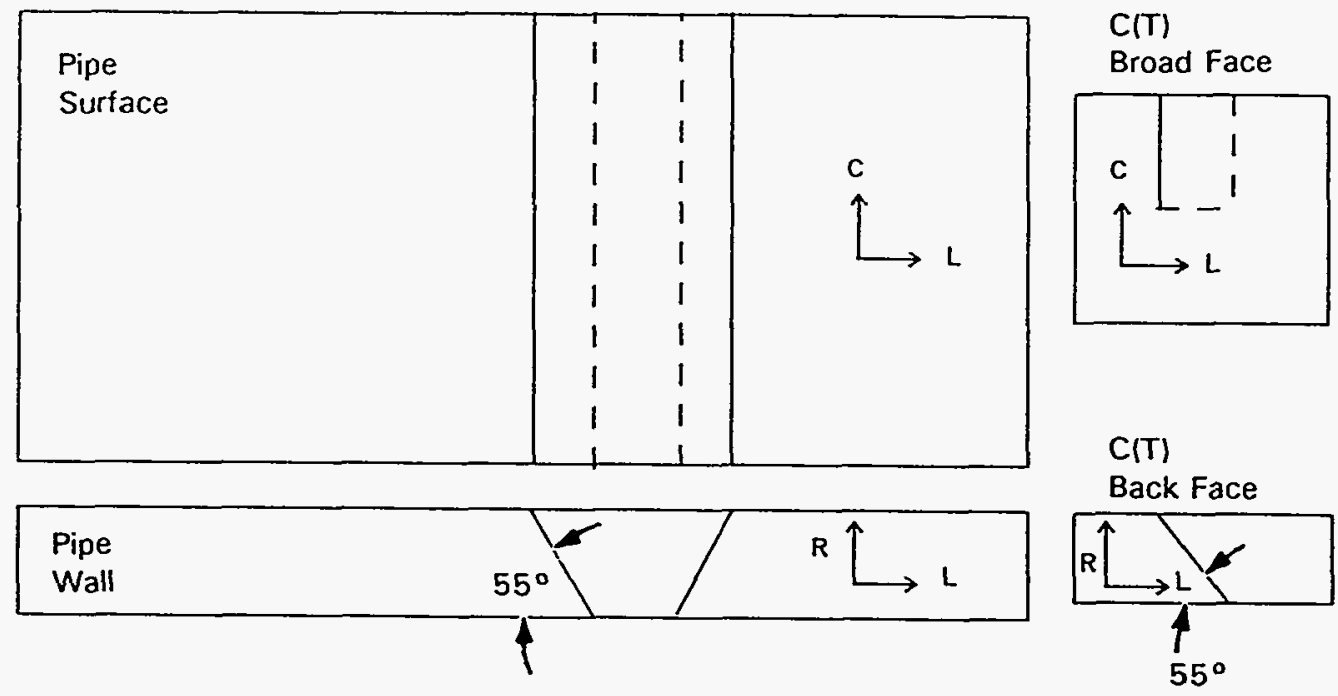

Figure 2.5 Schematic diagram of compact specimen test geometry

A variety of steels have been tested in other programs at Battelle using the slant-notch geometry, and several behaviors have been reported in References 2.3 and 2.4 The initial research was conducted using a very tough steel, designated ASTM-A710. At initiation, this material exhibited total values of $\mathrm{J}\left(\mathrm{J}_{\text {tot }}=\mathrm{J}_{\mathrm{i}}+\mathrm{J}_{\mathrm{iii}}\right)^{\text {(a) }}$ that were fairly insensitive to crack orientation; however, $\mathrm{J}_{\text {tot }}$ became sensitive to crack angle after $3 \mathrm{~mm}$ of crack growth, passing through a minimum between pure Mode-I and pure Mode-III loading. This result suggested a complex relation between the J-R curve and crack-plane orientation. In Reference 2.5, Schroth, and others, argued that lower J values for mixed-mode failure were consistent with the observation that large structures of high toughness steels fail along inclined planes. Subsequently, in Reference 2.3, Manoharan, and others, suggested that the minimum occurs when the crack opening (Mode-I) displacement falls to a value about equal to the surface roughness, and that the increase in toughness as the crack plane becomes more closely parallel with the specimen surface is due to frictional rubbing associated with Mode-III displacements.

Later research revealed that the minimum in the toughness-versus-orientation curve does not always occur in mixed-mode fracture. Figure 2.6 illustrates initiation data and shows examples of the differing behaviors that have been observed in References 2.6, 2.7, and 2.8. The data in this figure suggest that there are situations where measuring $\mathrm{J}_{\mathrm{ic}}$ is sufficient to obtain the minimum toughness. According to the analysis of the extensive data base by Kamat and Hirth in Reference $2.9, \mathrm{~J}_{\mathrm{ic}}$ is the

(a) We have used the terminology $\mathrm{J}_{\mathrm{i}}$ and $\mathrm{J}_{\mathrm{iii}}$ to characterize $\mathrm{J}$ components in mixed-mode loading and to emphasize that the data were generated using a non-standard specimen. 


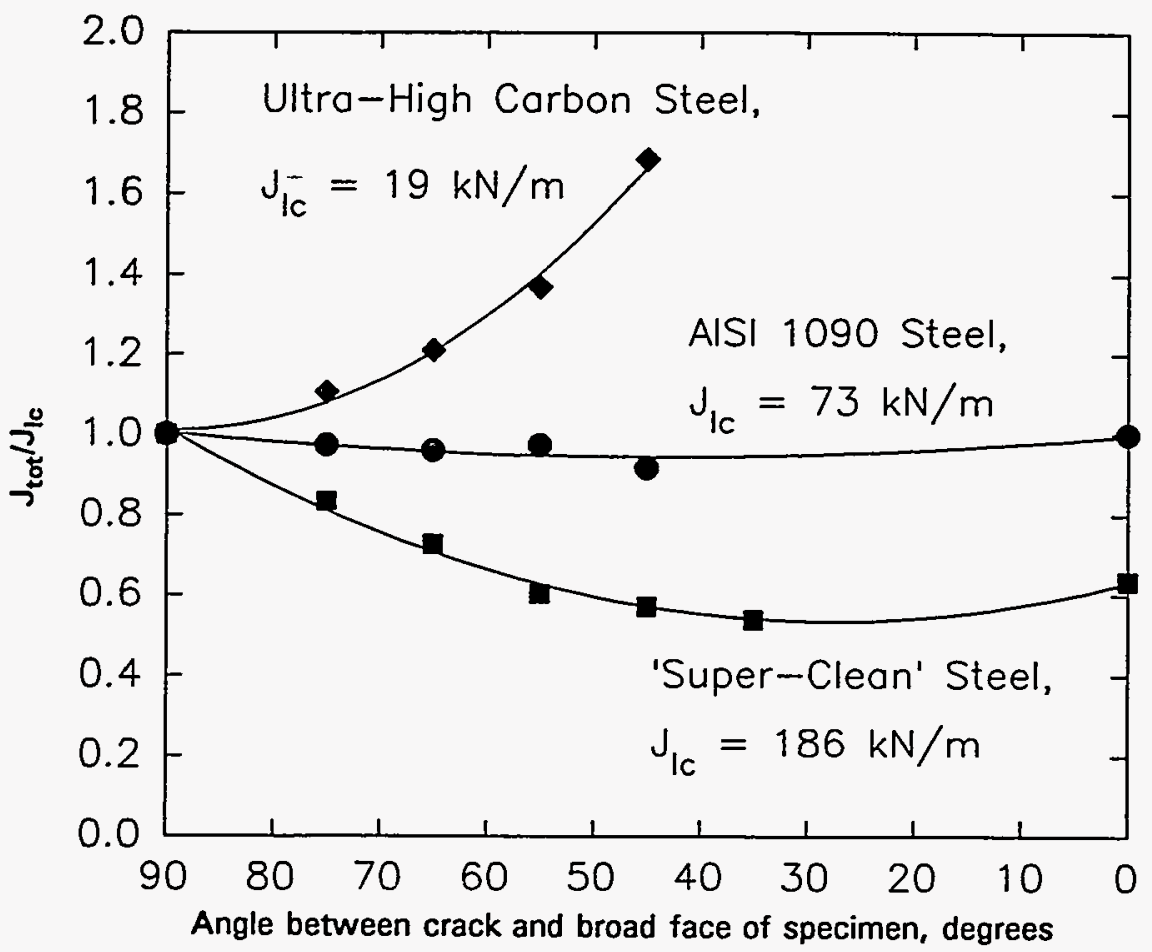

Figure 2.6 Initiation data for a variety of steels containing inclined precracks ${ }^{(a)}$

minimum toughness at two extremes: brittle materials $\left(\mathrm{J}_{\mathrm{ic}} / \sigma_{\mathrm{y}}<0.1 \mathrm{~mm}\right)$ and very tough materials $\left(\mathrm{J}_{\mathrm{ic}} / \sigma_{\mathrm{y}}>0.7 \mathrm{~mm}\right)$. For materials of intermediate toughness, the minimum lies somewhere in $\mathrm{J}_{\mathrm{i}}-\mathrm{J}_{\mathrm{iii}}$ space. However, it should be pointed out that Kamat and Hirth did not include stainless steel in their correlation.

A simpler representation of the mixed-mode fracture criterion is illustrated by Figure 2.7. Here it is seen that the $\mathrm{J}_{\mathrm{ic}}$ versus $\mathrm{J}_{\mathrm{iiic}}$ relation is linear except for $\mathrm{J}_{\mathrm{ic}}$ levels below about 30 percent of $\mathrm{J}_{\mathrm{Ic}}$. For these low levels, the $J_{\text {iiic }}$ levels are higher than might be anticipated by extrapolation of the linear portion of the curve, suggesting that rubbing induces an apparent added component to toughness.

Figure 2.7 also suggests that a linear relation may be used to characterize other materials where the data are more limited, provided caution is used regarding accounting for rubbing. This linear relation can be expressed as the failure criterion:

$$
\mathrm{J}_{\mathrm{ic}}+\mathrm{kJ}_{\mathrm{iiic}}=\mathrm{J}_{\mathrm{Ic}} \text {. }
$$

The failure criterion is $\mathrm{J}_{\text {tot }}=\mathrm{J}_{\mathrm{Ic}}$ for the special case where $\mathrm{k}=1$.

As part of the data reduction procedure, it is also convenient to calculate $J_{\text {nom }}$, which is defined as the value of $\mathrm{J}$ calculated using the measured load/displacement/crack-growth history and assuming a flat

(a) The zero-degree points on this graph were obtained using the pure shear specimen described in Reference 2.8. 


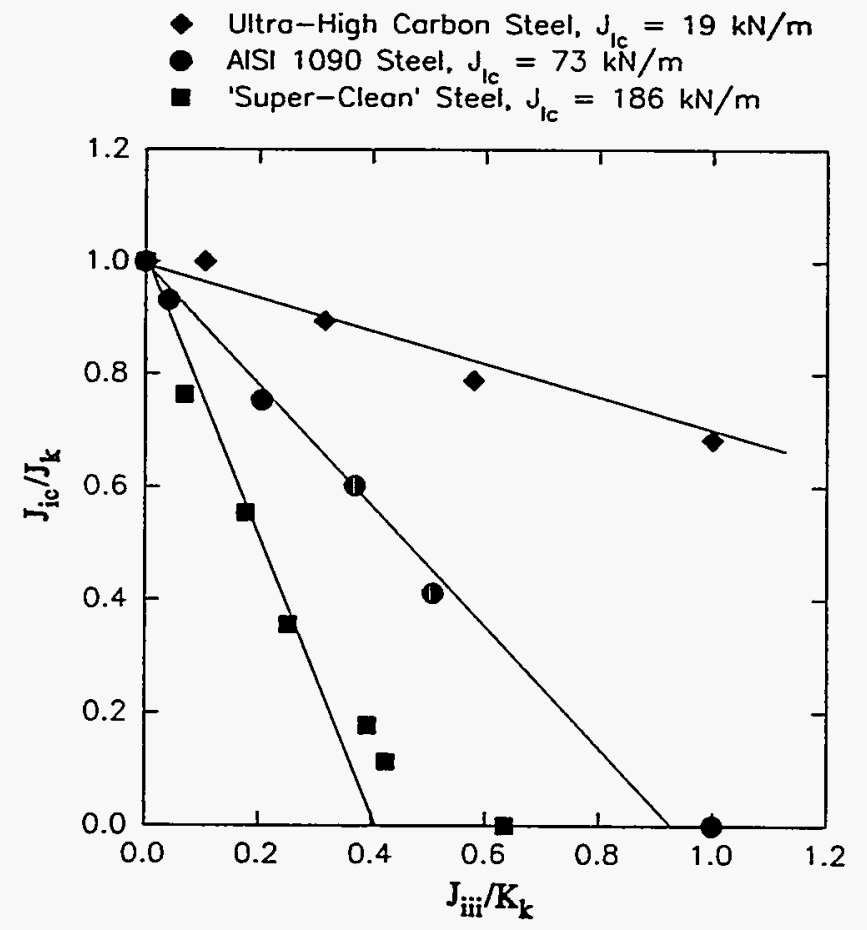

Figure 2.7 Relation between opening-mode and shear-mode toughness

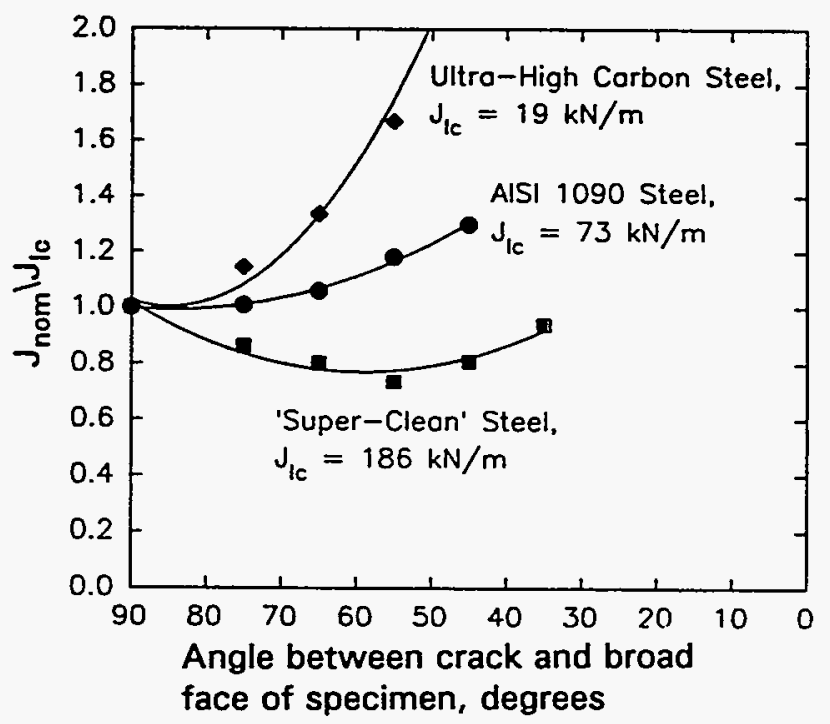

Figure 2.8 Effect of angle of crack plane on nominal fracture toughness 
crack whose width is equal to the specimen thickness. $J_{\text {nom }}$ is a useful quantity because it is the $J$ value that would be assumed if a crack were found in a pipe, since the angle of inclination of the crack plane would be unknown from surface observations alone. Figure 2.8 shows the same results as Figure 2.6, but expressed as $J_{\text {nom }}$ instead of $J_{\text {tot }}{ }^{(a)}$. Here it is seen that use of $J_{\text {nom }}$ does not necessarily eliminate the minimum in the toughness-versus-orientation curve.

All of the experiments described in the last paragraph employed side-grooved specimens. In Reference 2.10, Miglin reported tests on the same plate of ASTM A710 steel that Schroth used, but using plane-sided specimens. Miglin found that the geometry of crack growth was complex and depended on heat treatment. Of particular interest to the present program were observations of crack growth accompanied by crack plane rotation towards a plane of weakness, which contained clustering of elongated inclusions in the A710 steel. These experiments are germane to the present work because weld fusion lines also involve structural heterogeneities. If the precrack is placed close to the fusion line, the growing crack might be expected to 'seek out' the low toughness region of the weldment as it grows. Thus, the slant-notch specimen is useful in two situations:

(1) Homogeneous materials where fracture occurs along inclined planes.

(2) heterogeneous materials where planes of weakness are inclined at an angle to the principal normal stress.

In both situations, the slant-notch specimen is a promising method for evaluating LBB requirements to assess the lowest toughness region of the material as required by NRC's Standard Review Plan 3.6.3.

\subsubsection{Procedures}

The test procedures for the modified compact specimen shown in Figure 2.5 are described in detail by Manoharan, and others (Ref. 2.3). The specimen has the capability of measuring both Mode-I and Mode-III toughness components simultaneously. It was originally developed to overcome the shortcomings of combined torsion and tension, the alternative method of obtaining such data. Not only are experimental procedures for the modified compact specimen simpler, but the design also allows for determination of mixed-mode J-R curves, since significant amounts of crack growth can be monitored.

Preliminary test-procedure evaluation was performed using four specimens of austenitic stainless steel base metal from Pipe DP2-F33, two with flat notches and two with slant notches. In addition, five compact specimens were machined from each of the two welds that were fabricated and tested. The flat-notch specimens (Weld DP2-A53W1) were of standard compact design with the notch in the L-C orientation in order to simulate the circumferential through-wall crack of a pipe test, while the slant-notch specimens (Weld A8W4) were designed according to the sketch in Figure 2.5.

(a) $\mathrm{J}_{\text {nom }}=\mathrm{J}_{\mathrm{tot}} / \sin \theta$, where $\theta=$ angle between the crack and the broad face of the specimen. 
Table 2.5 Compact specimen dimensions

\begin{tabular}{ccccc}
\hline $\begin{array}{c}\text { Specimen } \\
\text { No.DP2- }\end{array}$ & $\begin{array}{c}\text { Notch } \\
\text { Orientation }\end{array}$ & $\begin{array}{c}\text { Width, } \\
\text { mm (in) }\end{array}$ & $\begin{array}{c}\text { Thickness, } \\
\text { mm (in) }\end{array}$ & $\begin{array}{c}\text { Crack Length, } \\
\text { mm (in) }\end{array}$ \\
\hline F33-4-SS-1 & TP304 base metal crack location & & \\
F33-4-SS-2 & Flat & $51.0(2.007)$ & $25.5(1.005)$ & $28.8(1.133)$ \\
F33-4-SSS-1 & Flat & $51.0(2.007)$ & $25.4(1.000)$ & $28.5(1.123)$ \\
F33-4-SSS-2 & Slant & $51.2(2.016)$ & $21.4(0.842)$ & $26.7(1.050)$ \\
& Slant & $50.9(2.005)$ & $21.4(0.841)$ & $26.5(1.044)$ \\
A8W4-FL-1 & SAW Single-Vee fusion-line crack location & \\
A8W4-FL-2 & Slant & $50.7(1.998)$ & $17.8(0.702)$ & $26.0(1.025)$ \\
A8W4-FL-3 & Slant & $50.7(1.999)$ & $17.7(0.699)$ & $26.0(1.025)$ \\
A8W4-FL-5 & Slant & $50.8(2.000)$ & $17.6(0.694)$ & $26.7(1.053)$ \\
& Slant & $50.7(1.996)$ & $17.7(0.698)$ & $25.8(1.017)$ \\
A53W1-FL-1 & SAW Slant-Vee fusion-line crack location & \\
A53W1-FL-2 & Flat & $51.1(2.011)$ & $17.1(0.675)$ & $26.6(1.046)$ \\
A53W1-FL-3 & Flat & $50.9(2.006)$ & $17.4(0.685)$ & $26.6(1.048)$ \\
A53W1-FL-4 & Flat & $50.7(1.998)$ & $17.1(0.675)$ & $26.6(1.048)$ \\
A53W1-FL-5 & Flat & $50.8(2.000)$ & $17.2(0.676)$ & $26.8(1.056)$ \\
\hline & Flat & $50.7(1.998)$ & $17.1(0.674)$ & $26.6(1.049)$ \\
\hline
\end{tabular}

Each starter notch was machined so that the tip of the fatigue precrack would lie along the fusion line of the weld. However, the irregularities in the fusion line made it difficult to satisfy this requirement exactly. In order to more closely approximate piping, none of the specimens were side-grooved. Dimensions of the compact specimens are given in Table 2.5. Note that the preliminary-test specimens (DP2-F33-4 series) had different thicknesses; the slant-notch specimens were thinner than the flat-notch specimens so that the crack fronts would be the same length in both geometries.

All specimens were tested at $288 \mathrm{C}(550 \mathrm{~F})$ in displacement control in a screw-driven machine having a capacity of $225 \mathrm{kN}(50,000 \mathrm{lb})$. The crosshead speed was $0.021 \mathrm{~mm} / \mathrm{sec}(0.05 \mathrm{in} / \mathrm{min})$ and was intended to cause crack initiation in four to seven minutes. In principle, four measurements are required for evaluation of both Mode-I and Mode-III components of J: load, displacement parallel to the load line, out-of-plane displacement, and crack growth. However, the out-of-plane displacement tends to be negligible if the specimen thickness is sufficiently large relative to the face dimensions. Independent post-mortem measurements demonstrated that this was the case for the designs used in the experiments reported here. 
The electric potential method was used to indicate the point of crack initiation and the amount of crack extension. A modified procedure was used in which polarity was periodically reversed in order to account for possible zero drift. The data reduction software was also modified to accommodate this change.

The point of crack initiation was estimated from the electric potential, $U$. To achieve this estimate, graphs of $U$ versus load-line displacement were examined for points of slope change. Engineering judgment was then used to estimate the value of $U$ at crack initiation, $U_{0}$. Crack growth beyond initiation was calculated from the ratio $U / \mathrm{U}_{\mathrm{o}}$ using the Johnson expression as given in Reference 2.11. Note that the term for the spacing of the voltage probes in the Johnson expression was allowed to increase in proportion to load-line displacement as the test progressed, because experience has shown that this procedure provides a more accurate estimate of crack growth in ductile materials as shown in Reference 2.12. Each test was terminated when the crack had extended by an amount equal to 40 to 55 percent of the original ligament. The total elapsed time for each test was approximately six to thirteen minutes. Note the data reduction procedure makes a linear correction on the crack growth difference between the electric potential calculated and final measured crack length, so that the final value in the J-R curve data is the final measured value.

The procedures used to calculate $J$ values from each compact specimen test on flat-notch specimens were those specified in ASTM E1152-87, Standard Test Method for Determining J-R Curves $^{(\mathrm{a})}$. Several values of $J$ were calculated for slant-notch specimens. The initial calculation was of a quantity designated $\mathrm{J}_{\text {nom }}$, which was defined as the value of $\mathrm{J}$ that the specimen would have if it were flat notched. Because there were no out-of-plane displacements, the analysis of Manoharan, and others, in Reference 2.3 , provides simple relations for the individual components of $\mathrm{J}$ :

$$
\begin{array}{ll}
\mathrm{J}_{\mathrm{i}} & =\mathrm{J}_{\text {nom }}\left(\sin ^{3} \theta\right)=0.550 \mathrm{~J}_{\text {nom }} \\
\mathrm{J}_{\mathrm{iii}} & =\mathrm{J}_{\text {nom }} \sin \theta\left(\cos ^{2} \theta\right)=0.269 \mathrm{~J}_{\text {nom }} \\
\mathrm{J}_{\text {tot }} & =\mathrm{J}_{\mathrm{i}}+\mathrm{J}_{\mathrm{iii}}=0.819 \mathrm{~J}_{\text {nom }}
\end{array}
$$

where $\mathrm{J}_{\text {nom }}$ is the value of $\mathrm{J}$ calculated using measured load and displacement with the assumption that the crack is normal to the broad face of the specimen. The above equations for the individual components of $\mathrm{J}$ are derived for a 55-degree angle between the specimen face and the crack plane and no out-of-plane displacements, as was the case for the slant-notch specimen experiments.

Figure 2.9 shows the individual components of the J-R curves for the stainless steel safe end, DP2-F33. The solid points are for a flat-notch specimen, while the open points are for a

(a) Although ASTM is in the process of combining E813 and E1152 into a unified standard, these experiments were carried out using guidelines from the standard in force at the time. We believe that use of the new standard would not significantly change any of the information in this report. 


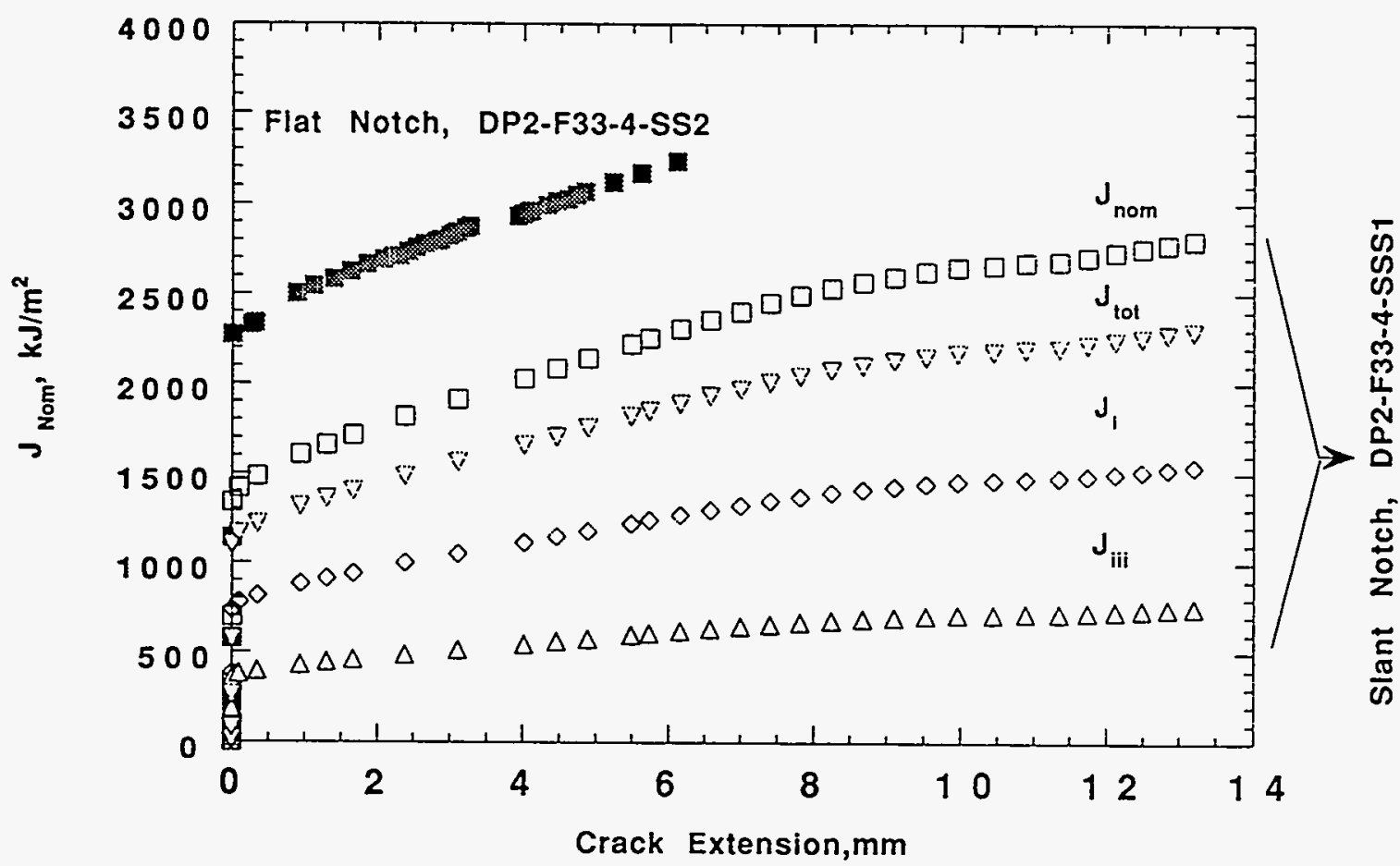

Figure 2.9 Comparison of toughness parameters for the slant-notch specimens

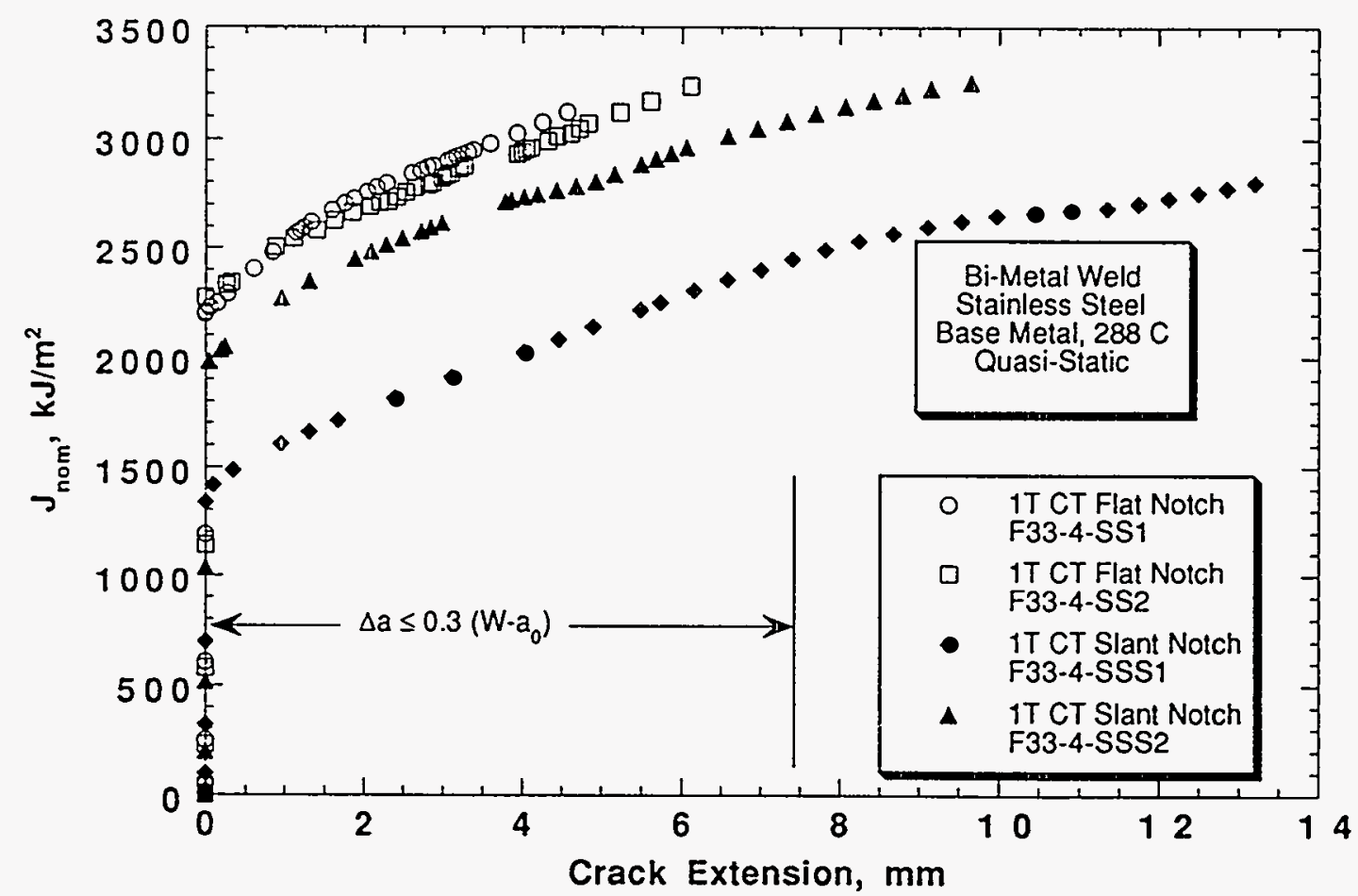

Figure 2.10 J-resistance curves for flat- and slant-notch specimens [limit on J-R curve data is $\Delta \mathrm{a} \leq \mathbf{0 . 3}\left(\mathrm{W}-\mathrm{a}_{\mathbf{0}}\right)$ ] 
slant-notch specimen. As noted above, $\mathrm{J}_{\text {nom }}$ is the value of $\mathrm{J}$ calculated from load and displacement using the thickness as the breadth of the crack front. Because loads and displacements are not resolved on the crack plane, $J_{\text {nom }}$ is always the largest toughness value calculated from a slant-notch specimen for a 55-degree crack angle. Conversely, the actual $J$ components, $\mathrm{J}_{\mathrm{i}}$ and $\mathrm{J}_{\mathrm{iij}}$, are the lowest values of $J$. $J_{\text {tot }}$ can be thought of in two ways, as the total of the Mode-I and Mode-III components or as the value of $\mathbf{J}_{\text {nom }}$ resolved on the crack plane.

When applying the equations in this section to fusion lines, it should be kept in mind that they are analytically based for a homogeneous material. The actual situation at the crack tip includes constraint and triaxiality effects due to the overmatched nature of the welds. However, it is believed that this effect of constraint and triaxiality would not have a large effect on the conclusions because the same constraint and triaxiality effects will occur in a pipe girth weld with a fusion line crack.

\subsubsection{Results}

Table 2.6 summarizes the initiation $\mathrm{J}$ and $\mathrm{dJ} / \mathrm{da}$ results; the detailed specimen data (load, displacement, crack growth, $\mathrm{J}_{\mathrm{i}}, \mathrm{J}_{\mathrm{iii}}, \mathrm{J}_{\text {tot }}$, and $\mathrm{J}_{\text {nom }}$ values) are in Appendix A.

\subsubsection{TP304 Base Metal Experiments (Steel DP2-F33-4)}

Figure 2.10 shows the crack-growth data expressed as $\mathrm{J}_{\text {nom }}$, the value of $\mathrm{J}$ calculated as if all specimens had flat notches. While the data for the two flat-notch specimens agree quite well with one another, there is a discrepancy in the slant-notch data. Data for one of the slant-notch specimens lie along the lower edge of the flat-notch data, while the toughness of the other slant-notch specimen is about $600 \mathrm{~kJ} / \mathrm{m}^{2}\left(3,426 \mathrm{in}-\mathrm{lb} / \mathrm{in}^{2}\right)$ below that level. The difference between the two slant-notch specimens is believed to be associated with crack initiation since their crack growth curves are essentially parallel. Note: the $\Delta \mathrm{a}$ value of $0.3\left(\mathrm{~W}-\mathrm{a}_{\mathrm{o}}\right)$ has been found to be the limit of useable J-R curve data in the past, see Reference 2.13.

In comparison with other steels studied previously, the stainless steel slant-notch data most resemble those for the 'Super-Clean' ferritic steel in Figure 2.7 in that both of the J components in mixed-mode loading for the stainless steel are significantly less than the $\mathrm{J}$ levels for flat specimens. A closer comparison to 'Super-Clean' is seen in Figure 2.11, which suggests that the extrapolated $\mathrm{J}_{\text {IIIc }}$ of approximately 40 percent of $\mathrm{J}_{\mathrm{Ic}}$ is similar for the two steels provided the linear relation of Figure 2.7 holds for the stainless steels tested here. As a result, $\mathrm{k}$ (from Equation 2.2) $=2.5$. Such a high value of $k$ suggests a large degree of shear sensitivity and the occurrence of a minimum value of $\mathrm{J}$ below $\mathrm{J}_{\mathrm{Ic}}$. This stainless steel violates the Kamat-Hirth criterion of Reference 2.9 , since $\mathrm{J}_{\mathrm{ic}} / \sigma_{\mathrm{y}}$ $=14.5 \mathrm{~mm}$ ( $0.57 \mathrm{inch})$; thus, it is not yet possible to predict mixed-mode behavior for all steels using their criterion.

DP2-F33-4 was the first austenitic steel tested using the technique of Manoharan, and others, as described in Reference 2.3 and the first to be tested at high temperatures. The behavior of the steel was reasonably comparable to the tough steels tested by Schroth (Ref. 2.5) and by Raghavachary (Ref. 2.6), giving support to the experimental technique chosen for this program. 
Table 2.6 Summary of compact specimen data $^{(a)}$

\begin{tabular}{lccc}
\hline Specimen No. DP2- & $\begin{array}{c}\text { Notch } \\
\text { Orientation }\end{array}$ & $\begin{array}{c}\text { J at Initiation, } \\
\mathbf{k N / m}(\mathbf{l b} / \mathbf{i n})\end{array}$ & $\begin{array}{c}\text { Initial dJ/da, } \\
\text { MPa (ksi) }\end{array}$ \\
\hline TP304 base metal crack location \\
F33-4-SS-1 & Flat & $2,204(12,600)$ & $304(44.1)$ \\
F33-4-SS-2 & Flat & $2,272(13,000)$ & $221(32.0)$ \\
F33-4-SSS-1 & Slant $^{(b)}$ & $1,414(8,080)$ & $186(27.0)$ \\
F33-4-SSS-2 & Slant $^{(b)}$ & $1,986(11,400)$ & $261(37.9)$ \\
SAW single-Vee fusion-line crack location & \\
A8W4-FL-1 & Slant & $600(3,420)$ & $326(47.2)$ \\
A8W4-FL-2 & Slant & $899(5,132)^{(\mathfrak{c})}$ & $400(58.0)$ \\
A8W4-FL-3 & Slant & $803(4,587)$ & $76(11.0)$ \\
A8W4-FL-5 & Slant & $762(4,352)$ & $354(51.4)$ \\
\multicolumn{5}{c}{ SAW slant-Vee fusion-line crack location } & \\
A53W1-FL-1 & Flat & $475(2,717)$ & $208(30.1)$ \\
A53W1-FL-2 & Flat & $2,088(11,923)^{(\mathrm{c})}$ & $-30(-4.3)$ \\
A53W1-FL-3 & Flat & $1,324(7,560)^{(\mathrm{c})}$ & $256(37.1)$ \\
A53W1-FL-4 & Flat & $510(2,912)$ & $304(44.1)$ \\
A53W1-FL-5 & Flat & $1,490(8,508)^{(\mathrm{c})}$ & $134(19.4)$ \\
\hline
\end{tabular}

(a) Slant-notch values are $J_{\text {nom }}$

(b) Slant notch specimens machined at an angle so crack plane breadth is the same as for flat notch specimens.

(c) Crack tip not on fusion line. 


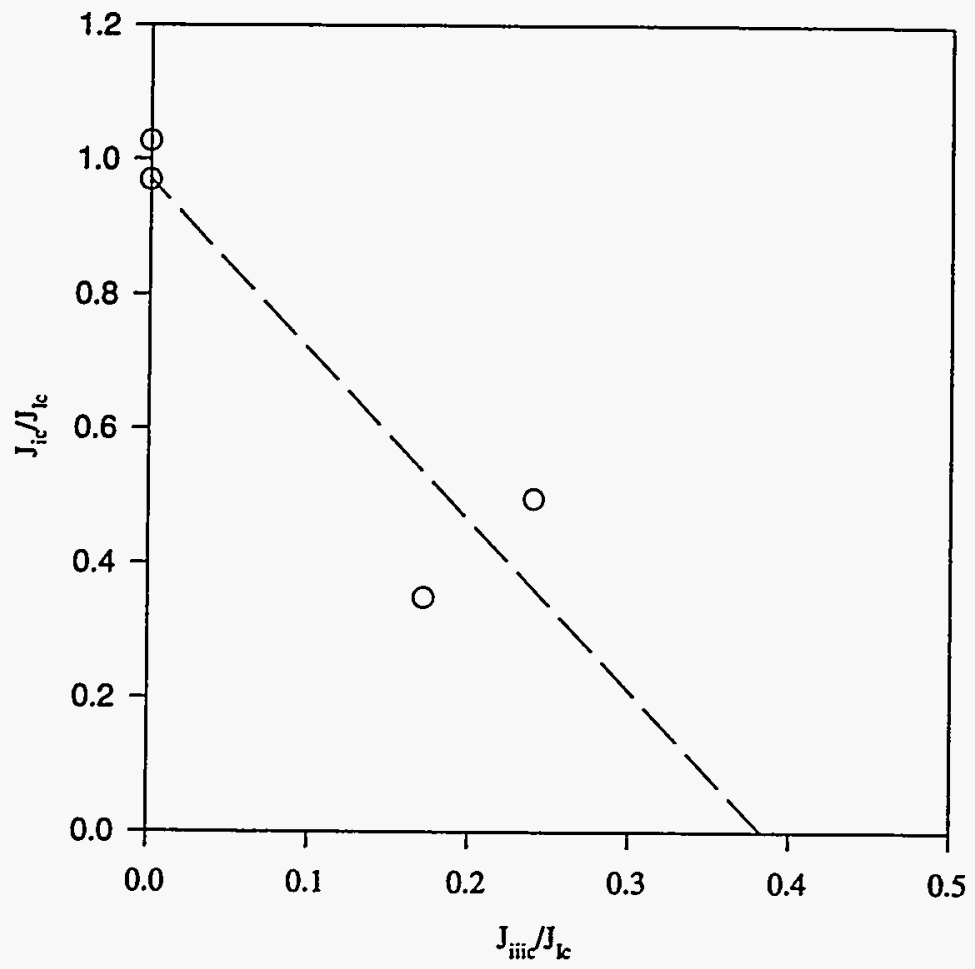

Figure 2.11 Mixed-mode failure envelope for stainless steel safe end DP2-F33

\subsubsection{Flat-Notch Fusion-Line Experiments (Weld DP2-A53W1)}

Figure 2.12 shows the load/displacement curves for five nominally identical specimens. It was found that crack initiation occurred near maximum load in all cases.

The J-resistance curves associated with the flat-notch fusion-line specimens are unusual, as illustrated by Figure 2.13. The graph shows a large discrepancy in initiation toughness but a convergence of $\mathrm{J}$ values as the crack grows. The most striking observation is the toughness decrease with increasing crack growth of Specimen DP2-A53W1-FL-2. Here the crack tip was in the base metal, but the crack then grew to the fusion line. The data in Figure 2.13 show the need for replicate specimens when doing fusion line testing. For this fusion line only two of the five specimens (DP2-A53W-FL-1 and -4 ) exhibited what is believed to be lower bound behavior and these are the only specimens where the initial crack tip was on the fusion line. The other three specimens have much higher initiation toughness, but $\mathrm{dJ} / \mathrm{da}$ becomes negative. For Specimen DP2-A53W1-FL-2, the initiation toughness is the highest, but $\mathrm{dJ} / \mathrm{da}$ is negative immediately after crack initiation. With large amounts of crack growth, all the specimens seem to be approaching an asymptotic value around $1,300 \mathrm{~kJ} / \mathrm{m}^{2}$ $\left(7,423 \mathrm{in}-\mathrm{lb} / \mathrm{in}^{2}\right)$.

The appearance of the specimens reflects the differences in initiation toughness of the DP2-A53W1 series. Fracture surfaces are shown in Figure 2.14 and it is seen that the low-initiation-toughness specimen (DP2-A53W1-FL-1) has a relatively normal appearance while the high-initiation-toughness specimen (DP2-A53W1-FL-2) exhibits asymmetric irregular crack growth. 


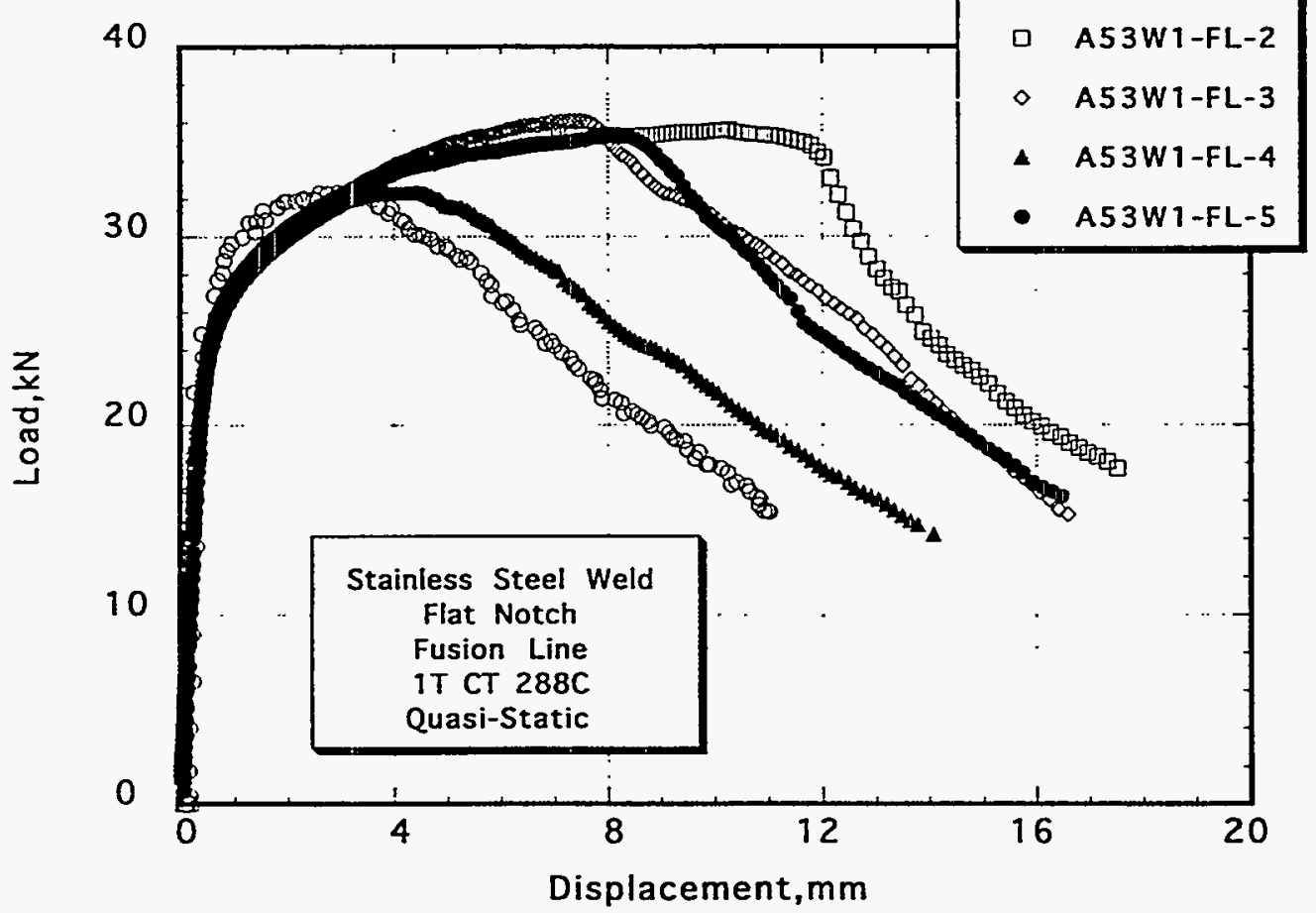

Figure 2.12 Load-disvlacement curves for flat-notch, fusion-line specimens

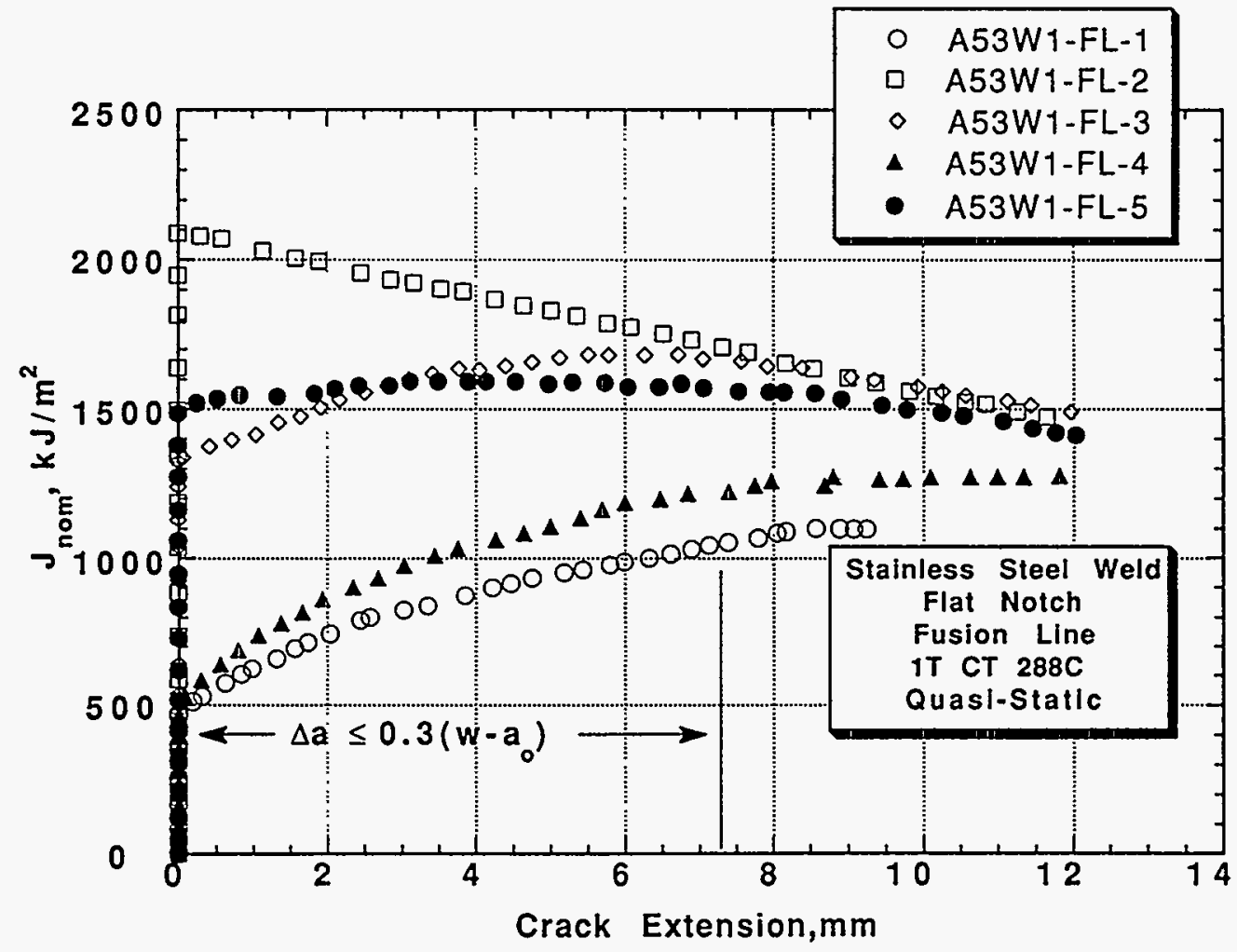

Figure 2.13 J-resistance curves for flat-notch, fusion-line specimens from DP2-A53W [limit on J-R curve data is $\Delta \mathrm{a} \leq 0.3\left(\mathrm{~W}-\mathrm{a}_{\mathbf{0}}\right)$ ] 


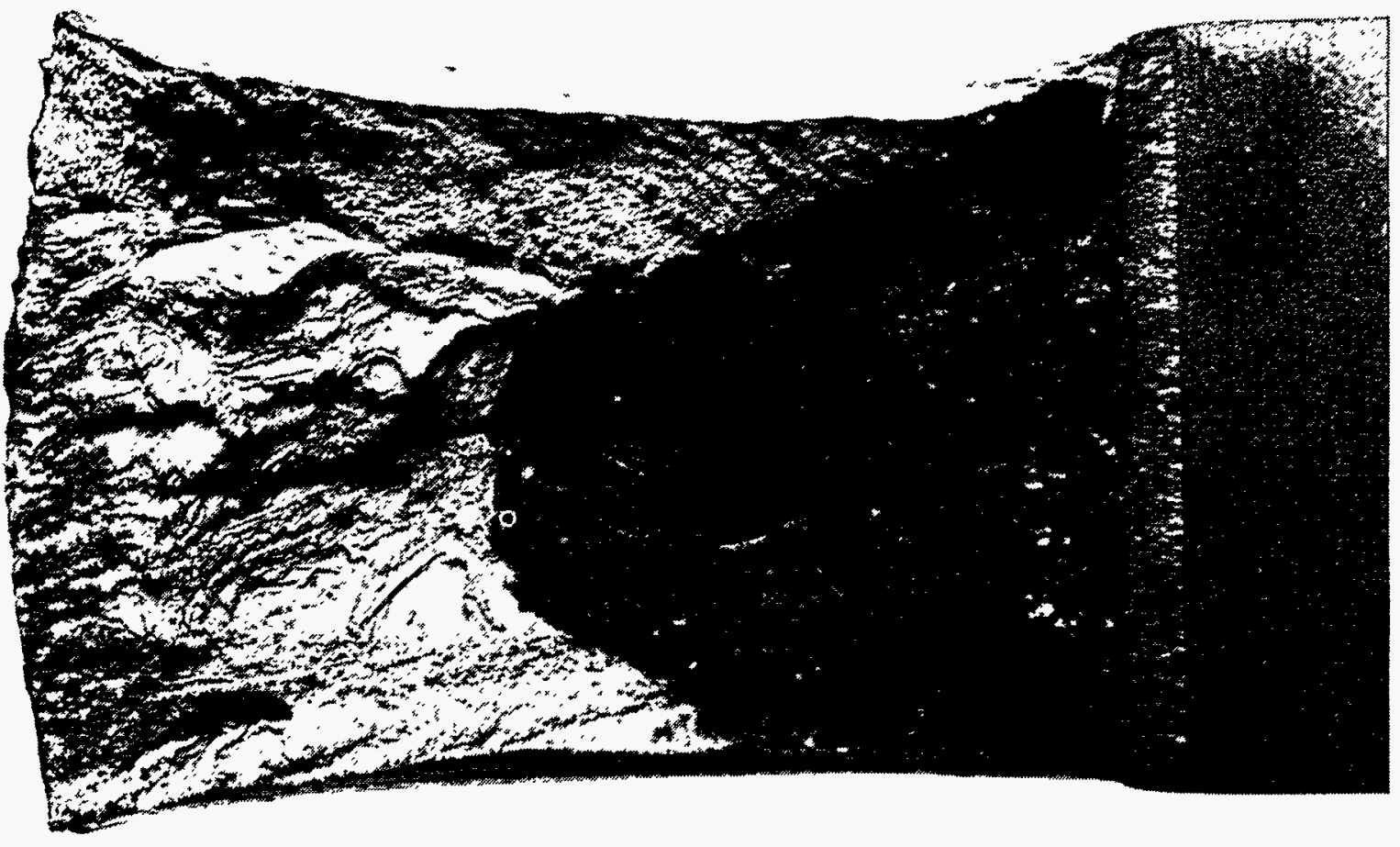

(a) Specimen DP2-A53W1-FL-1 (lowest toughness)

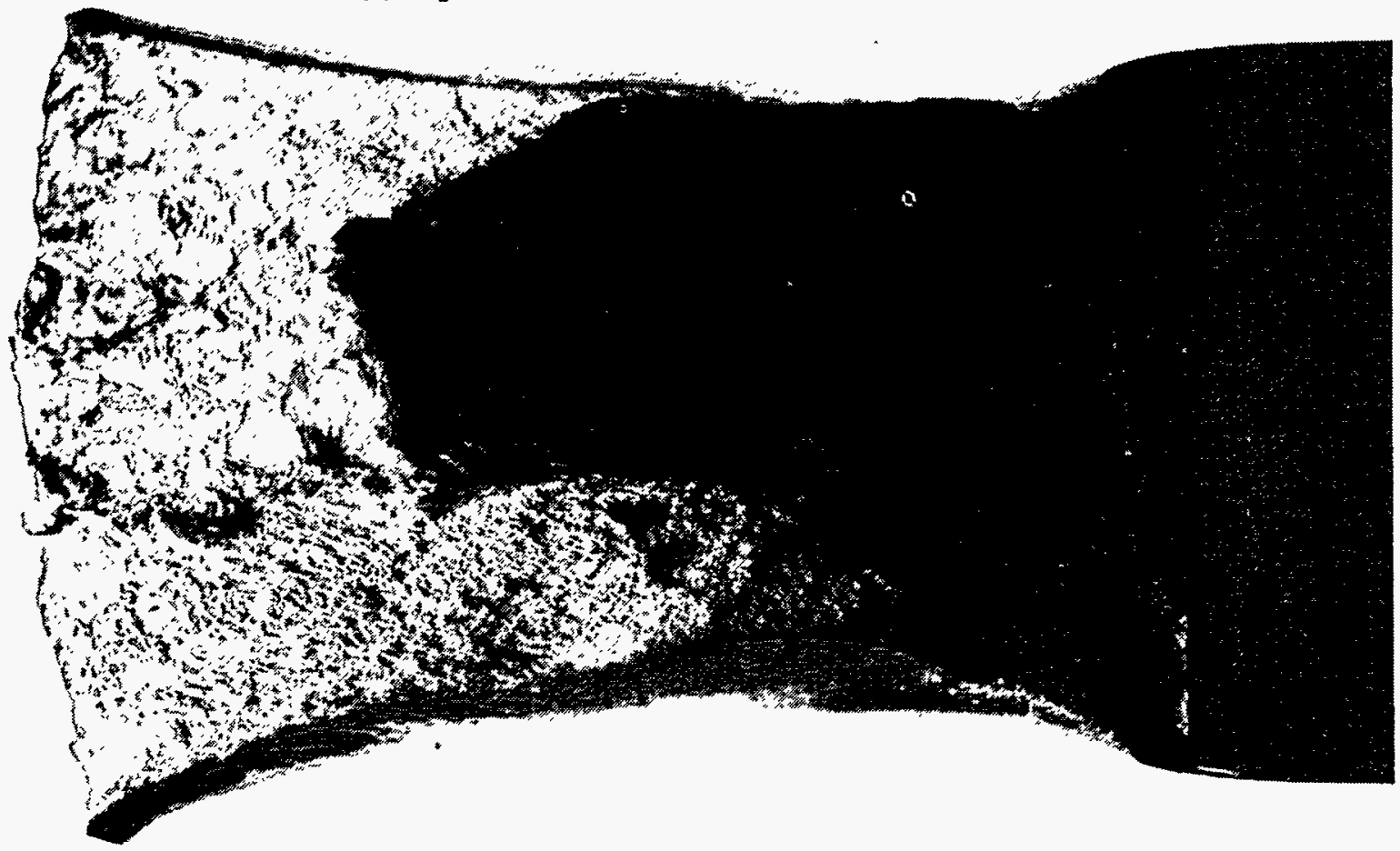

(b) Specimen DP2-A53W1-FL-2 (highest toughness)

Figure 2.14 Fracture surfaces of flat-notch specimens (Note: less crack growth on side adjacent to the TIG weld root passes.) 
The differences are also seen in the profiles, illustrated by Figure 2.15 . The low-initiation-toughness specimen (DP2-A53W1-FL-1) has a relatively flat fracture path that lies within the weld metal, while the crack in the high-initiation-toughness specimen (DP2-A53W1-FL-2) starts in the base metal and diverts out of the crack plane until it reaches the fusion line at which time $\mathrm{dJ} / \mathrm{da}$ becomes negative.

\subsubsection{Slant-Notch Fusion-Line Experiments (Weld DP2-A8W4)}

Figure 2.16 shows that the load/displacement curves for these slant-notch specimens were reasonably reproducible. Unexplained sudden load drops occurred during testing of Specimens A8W4-FL-3 and A8W4-FL-5. (Test problems occurred for Specimen A8W4-FL-4, and hence these data are not provided.) The J-R curves were also quite reproducible, as shown in Figure 2.17. Note that the load drop for Specimen A8W4-FL-5 corresponded to a crack jump as seen in the J-R curve. The load drop for Specimen A8W4-FL-3 was smaller and the crack jump is not evident in the J-R curve. The curves in Figure 2.17 are reminiscent of the intermediate curves of the slant-Vee weld (see Fig. 2.13 ) in that they are essentially flat; almost all of the data for crack growths greater than $2 \mathrm{~mm}$ (0.079 inch) lie between $J$ values of 800 and $1,200 \mathrm{~kJ} / \mathrm{m}^{2}\left(4,568\right.$ and $\left.6,852 \mathrm{in}-\mathrm{lb} / \mathrm{in}^{2}\right)$. There appears to be a steady-state $\mathrm{J}$ value between 900 and $1,100 \mathrm{~kJ} / \mathrm{m}^{2}\left(5,139 \mathrm{in}-\mathrm{lb} / \mathrm{in}^{2}\right.$ and $\left.6,281 \mathrm{in}-1 \mathrm{~b} / \mathrm{in}^{2}\right)$, which is slightly lower than the $1,300 \mathrm{~kJ} / \mathrm{m}^{2}\left(7,423 \mathrm{in}-\mathrm{lb} / \mathrm{in}^{2}\right)$ asymptotic value from the DP2-A53W1 flatnotch fusion-line specimens. Figure 2.18 shows that the crack was, indeed, very close to the fusion line, but actually propagated in the weld metal a small distance from the fusion line. Hence, it may have been better to place the notch at this location to test the least-fracture-resistant plane.

Figure 2.19 compares the J-R curves for the base metal, the weld metal, and the fusion line. There is a scatter band for the fusion line because the $\mathrm{k}$ parameter in the failure criterion, Equation 2.2 , cannot be determined when experiments are conducted at only one angle. Values of $k=0$ and 1 have been arbitrarily chosen as bounds for the data. It is seen that the weld is the low toughness component of the weldment until about $10 \mathrm{~mm}$ ( 0.394 inch) of crack growth, at which point the weld metal and fusion line have roughly comparable toughnesses. It is possible that the $\mathrm{dJ} / \mathrm{da}$ of the weld is positive; whereas, for the fusion line $\mathrm{dJ} / \mathrm{da}$ it is close to zero. This observation suggests that further crack growth might occur along the fusion line.

\subsection{Discussion on Integration of Specimen Test Results with Past Results}

The experiments presented above show that the slant-notch technique works well at elevated temperatures and on fusion lines. They also present evidence that flat-notch toughness may be higher than when the crack plane is inclined.

There are problems illuminated by the flat-notch specimens, however. Unlike the slant-notch specimens, these specimens exhibit large scatter at initiation. While this scatter decreases with increasing crack growth (Figure 2.13), it still persists after $8 \mathrm{~mm}$ (0.315 inch) of growth.

There seems to be a higher steady-state $\mathrm{J}$ value, $\mathbf{J}_{\mathrm{ss}}$, for Weld DP2-A53W1 than for Weld DP2-A8W4 by about 30 percent. However, the Charpy data (Table 2.4) show the flat-notch fusion 


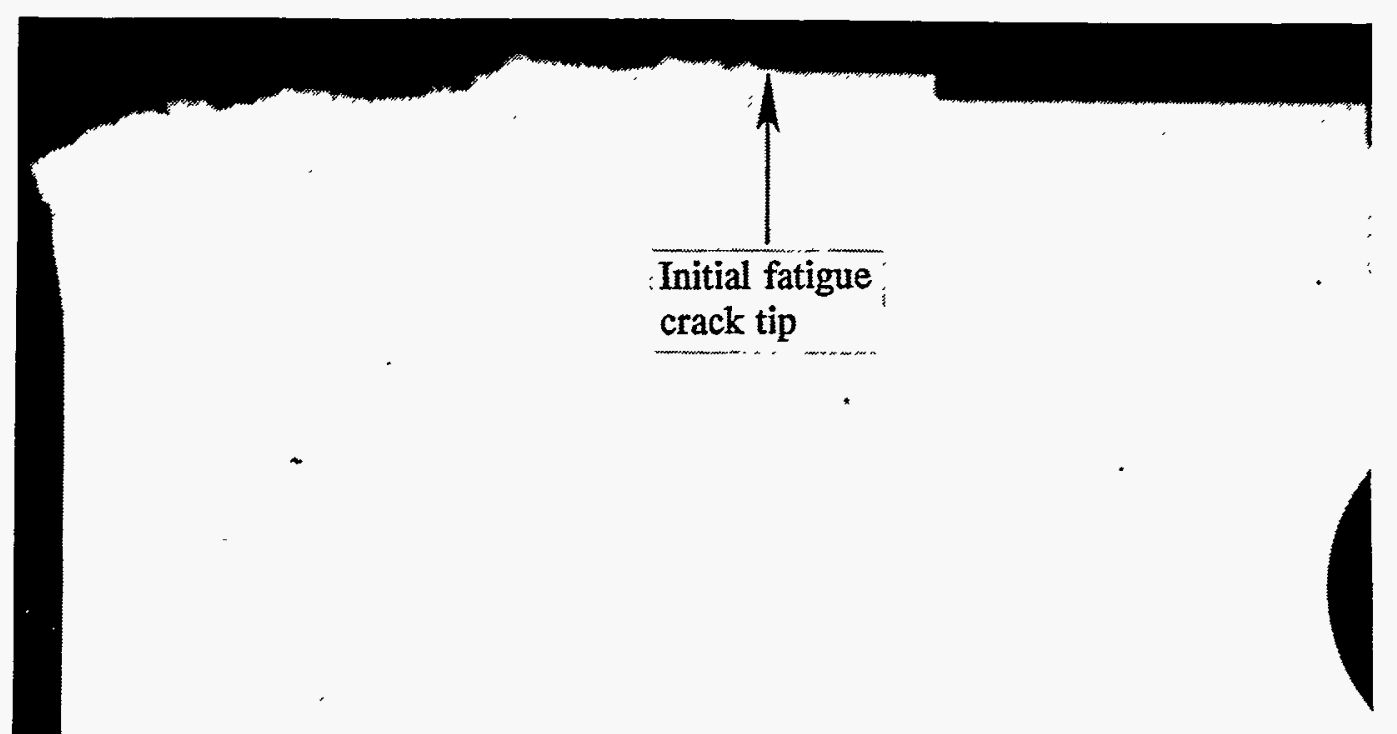

(a) Specimen DP2-A53W1-FL-1 (3X); low initiation toughness in weld metal near fusion line

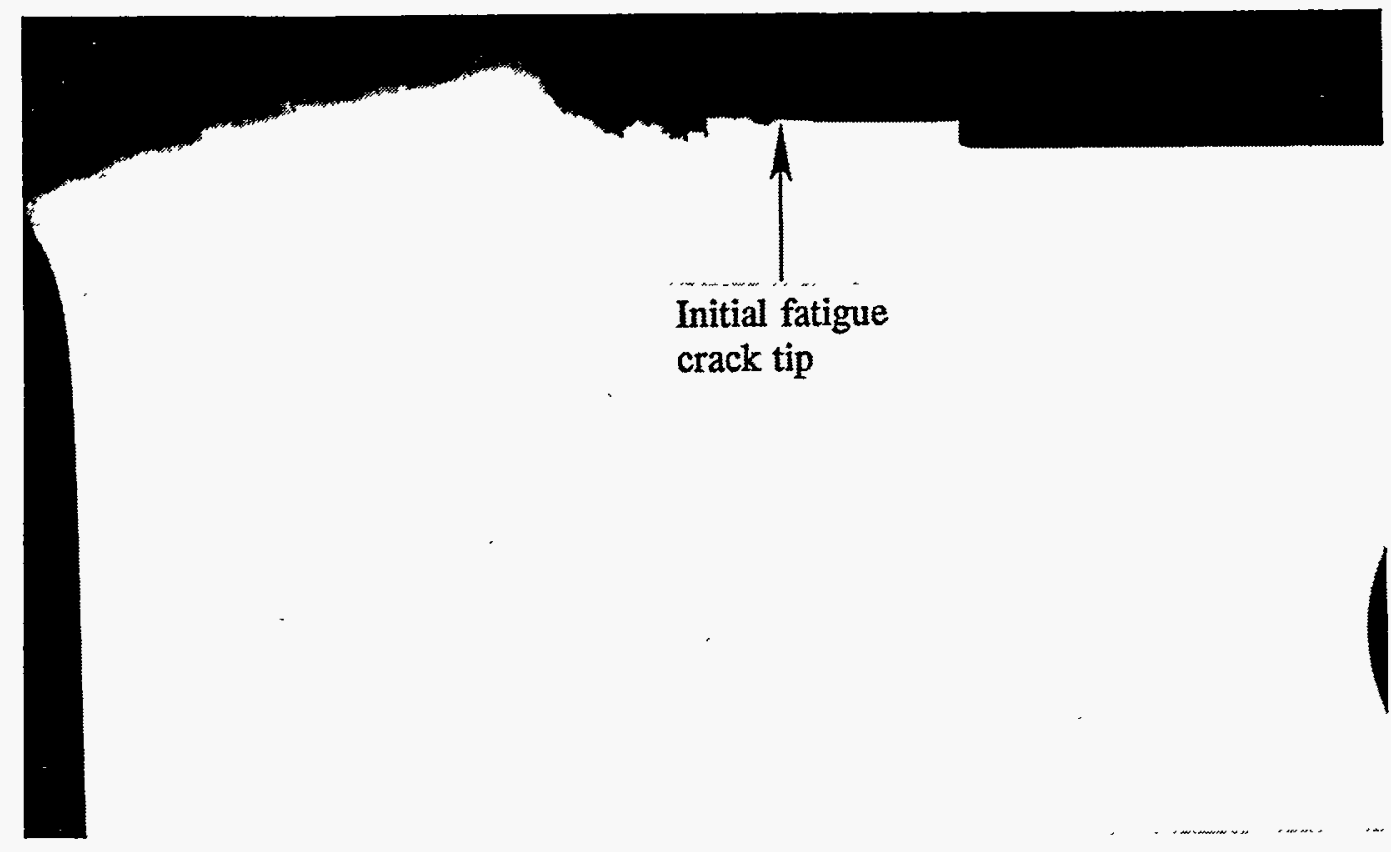

(b) Specimen DP2-A53W1-FL-2 (3X); high initiation toughness in base metal near fusion line

Figure 2.15 Low magnification profiles of centerlines of flat-notch, fusion line specimens to illustrate importance of precise crack-tip location on initiation toughness 


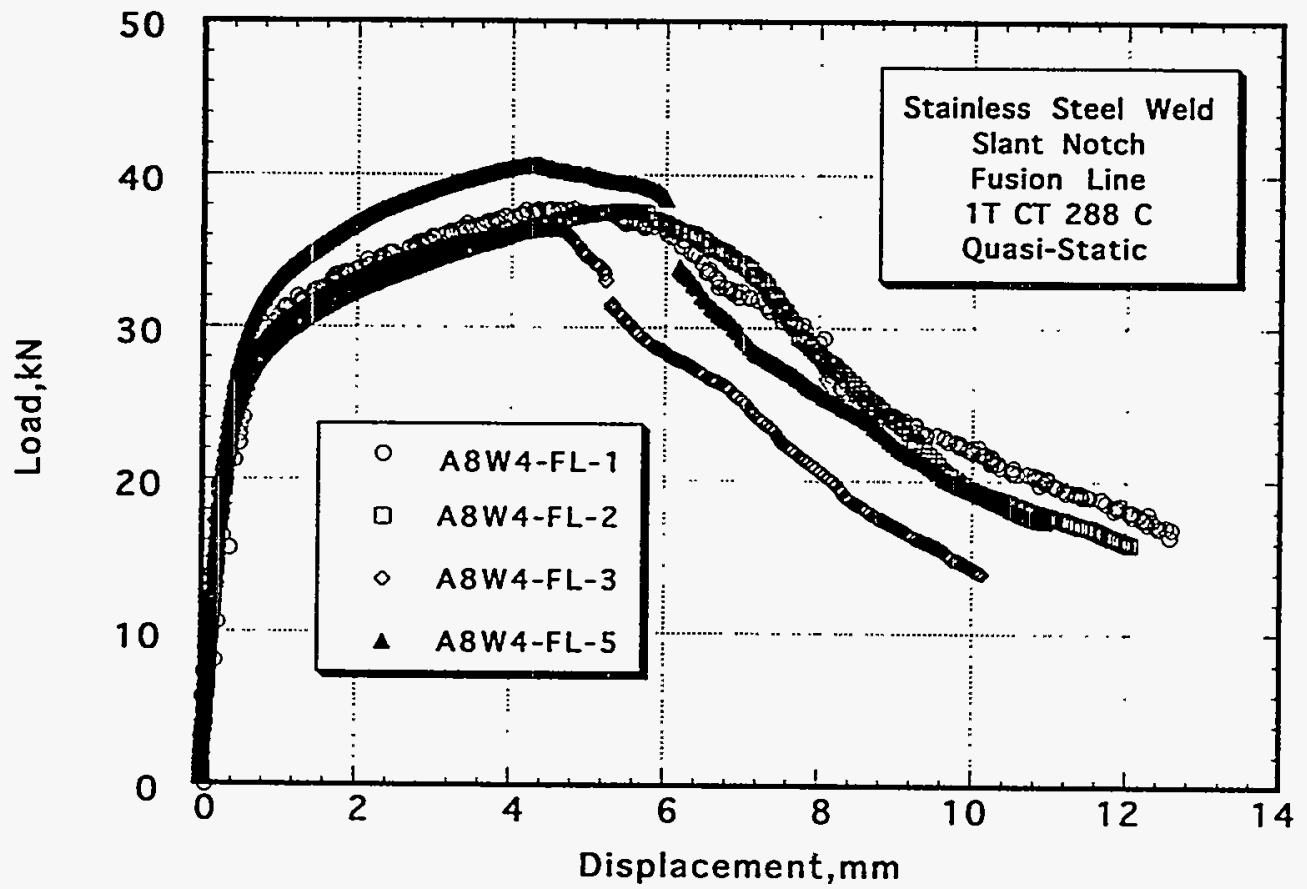

Figure 2.16 Load-displacement curves of slant-notch, fusion-line specimens (Note: There were sudden load drops in Specimens A8W4-FL-3 and -5.)

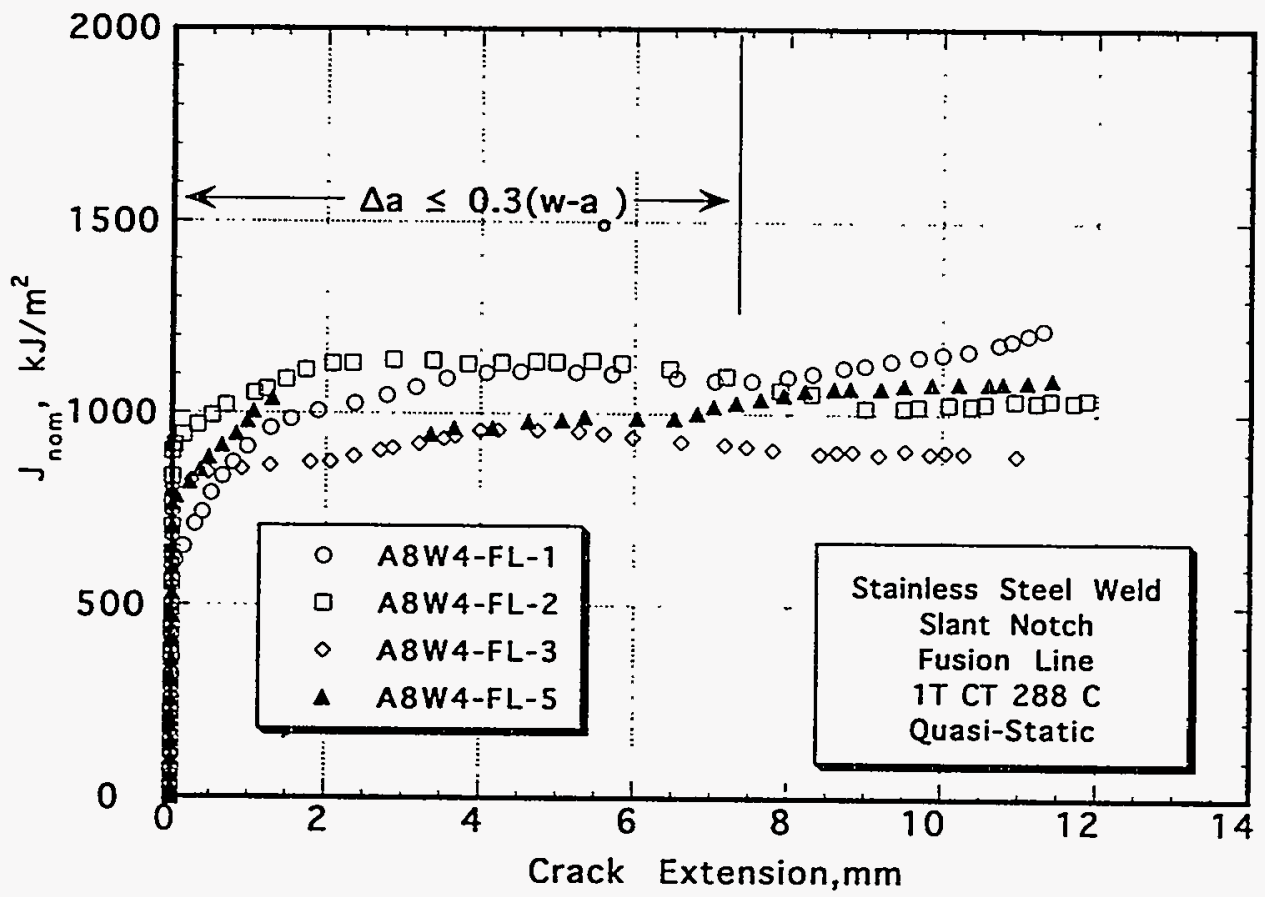

Figure 2.17 J-resistance curves of slant-notch, fusion-line specimens [limit on $\mathrm{J}$-R curve data is $\left.\Delta \mathrm{a} \leq \mathbf{0 . 3}\left(\mathrm{W}-\mathrm{a}_{0}\right)\right]$ (Note: The sudden load drop for Specimen A8W4-FL-5 corresponded to a significant crack jump as shown in the load-displacement data.) 


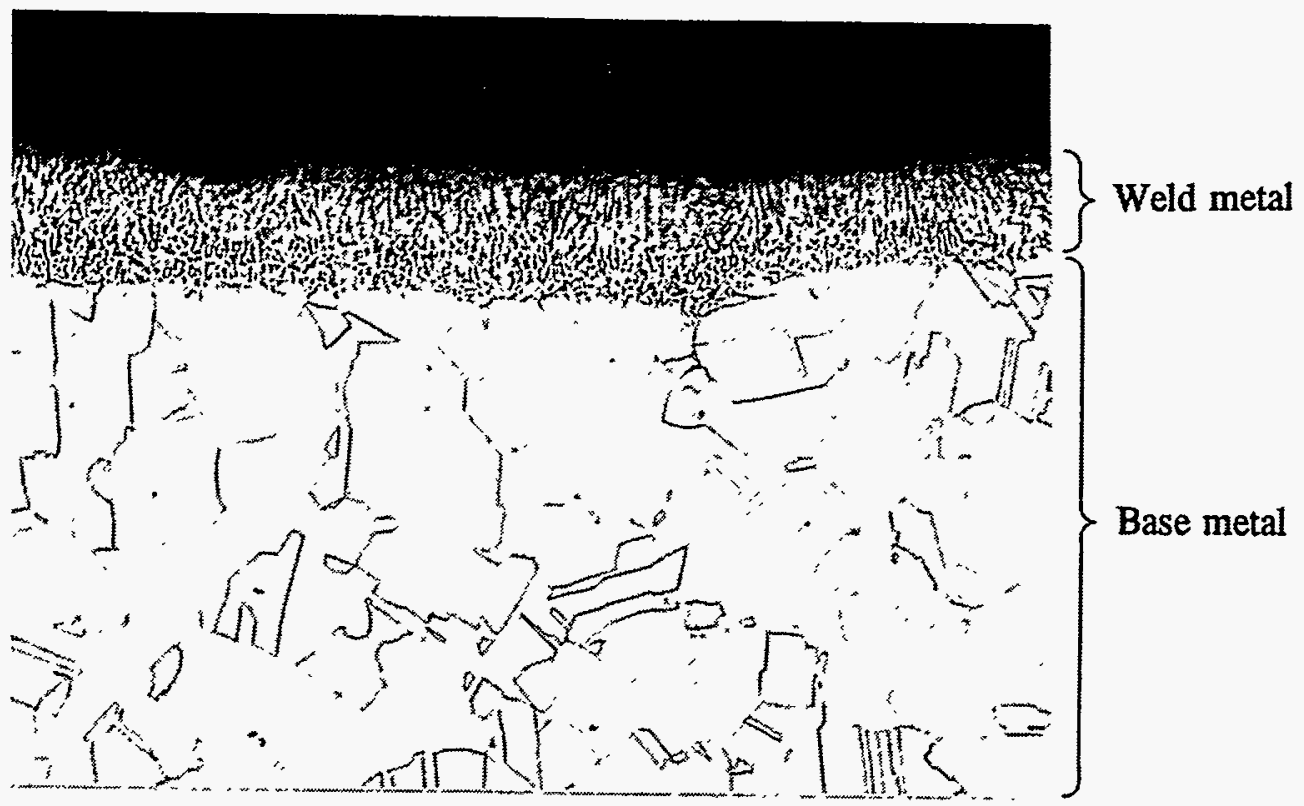

Figure 2.18 High-magnification (100X) profile of slant-notch, fusion-line Specimen DP2-A8W-1

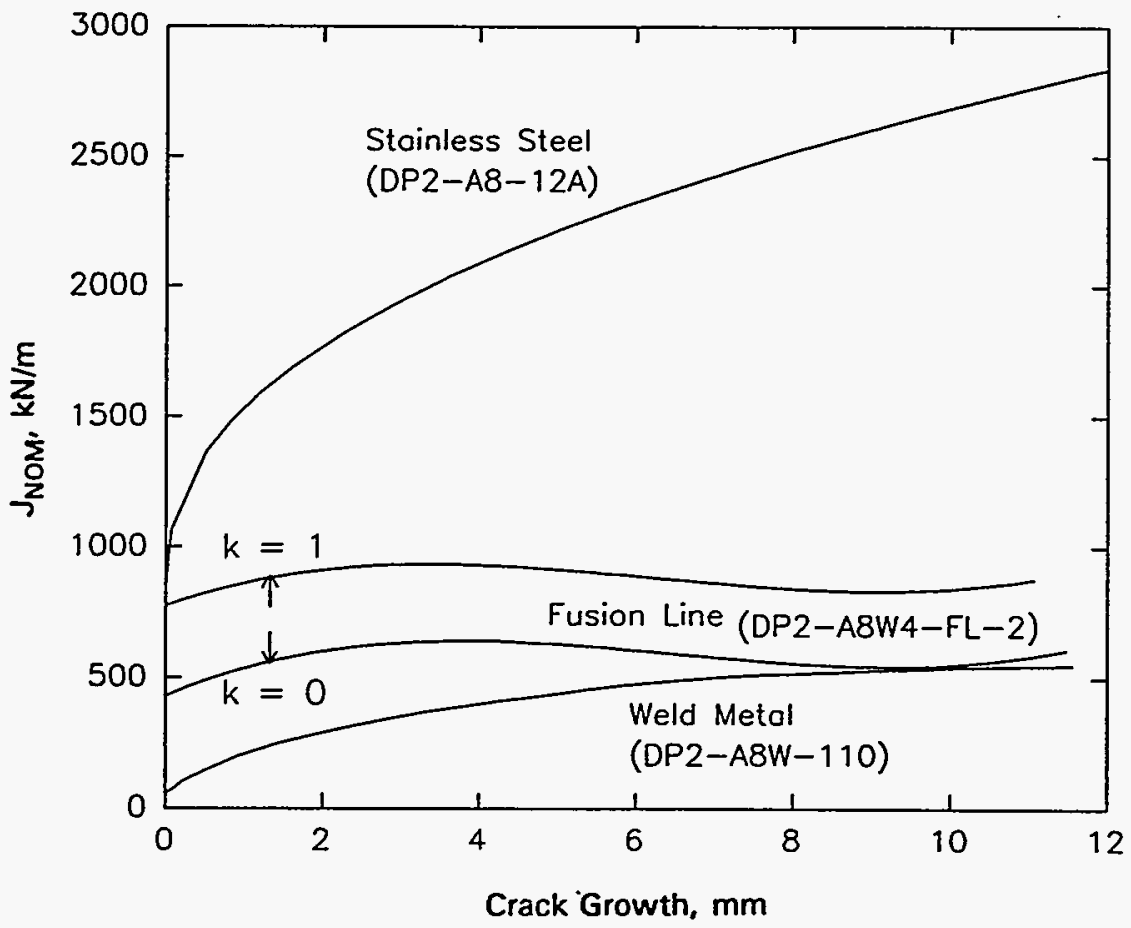

Figure 2.19 Comparison of $J_{\text {nom }}$ resistance curves for base metal, weld, and fusion line 
line (DP2-A53W1) to have about a factor of 5 higher impact energy than the slant-notch fusion line (DP2-A8W4), a result at variance with the compact specimen data. There are three possible reasons for Charpy-specimen data not mirroring those of compact specimens:

(1) High loading rate.

(2) Use of a notch instead of a crack.

(3) Low constraint.

Since stainless steel is not highly sensitive to loading rate at $288 \mathrm{C}(550 \mathrm{~F})$, Ref. 2.12 , the high loading rate argument does not hold. Use of a blunter notch, rather than a sharp crack, spreads out the stress field, so that the resulting crack can pick out the fracture path of least resistance.

However, it is difficult to see how this factor can explain the results. The constraint explanation is even more difficult to assess because of the additional constraint due to weld mismatch (both weldments appeared to have the same degree of overmatching strength, judging from the hardness results in Table 2.2). As a result, the reason that the Charpy specimen does not provide a good screening test is unresolved. The practical effect was that the ASME Section XI Charpy energy versus $\mathrm{J}_{1 \mathrm{~mm}}$ correlation was very conservative and could not be used to estimate toughness accurately. Also, to determine the steady-state J-R curve value, there is a great degree of conservatism in the ASME $\mathrm{J}_{1 \mathrm{~mm}}$ values. Hence, to take advantage of this conservatism the $\mathrm{J}_{\mathrm{ss}}$ value would have to be developed from compact specimen experiments.

The crack growth resistance of the fusion line appeared to reach a steady-state value, while the SAW $\mathrm{J}-\mathrm{R}$ curve had an increasing J-R curve. Figure 2.20, which came from Degraded Piping Program

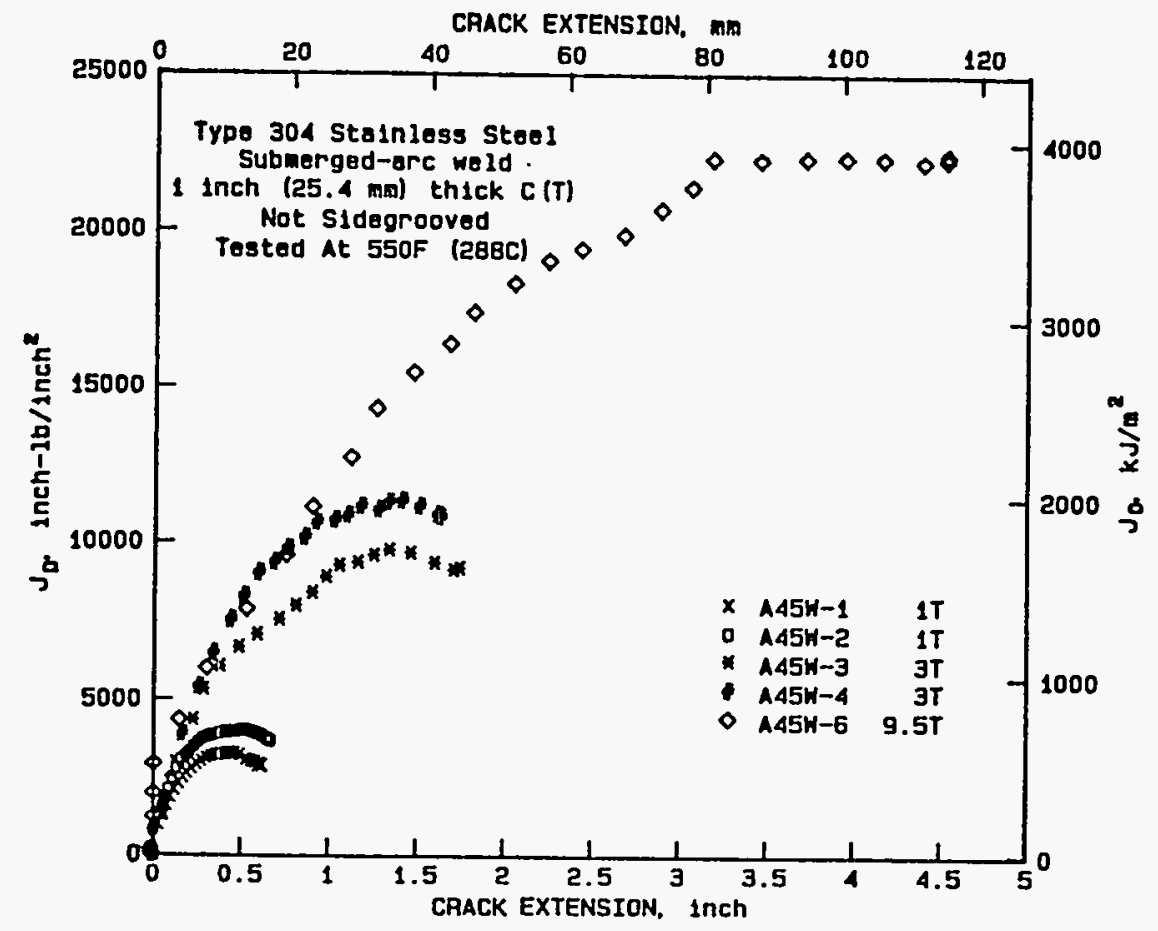

Figure 2.20 $J_{D}-R$ curves for austenitic SAW C(T) specimens of various planform sizes (Ref. 2.14) 
experiments, Ref. 2.14, also shows an increasing J-R curve. The $C(T)$ specimens in Figure 2.20 were all 25.4-mm (1.0-inch) thick. In checking the fracture surface on the $9.5 \mathrm{~T} \mathrm{C}(\mathrm{T})$ specimen (still in the Battelle specimen archive room), it was found that during the initial 38 to $51 \mathrm{~mm}$ (1.5 to 2.0 inches) of growth, the crack was in the weld metal, but then later turned into the fusion line. Hence, with the larger $C(T)$ specimen, the SAW $J_{D}-R$ curve continued to increase with larger amounts of crack growth than that shown in Figure 2.19. It is unclear whether the growth into the fusion line caused the 9.5T C(T) specimen J-R curve to decrease in slope or whether the decrease was due to approaching the crack growth limit of 30 percent of the initial ligament $[72.4 \mathrm{~mm}$ (2.85 inch)] as suggested in Reference 2.13. This result suggests that to ensure conservatism for stainless steel welds with cracks close to the fusion line, the weld metal J-R curve should be used up to the point of the fusion-line steady-state value. Large C(T) specimen tests (such as those done in Reference 2.14) with the initial crack in the fusion line would help to confirm this hypothesis.

An important implication of this work is that the toughness of wrought stainless steel fusion lines can be lower than the toughness from SAW or SMAW weld metal after small amounts of crack growth. The ASME austenitic pipe flaw evaluation criterion was the SAW and SMAW J-R curves. These Zfactors will be affected if calculated using the fusion-line toughness J-R curves established in this report. The Z-factors would probably increase for larger diameter pipe where there is more crack growth in the analysis. The magnitude of these changes to the $Z$-factors has not been determined in this report.

This effect of the wrought stainless steel fusion-line toughness reaching a steady-state value after a small amount of crack growth can also be important for LBB implications. It is anticipated that the same effect of a steady-state toughness in the fusion line may also exist for cast stainless steel welds, since the welding procedures are very similar. A question of the applicability of these results is whether cracks will form along the fusion line in cast stainless steel piping. IGSCC may not be as likely in the cast stainless steels, but weld fabrication defects (i.e., lack of side wall fusion) may occur. Hence, fusion line cracks can be relevant to cast stainless steel piping.

In regard to the lower fusion-line crack-tip-opening angle in Figure 1.6, the implication from the comparisons of the weld metal and fusion-line crack-tip-opening angles was that the fusion-line toughness was a factor of 3 less than that of the weld in that work. This difference in the fusion-line and weld-metal toughness was not observed in the work performed in this effort. A contributing factor may be the direction of crack growth. In the C(T) tests performed in this effort, the crack grew as a through-wall crack; whereas in the past work on the Figure 1.6 specimens, the crack was growing as a surface crack. Some tests in the through-thickness or radial direction with single-edge-notched specimens with smaller specimen thicknesses than used in the past study might help to clarify this discrepancy.

As a final note, it appears from the metallographic evaluations that the low fracture resistance path in these tests was actually in the weld metal about $0.1 \mathrm{~mm}(0.004 \mathrm{inch})$ from the fusion line. Hence, we may have seen more consistent results if we put the initial crack tip at that location, although frequently IGSCCs just stop at the fusion line. The fracture locations in these C(T) tests, however, appear to be more in the weld metal; whereas the metallographic sections in Figure 1.8 from a pipe experiment showed that the crack may propagate in either the fusion line or the weld metal, and 
possibly also in the base metal close to the fusion line. Hence, there may be a composite toughness for such a case.

\subsection{References}

2.1 Wilkowski, G. M., and others, "Analysis of Experiments on Stainless Steel Flux Welds," NUREG/CR-4878, April 1987.

2.2 Welding Handbook - Volume 2 - Welding Processes - Arc and Gas Welding and Cutting, Brazing, and Soldering, 7th edition, ISBN 0-87171-1486, published by American Welding Society, 1978.

2.3 Manoharan, M., Hirth, J. P., and Rosenfield, A. R., "A Suggested Procedure for Combined Mode I - Mode III Fracture Toughness Testing," J. Testing and Evaluation, Vol. 18, 106-114, (1990).

2.4 Manoharan, M., "On the Relationship Between Mode I Fracture Toughness and Susceptibility to Mixed-Mode Fracture," Scripta Met. Mat., Vol. 26, 1187-1192, (1992).

2.5 Schroth, J. G. and others, "Combined Mode I-Mode III Fracture of a High-Strength Low Alloy Steel," Metall. Trans. A, Vol. 18A, 1061-1072, (1987).

2.6 Raghavachary, S., Rosenfield, A. R., and Hirth, J. P., "Mixed Mode I/III Fracture Toughness of an Experimental Rotor Steel," Metall. Trans. A, Vol. 21A, 2539-2545, (1990).

2.7 Manoharan, M., Hirth, J. P., and Rosenfield, A. R., "Combined Mode I-Mode III Fracture Toughness of a High Carbon Steel," Scripta Met., Vol. 23, 763-766, (1989).

2.8 Manoharan, M., Hirth, J. P., and Rosenfield, A. R., "Combined Mode I-Mode III Fracture Toughness of a Spherodized 1090 Steel," Acta Met. Mat., Vol. 39, 1203-1210, (1991).

2.9 Kamat, S. V., and Hirth, J. P., "A Mixed Mode I/III Fracture Toughness Correlation," Scripta Met. et Mat., Vol. 30, 145-148, (1994).

2.10 Miglin, M. T., Hirth, J. P., and Rosenfield, A. R., "Development of Fractographic Features During Shear Failure of an HSLA Steel," Res. Mechanica, Vol. 11, 85-95, (1984).

2.11 Marschall, C. W. and others, "Use of the Direct-Current Electric Potential Method to Monitor Large Amounts of Crack Growth in Highly Ductile Metals," Fracture Mechanics: Twenty First Symposium, ASTM STP 1074, J. P. Gudas, J. A. Joyce, and E. M. Hackett, Eds., American Society for Testing and Materials, Philadelphia, 581-593, (1990).

2.12 Marschall, C. W., Landow, M., and Wilkowski, G. M., "Loading Rate Effects on Strength and Fracture Toughness of Pipe Steels Used in Task 1 of the IPIRG Program," NUREG/CR-6098, October 1993. 
2.13 Wilkowski, G. M., Marschall, C. W., and Landow, M., "Extrapolations of C(T) Specimens J-R Curves for Use in Pipe Flaw Evaluations," ASTM STP 1074, 1990, pp 56-84.

2.14 Wilkowski, G. M. and others, "Degraded Piping Program - Phase II," Sixth Program Report, October 1986-September 1987, by Battelle Columbus Laboratories, NUREG/CR-4082, Vol. 6, April 1988. 


\subsection{SUMMARY AND CONCLUSIONS}

From past data, and data developed in this program, several observations and conclusions can be made.

(1) Measurements of the toughness in the fusion line with a sharp crack specimen are highly sensitive to the crack tip location relative to the fusion line. The plane of lowest fracture resistance was about $0.1 \mathrm{~mm}(0.004 \mathrm{inch})$ from the fusion line in the weld metal for these tests. Preferably, more replicate specimens than typically used for base metal tests should be tested for fusion line evaluations, and the specimens may require metallographic sectioning to explain any unusual results. This need for a greater number of specimens for fusion-line testing is not surprising. Perhaps the Charpy tests were more reproducible because it is easier to get the fusion line in the high stress region ahead of the blunt notch.

(2) The energy values of the Charpy fusion-line specimens were more consistent than the $C(T)$ specimen $J_{I c}$ values and gave the same relative ranking of the initiation toughness of the two welds evaluated; however, the consistency of the $J_{\mathrm{Ic}}$ data to Charpy energy data was not very good. The Charpy energy data at $288 \mathrm{C}(550 \mathrm{~F})$ showed that Weld DP2-A53W1 was 4.8 times tougher than Weld DP2-A8W4; whereas the C(T) specimen data showed that, for the valid specimens, the $\mathrm{J}_{\mathrm{Ic}}$ of Weld DP2-A53W1 was 1.5 times tougher than Weld DP2-A8W4.

(3) The $J_{1 \mathrm{~mm}}$ values calculated from the Charpy energy data using the ASME Section XI Appendix H, Ref. 3.1, correlation (see Table 3.1) were conservative for both fusion lines. Based on the mean values, the conservatism was extreme for both DP2-A8W4 and DP2-A53W1.

If the ASME Charpy energy correlation is to be used, it may be very conservative, e.g., by a factor of 9 in the case of Weld DP2-A8W4. The effect of this conservatism on estimating pipe failure loads was not investigated.

Table 3.1 Crack growth resistance parameters

\begin{tabular}{|c|c|c|c|}
\hline \multirow[b]{2}{*}{$\begin{array}{l}\text { Fusion Line } \\
\text { Designation }\end{array}$} & \multicolumn{2}{|c|}{$J_{1 \mathrm{~mm}}, \mathrm{kN} / \mathrm{m}(\mathrm{lb} / \mathrm{in})$} & \multirow[b]{2}{*}{$\begin{array}{c}\mathrm{J}_{\mathrm{ss}} \\
\mathrm{kN} / \mathrm{m} \text { (lb/in) }\end{array}$} \\
\hline & $\begin{array}{c}\text { ASME Section XI } \\
\text { Appendix H } \\
\text { Charpy Estimate }\end{array}$ & Actual & \\
\hline DP2-A8W4 & $\begin{array}{c}85 \pm 5 \\
(486 \pm 29)\end{array}$ & $\begin{array}{c}766 \pm 150 \\
(4372 \pm 856)\end{array}$ & $\begin{array}{c}1030 \pm 117 \\
(5890 \pm 669)\end{array}$ \\
\hline DP2-A53W1 & $\begin{array}{c}407 \pm 72 \\
(2325 \pm 411)\end{array}$ & $\begin{array}{c}1177 \pm 806 \\
(6724 \pm 4603)\end{array}$ & $\begin{array}{c}1321 \pm 171 \\
(7550 \pm 977)\end{array}$ \\
\hline
\end{tabular}


(4) For the materials evaluated in this report, the initiation toughness of the stainless steel base metal was much higher than the SAW or the fusion line. The fusion line toughness $\mathrm{J}_{\mathrm{Ic}}$ was greater than the SAW toughness.

(5) A comparison of toughness values from slant-notch to flat-notch specimens generally requires two different angled notches. The two welds used, one for flat and one for slant notch specimens, had drastically different Charpy energies along their fusion lines. Hence, the effect of notch type on fusion-line toughness was clouded by the toughness variation between the welds.

(6) The nominal mixed-mode toughness of the stainless steel base metal was significantly less than $\mathbf{J}_{\text {ic }}$. This result is consistent with the general behavior of steels illustrated in this report, where higher toughness leads to greater shear sensitivity. As a result, this orientation effect might cause a fusion-line crack to grow into the base metal near the weld.

(7) The crack growth resistance of the fusion line appeared to reach a steady-state value, while the SAW J-R curve had an increasing J-R curve. This result suggests that to be conservative for stainless steel welds with cracks close to the fusion line, the weld metal J-R curve should be used up to the point of the fusion-line steady-state value; thereafter, the J-R curve should remain at the fusion-line steady-state $J$ value. A large $C(T)$ specimen test with the initial crack in the fusion line would help to confirm this hypothesis.

(8) If the crack tip is slightly off the fusion line in the base metal, the initiation toughness may be high, but the crack can quickly grow into the lower tougher fusion line and produce a decreasing J-R curve as was seen with Specimen A53W1-FL-2. From our knowledge, such a decreasing toughness curve has never been observed when testing homogeneous specimens.

(9) The final and most important conclusion is that the fusion-line J-R curve results can have an impact on the ASME Section XI austenitic pipe flaw evaluation criteria and LBB analyses for wrought and probably cast stainless steels.

In trying to rationalize the observed fracture behavior in Section 1 of this report, the apparent steadystate fusion-line toughness compared with the increasing weld metal J-R curve may explain why the cracks in many of the pipe tests grew out of the center of the weld and followed the fusion line. Other factors that could also force the crack to follow the fusion line are: the center of the weld in most of the pipe experiments was thicker than the pipe due to the weld crown being left on. The crack may want to turn to the toe of the weld crown where the thickness is less and where there is a slight stress concentration. It has also been observed that on the inside of the pipe, the crack will go to either the root of the weld or to the counterbore. The root of the weld and counterbore are slight stress risers, which would help to guide the crack, like using side grooves in a laboratory specimen. However, in one pipe experiment, see Figure 1.8, the weld crown was removed, and the crack still followed the fusion line. Hence, the presence of a weld crown may have helped the crack turn to the fusion line, but perhaps, due to the lower crack growth resistance of the fusion line, the crack may have turned into the fusion line anyway. From these results it is concluded that the presence of the weld crown is not a sufficient condition to cause a crack to follow the fusion line. 
Finally, in regard to the lower fusion-line crack-tip-opening angle in Figure 1.6, the implication from the comparisons of the weld metal and fusion-line crack-tip-opening angles was that the fusion-line toughness was a factor of 3 less than that of the weld in that work. This degree of difference in the fusion-line and weld-metal toughness was not observed in the work performed in this effort. A contributing factor may be the direction of crack growth. Some tests in the through-thickness or radial direction with single-edge-notched specimens might help to clarify this discrepancy.

\subsection{References}

3.1 American Society of Mechanical Engineers, 1992 ASME Boiler and Pressure Vessel Code, Section XI, Appendix H, 1992 Edition, July 1, 1992. Published by American Society of Mechanical Engineers, New York, N.Y. 10017. 


\section{APPENDIX A}

Detailed Data from C(T) Tests 
Table A.1a J-resistance test data for Compact Specimen A53W1-FL-1 tested at $288 \mathrm{C}(550 \mathrm{~F})$; SI units

\begin{tabular}{|c|c|c|c|c|c|}
\hline $\begin{array}{c}\text { Load, } \\
\text { kN }\end{array}$ & $\begin{array}{c}\text { Load-Line } \\
\text { Displacement, } \\
\text { mm }\end{array}$ & $\begin{array}{c}\text { Crack } \\
\text { Length, } \\
\text { mm }\end{array}$ & $\begin{array}{c}\text { Crack } \\
\text { Extension, } \\
\text { mm }\end{array}$ & $\underset{\mathbf{k J} / \mathbf{m}^{2}}{\mathbf{J}_{\mathbf{D}}}$ & $\underset{\mathbf{k J} / \mathbf{m}^{2}}{\mathbf{J}_{M}}$ \\
\hline 0.000 & 0.000 & 26.561 & 0.000 & 0.0 & 0.0 \\
\hline 11.325 & 0.223 & 26.561 & 0.000 & 7.3 & 7.3 \\
\hline 26.765 & 0.620 & 26.561 & 0.000 & 47.4 & 47.4 \\
\hline 27.308 & 0.657 & 26.561 & 0.000 & 52.7 & 52.7 \\
\hline 29.123 & 0.868 & 26.561 & 0.000 & 84.2 & 84.2 \\
\hline 30.355 & 1.141 & 26.561 & 0.000 & 127.2 & 127.2 \\
\hline 31.020 & 1.389 & 26.561 & 0.000 & 167.5 & 167.5 \\
\hline 31.331 & 1.526 & 26.561 & 0.000 & 190.0 & 190.0 \\
\hline 31.906 & 1.798 & 26.561 & 0.000 & 235.6 & 235.6 \\
\hline 32.118 & 1.922 & 26.561 & 0.000 & 256.6 & 256.6 \\
\hline 32.325 & 2.282 & 26.561 & 0.000 & 318.0 & 318.0 \\
\hline 32.427 & 2.468 & 26.561 & 0.000 & 349.9 & 349.9 \\
\hline 32.473 & 2.592 & 26.561 & 0.000 & 371.2 & 371.2 \\
\hline 32.545 & 2.915 & 26.561 & 0.000 & 426.7 & 426.7 \\
\hline 32.527 & 3.138 & 26.561 & 0.000 & 465.1 & 465.1 \\
\hline 32.512 & 3.200 & 26.561 & 0.000 & 475.8 & 475.8 \\
\hline 32.512 & 3.200 & 26.561 & 0.000 & 475.8 & 475.8 \\
\hline 32.318 & 3.460 & 26.752 & 0.191 & 515.1 & 520.0 \\
\hline 32.181 & 3.584 & 26.874 & 0.313 & 532.7 & 540.9 \\
\hline 31.679 & 3.894 & 27.179 & 0.618 & 576.0 & 593.2 \\
\hline 31.191 & 4.130 & 27.398 & 0.837 & 608.6 & 632.7 \\
\hline 30.884 & 4.266 & 27.542 & 0.981 & 626.5 & 655.4 \\
\hline 30.329 & 4.552 & 27.873 & 1.312 & 661.9 & 702.4 \\
\hline 29.947 & 4.812 & 28.122 & 1.561 & 695.5 & 745.3 \\
\hline 29.681 & 4.973 & 28.300 & 1.739 & 715.0 & 771.8 \\
\hline 29.248 & 5.234 & 28.597 & 2.036 & 745.3 & 814.3 \\
\hline 28.265 & 5.631 & 29.006 & 2.445 & 791.5 & 878.4 \\
\hline 27.919 & 5.730 & 29.132 & 2.571 & 801.6 & 894.2 \\
\hline 26.917 & 6.027 & 29.581 & 3.020 & 826.5 & 940.4 \\
\hline 26.267 & 6.226 & 29.915 & 3.354 & 840.4 & 970.8 \\
\hline 25.264 & 6.635 & 30.414 & 3.853 & 876.7 & 1032.8 \\
\hline 24.573 & 6.945 & 30.782 & 4.221 & 903.1 & 1079.2 \\
\hline 24.113 & 7.131 & 31.028 & 4.467 & 916.8 & 1106.8 \\
\hline 23.517 & 7.367 & 31.309 & 4.748 & 935.2 & 1141.5 \\
\hline 22.677 & 7.677 & 31.737 & 5.176 & 954.0 & 1186.0 \\
\hline 22.222 & 7.851 & 31.990 & 5.429 & 963.1 & 1210.6 \\
\hline 21.515 & 8.136 & 32.357 & 5.796 & 979.8 & 1250.7 \\
\hline 21.209 & 8.297 & 32.551 & 5.990 & 989.8 & 1273.3 \\
\hline 20.733 & 8.558 & 32.885 & 6.325 & 1003.4 & 1309.2 \\
\hline 20.358 & 8.793 & 33.176 & 6.615 & 1016.1 & 1341.7 \\
\hline 19.911 & 9.054 & 33.453 & 6.892 & 1032.4 & 1377.6 \\
\hline 19.492 & 9.277 & 33.691 & 7.130 & 1045.8 & 1408.1 \\
\hline 18.994 & 9.488 & 33.948 & 7.387 & 1055.1 & 1436.4 \\
\hline 18.269 & 9.835 & 34.354 & 7.793 & 1069.9 & 1482.0 \\
\hline 17.750 & 10.108 & 34.615 & 8.055 & 1085.3 & 1517.8 \\
\hline 17.528 & 10.232 & 34.737 & 8.176 & 1091.8 & 1534.0 \\
\hline 16.796 & 10.579 & 35.134 & 8.573 & 1103.1 & 1577.8 \\
\hline 16.254 & 10.778 & 35.441 & 8.880 & 1101.9 & 1602.1 \\
\hline 15.851 & 10.902 & 35.632 & 9.071 & 1100.8 & 1617.2 \\
\hline 15.485 & 11.013 & 35.801 & 9.241 & 1099.8 & 1630.6 \\
\hline
\end{tabular}


Table A.1b J-resistance test data for Compact Specimen A53W1-FL-1 tested at $288 \mathrm{C}$ (550 F); English units

\begin{tabular}{|c|c|c|c|c|c|}
\hline $\begin{array}{l}\text { Load, } \\
\text { lb }\end{array}$ & $\begin{array}{l}\text { Load-Line } \\
\text { Displacement, } \\
\text { inch }\end{array}$ & $\begin{array}{c}\text { Crack } \\
\text { Length, } \\
\text { inch }\end{array}$ & $\begin{array}{c}\text { Crack } \\
\text { Extension, } \\
\text { inch }\end{array}$ & $\begin{array}{c}\begin{array}{c}J_{D}, \\
\text { inch-lb }\end{array} \\
\text { inch }^{2}\end{array}$ & $\frac{\begin{array}{c}\mathbf{J}_{\mathrm{M}} \\
\text { inch-lb }\end{array}}{\text { inch }^{2}}$ \\
\hline 0 & 0.0000 & 1.0457 & 0.0000 & 0 & 0 \\
\hline 2517 & 0.0088 & 1.0457 & 0.0000 & 42 & 42 \\
\hline 5948 & 0.0244 & 1.0457 & 0.0000 & 271 & 271 \\
\hline 6069 & 0.0259 & 1.0457 & 0.0000 & 301 & 301 \\
\hline 6472 & 0.0342 & 1.0457 & 0.0000 & 481 & 481 \\
\hline 6746 & 0.0449 & 1.0457 & 0.0000 & 726 & 726 \\
\hline 6893 & 0.0547 & 1.0457 & 0.0000 & 956 & 956 \\
\hline 6963 & 0.0601 & 1.0457 & 0.0000 & 1085 & 1085 \\
\hline 7090 & 0.0708 & 1.0457 & 0.0000 & 1345 & 1345 \\
\hline 7137 & 0.0757 & 1.0457 & 0.0000 & 1465 & 1465 \\
\hline 7183 & 0.0898 & 1.0457 & 0.0000 & 1816 & 1816 \\
\hline 7206 & 0.0972 & 1.0457 & 0.0000 & 1998 & 1998 \\
\hline 7216 & 0.1021 & 1.0457 & 0.0000 & 2119 & 2119 \\
\hline 7232 & 0.1148 & 1.0457 & 0.0000 & 2436 & 2436 \\
\hline 7228 & 0.1235 & 1.0457 & 0.0000 & 2656 & 2656 \\
\hline 7225 & 0.1260 & 1.0457 & 0.0000 & 2717 & 2717 \\
\hline 7225 & 0.1260 & 1.0457 & 0.0000 & 2717 & 2717 \\
\hline 7182 & 0.1362 & 1.0532 & 0.0075 & 2941 & 2969 \\
\hline 7151 & 0.1411 & 1.0580 & 0.0123 & 3042 & 3089 \\
\hline 7040 & 0.1533 & 1.0700 & 0.0243 & 3289 & 3387 \\
\hline 6931 & 0.1626 & 1.0786 & 0.0329 & 3475 & 3613 \\
\hline 6863 & 0.1680 & 1.0843 & 0.0386 & 3577 & 3742 \\
\hline 6740 & 0.1792 & 1.0974 & 0.0517 & 3779 & 4011 \\
\hline 6655 & 0.1895 & 1.1072 & 0.0615 & 3971 & 4256 \\
\hline 6596 & 0.1958 & 1.1142 & 0.0685 & 4083 & 4407 \\
\hline 6500 & 0.2061 & 1.1259 & 0.0802 & 4256 & 4650 \\
\hline 6281 & 0.2217 & 1.1420 & 0.0963 & 4519 & 5016 \\
\hline 6204 & 0.2256 & 1.1469 & 0.1012 & 4577 & 5106 \\
\hline 5982 & 0.2373 & 1.1646 & 0.1189 & 4719 & 5370 \\
\hline 5837 & 0.2451 & 1.1777 & 0.1320 & 4799 & 5543 \\
\hline 5614 & 0.2612 & 1.1974 & 0.1517 & 5006 & 5897 \\
\hline 5461 & 0.2734 & 1.2119 & 0.1662 & 5157 & 6162 \\
\hline 5358 & 0.2808 & 1.2216 & 0.1759 & 5235 & 6320 \\
\hline 5226 & 0.2900 & 1.2326 & 0.1869 & 5340 & 6518 \\
\hline 5039 & 0.3023 & 1.2495 & 0.2038 & 5447 & 6772 \\
\hline 4938 & 0.3091 & 1.2594 & 0.2137 & 5499 & 6913 \\
\hline 4781 & 0.3203 & 1.2739 & 0.2282 & 5594 & 7141 \\
\hline 4713 & 0.3267 & 1.2815 & 0.2358 & 5652 & 7270 \\
\hline 4607 & 0.3369 & 1.2947 & 0.2490 & 5730 & 7476 \\
\hline 4524 & 0.3462 & 1.3061 & 0.2604 & 5802 & 7661 \\
\hline 4425 & 0.3565 & 1.3170 & 0.2713 & 5895 & 7866 \\
\hline 4332 & 0.3652 & 1.3264 & 0.2807 & 5971 & 8040 \\
\hline 4221 & 0.3735 & 1.3365 & 0.2908 & 6025 & 8202 \\
\hline 4060 & 0.3872 & 1.3525 & 0.3068 & 6109 & 8462 \\
\hline 3944 & 0.3980 & 1.3628 & 0.3171 & 6197 & 8667 \\
\hline 3895 & 0.4028 & 1.3676 & 0.3219 & 6234 & 8759 \\
\hline 3733 & 0.4165 & 1.3832 & 0.3375 & 6299 & 9009 \\
\hline 3612 & 0.4243 & 1.3953 & 0.3496 & 6292 & 9148 \\
\hline 3522 & 0.4292 & 1.4028 & 0.3571 & 6286 & 9234 \\
\hline 3441 & 0.4336 & 1.4095 & 0.3638 & 6280 & 9311 \\
\hline
\end{tabular}


Table A.2a J-resistance test data for Compact Specimen A53W1-FL-2 tested at 288 C (550 F); SI units

\begin{tabular}{|c|c|c|c|c|c|}
\hline $\begin{array}{c}\text { Load, } \\
\text { kN }\end{array}$ & $\begin{array}{c}\text { Load-Line } \\
\text { Displacement, } \\
\text { mm }\end{array}$ & $\begin{array}{c}\text { Crack } \\
\text { Length, } \\
\text { mm }\end{array}$ & $\begin{array}{c}\text { Crack } \\
\text { Extension, } \\
\text { mm }\end{array}$ & $\underset{\mathbf{k J} / \mathbf{m}^{2}}{\mathbf{J}_{\mathbf{2}}}$ & $\underset{\mathrm{kJ} / \mathrm{m}^{2}}{\mathrm{~J}_{\mathrm{M}}}$ \\
\hline 0.000 & 0.000 & 26.617 & 0.000 & 0.0 & 0.0 \\
\hline 26.657 & 0.818 & 26.617 & 0.000 & 59.5 & 59.5 \\
\hline 29.552 & 1.631 & 26.617 & 0.000 & 179.5 & 179.5 \\
\hline 31.298 & 2.469 & 26.617 & 0.000 & 313.4 & 313.4 \\
\hline 32.669 & 3.274 & 26.617 & 0.000 & 448.7 & 448.7 \\
\hline 33.882 & 4.069 & 26.617 & 0.000 & 587.6 & 587.6 \\
\hline 34.961 & 4.892 & 26.617 & 0.000 & 736.4 & 736.4 \\
\hline 35.569 & 5.705 & 26.617 & 0.000 & 886.9 & 886.9 \\
\hline 35.938 & 6.510 & 26.617 & 0.000 & 1038.1 & 1038.1 \\
\hline 35.833 & 7.300 & 26.617 & 0.000 & 1186.9 & 1186.9 \\
\hline 35.701 & 8.161 & 26.617 & 0.000 & 1348.7 & 1348.7 \\
\hline 35.780 & 8.961 & 26.617 & 0.000 & 1498.8 & 1498.8 \\
\hline 35.886 & 9.705 & 26.617 & 0.000 & 1638.9 & 1638.9 \\
\hline 35.780 & 10.640 & 26.617 & 0.000 & 1814.7 & 1814.7 \\
\hline 35.543 & 11.349 & 26.617 & 0.000 & 1947.5 & 1947.5 \\
\hline 34.093 & 12.118 & 26.617 & 0.000 & 2088.2 & 2088.2 \\
\hline 32.827 & 12.266 & 26.908 & 0.292 & 2079.3 & 2112.8 \\
\hline 31.983 & 12.416 & 27.198 & 0.581 & 2070.4 & 2137.4 \\
\hline 30.823 & 12.576 & 27.748 & 1.131 & 2030.7 & 2161.4 \\
\hline 30.032 & 12.738 & 28.183 & 1.567 & 2005.3 & 2186.4 \\
\hline 29.057 & 12.911 & 28.508 & 1.891 & 1994.6 & 2213.4 \\
\hline 28.213 & 13.096 & 29.072 & 2.455 & 1955.7 & 2240.2 \\
\hline 27.685 & 13.259 & 29.462 & 2.846 & 1934.6 & 2264.5 \\
\hline 27.369 & 13.419 & 29.774 & 3.157 & 1922.7 & 2288.9 \\
\hline 26.657 & 13.581 & 30.148 & 3.531 & 1903.1 & 2313.2 \\
\hline 26.104 & 13.754 & 30.447 & 3.830 & 1894.1 & 2339.4 \\
\hline 24.996 & 13.927 & 30.871 & 4.255 & 1868.7 & 2364.2 \\
\hline 24.680 & 14.102 & 31.251 & 4.634 & 1848.8 & 2389.3 \\
\hline 24.179 & 14.275 & 31.613 & 4.997 & 1830.6 & 2414.2 \\
\hline 23.783 & 14.448 & 31.964 & 5.347 & 1813.6 & 2439.1 \\
\hline 23.414 & 14.623 & 32.373 & 5.757 & 1789.2 & 2463.8 \\
\hline 23.098 & 14.808 & 32.696 & 6.080 & 1777.4 & 2490.9 \\
\hline 22.676 & 15.006 & 33.123 & 6.507 & 1753.9 & 2519.1 \\
\hline 22.122 & 15.192 & 33.508 & 6.891 & 1733.6 & 2545.5 \\
\hline 21.595 & 15.380 & 33.922 & 7.305 & 1709.3 & 2571.8 \\
\hline 21.199 & 15.565 & 34.276 & 7.659 & 1692.4 & 2598.3 \\
\hline 20.751 & 15.751 & 34.778 & 8.161 & 1655.3 & 2622.9 \\
\hline 20.382 & 15.949 & 35.151 & 8.534 & 1637.5 & 2651.2 \\
\hline 20.039 & 16.137 & 35.609 & 8.993 & 1606.2 & 2676.7 \\
\hline 19.723 & 16.347 & 35.982 & 9.365 & 1590.2 & 2707.1 \\
\hline 19.433 & 16.546 & 36.427 & 9.810 & 1561.9 & 2734.5 \\
\hline 19.116 & 16.744 & 36.788 & 10.171 & 1545.2 & 2763.1 \\
\hline 18.774 & 16.942 & 37.175 & 10.558 & 1524.5 & 2791.5 \\
\hline 18.536 & 17.140 & 37.450 & 10.833 & 1519.3 & 2821.4 \\
\hline 18.246 & 17.338 & 37.869 & 11.252 & 1493.1 & 2849.2 \\
\hline 17.824 & 17.562 & 38.260 & 11.643 & 1474.9 & 2881.8 \\
\hline
\end{tabular}


Table A.2b J-resistance test data for Compact Specimen A53W1-FL-2 tested at $288 \mathrm{C}(550 \mathrm{~F})$; English units

\begin{tabular}{|c|c|c|c|c|c|}
\hline $\begin{array}{c}\text { Load, } \\
\text { lb }\end{array}$ & $\begin{array}{c}\text { Load-Line } \\
\text { Displacement, } \\
\text { inch }\end{array}$ & $\begin{array}{c}\text { Crack } \\
\text { Length, } \\
\text { inch }\end{array}$ & $\begin{array}{c}\text { Crack } \\
\text { Extension, } \\
\text { inch }\end{array}$ & $\frac{\begin{array}{c}\mathbf{J}_{\mathbf{D}}, \\
\text { inch-lb }\end{array}}{\text { inch }^{2}}$ & $\frac{J_{M},}{\text { inch-lb }}$ \\
\hline 0 & 0.0000 & 1.0479 & 0.0000 & 0 & 0 \\
\hline 5924 & 0.0322 & 1.0479 & 0.0000 & 340 & 340 \\
\hline 6567 & 0.0642 & 1.0479 & 0.0000 & 1025 & 1025 \\
\hline 6955 & 0.0972 & 1.0479 & 0.0000 & 1790 & 1790 \\
\hline 7260 & 0.1289 & 1.0479 & 0.0000 & 2562 & 2562 \\
\hline 7529 & 0.1602 & 1.0479 & 0.0000 & 3355 & 3355 \\
\hline 7769 & 0.1926 & 1.0479 & 0.0000 & 4205 & 4205 \\
\hline 7904 & 0.2246 & 1.0479 & 0.0000 & 5064 & 5064 \\
\hline 7986 & 0.2563 & 1.0479 & 0.0000 & 5927 & 5927 \\
\hline 7963 & 0.2874 & 1.0479 & 0.0000 & 6777 & 6777 \\
\hline 7934 & 0.3213 & 1.0479 & 0.0000 & 7701 & 7701 \\
\hline 7951 & 0.3528 & 1.0479 & 0.0000 & 8558 & 8558 \\
\hline 7975 & 0.3821 & 1.0479 & 0.0000 & 9358 & 9358 \\
\hline 7951 & 0.4189 & 1.0479 & 0.0000 & 10362 & 10362 \\
\hline 7898 & 0.4468 & 1.0479 & 0.0000 & 11120 & 11120 \\
\hline 7576 & 0.4771 & 1.0479 & 0.0000 & 11923 & 11923 \\
\hline 7295 & 0.4829 & 1.0594 & 0.0115 & 11873 & 12064 \\
\hline 7107 & 0.4888 & 1.0708 & 0.0229 & 11822 & 12205 \\
\hline 6850 & 0.4951 & 1.0924 & 0.0445 & 11595 & 12342 \\
\hline 6674 & 0.5015 & 1.1096 & 0.0617 & 11450 & 12484 \\
\hline 6457 & 0.5083 & 1.1224 & 0.0745 & 11389 & 12639 \\
\hline 6270 & 0.5156 & 1.1446 & 0.0967 & 11167 & 12791 \\
\hline 6152 & 0.5220 & 1.1599 & 0.1120 & 11047 & 12930 \\
\hline 6082 & 0.5283 & 1.1722 & 0.1243 & 10979 & 13070 \\
\hline 5924 & 0.5347 & 1.1869 & 0.1390 & 10867 & 13208 \\
\hline 5801 & 0.5415 & 1.1987 & 0.1508 & 10815 & 13358 \\
\hline 5555 & 0.5483 & 1.2154 & 0.1675 & 10670 & 13499 \\
\hline 5484 & 0.5552 & 1.2303 & 0.1824 & 10557 & 13643 \\
\hline 5373 & 0.5620 & 1.2446 & 0.1967 & 10453 & 13785 \\
\hline 5285 & 0.5688 & 1.2584 & 0.2105 & 10355 & 13927 \\
\hline 5203 & 0.5757 & 1.2745 & 0.2266 & 10216 & 14069 \\
\hline 5133 & 0.5830 & 1.2873 & 0.2394 & 10149 & 14223 \\
\hline 5039 & 0.5908 & 1.3041 & 0.2562 & 10015 & 14384 \\
\hline 4916 & 0.5981 & 1.3192 & 0.2713 & 9899 & 14535 \\
\hline 4799 & 0.6055 & 1.3355 & 0.2876 & 9760 & 14685 \\
\hline 4711 & 0.6128 & 1.3494 & 0.3015 & 9664 & 14836 \\
\hline 4611 & 0.6201 & 1.3692 & 0.3213 & 9452 & 14977 \\
\hline 4529 & 0.6279 & 1.3839 & 0.3360 & 9350 & 15138 \\
\hline 4453 & 0.6353 & 1.4019 & 0.3540 & 9172 & 15284 \\
\hline 4383 & 0.6436 & 1.4166 & 0.3687 & 9080 & 15457 \\
\hline 4318 & 0.6514 & 1.4341 & 0.3862 & 8919 & 15614 \\
\hline 4248 & 0.6592 & 1.4483 & 0.4004 & 8823 & 15778 \\
\hline 4172 & 0.6670 & 1.4636 & 0.4157 & 8705 & 15939 \\
\hline 4119 & 0.6748 & 1.4744 & 0.4265 & 8675 & 16110 \\
\hline 4055 & 0.6826 & 1.4909 & 0.4430 & 8526 & 16269 \\
\hline 3961 & 0.6914 & 1.5063 & 0.4584 & 8422 & 16455 \\
\hline
\end{tabular}


Table A.3a J-resistance test data for Compact Specimen A53W1-FL-3 tested at $288 \mathrm{C}$ (550 F); SI units

\begin{tabular}{|c|c|c|c|c|c|}
\hline $\begin{array}{c}\text { Load, } \\
\text { kN }\end{array}$ & $\begin{array}{c}\text { Load-Line } \\
\text { Displacement, } \\
\text { mm }\end{array}$ & $\begin{array}{c}\text { Crack } \\
\text { Length, } \\
\text { mm }\end{array}$ & $\begin{array}{c}\text { Crack } \\
\text { Extension, } \\
\text { mm }\end{array}$ & $\underset{\mathbf{k J} / \mathbf{m}^{2}}{\mathbf{J}_{\mathrm{D}}}$ & $\begin{array}{c}\mathrm{J}_{\mathbf{M}} \\
\mathbf{k J} / \mathbf{m}^{2}\end{array}$ \\
\hline 0.000 & 0.000 & 26.612 & 0.000 & 0.0 & 0.0 \\
\hline 25.101 & 0.549 & 26.612 & 0.000 & 37.4 & 37.4 \\
\hline 28.319 & 1.064 & 26.612 & 0.000 & 111.4 & 111.4 \\
\hline 29.848 & 1.570 & 26.612 & 0.000 & 190.3 & 190.3 \\
\hline 31.008 & 2.078 & 26.612 & 0.000 & 273.3 & 273.3 \\
\hline 31.983 & 2.611 & 26.612 & 0.000 & 363.5 & 363.5 \\
\hline 32.827 & 3.119 & 26.612 & 0.000 & 452.0 & 452.0 \\
\hline 33.539 & 3.609 & 26.612 & 0.000 & 539.3 & 539.3 \\
\hline 34.330 & 4.168 & 26.612 & 0.000 & 641.2 & 641.2 \\
\hline 34.884 & 4.663 & 26.612 & 0.000 & 733.2 & 733.2 \\
\hline 35.358 & 5.166 & 26.612 & 0.000 & 828.1 & 828.1 \\
\hline 35.701 & 5.679 & 26.612 & 0.000 & 926.0 & 926.0 \\
\hline 36.097 & 6.269 & 26.612 & 0.000 & 1039.6 & 1039.6 \\
\hline 36.308 & 6.741 & 26.612 & 0.000 & 1131.4 & 1131.4 \\
\hline 36.492 & 7.300 & 26.612 & 0.000 & 1240.7 & 1240.7 \\
\hline 36.308 & 7.727 & 26.612 & 0.000 & 1324.1 & 1324.1 \\
\hline 36.097 & 7.831 & 26.673 & 0.062 & 1339.6 & 1344.1 \\
\hline 34.963 & 8.174 & 27.030 & 0.418 & 1377.2 & 1408.2 \\
\hline 34.488 & 8.415 & 27.331 & 0.720 & 1398.4 & 1452.7 \\
\hline 33.645 & 8.656 & 27.650 & 1.038 & 1417.3 & 1496.7 \\
\hline 32.774 & 9.009 & 27.954 & 1.342 & 1456.8 & 1561.0 \\
\hline 32.484 & 9.271 & 28.256 & 1.644 & 1478.4 & 1607.9 \\
\hline 32.115 & 9.563 & 28.526 & 1.915 & 1507.8 & 1660.8 \\
\hline 31.720 & 9.830 & 28.780 & 2.168 & 1533.5 & 1708.9 \\
\hline 31.034 & 10.140 & 29.118 & 2.507 & 1557.9 & 1764.2 \\
\hline 30.507 & 10.424 & 29.421 & 2.809 & 1580.1 & 1814.7 \\
\hline 30.032 & 10.709 & 29.710 & 3.098 & 1602.7 & 1865.0 \\
\hline 29.426 & 10.988 & 30.028 & 3.417 & 1620.3 & 1913.9 \\
\hline 28.767 & 11.293 & 30.382 & 3.770 & 1637.6 & 1966.7 \\
\hline 28.345 & 11.440 & 30.664 & 4.052 & 1633.6 & 1991.6 \\
\hline 27.738 & 11.732 & 31.013 & 4.401 & 1647.5 & 2041.6 \\
\hline 27.132 & 12.029 & 31.363 & 4.752 & 1660.9 & 2092.1 \\
\hline 26.447 & 12.352 & 31.730 & 5.119 & 1675.5 & 2146.6 \\
\hline 25.919 & 12.662 & 32.111 & 5.499 & 1685.1 & 2198.3 \\
\hline 25.339 & 12.850 & 32.391 & 5.780 & 1684.6 & 2229.4 \\
\hline 24.390 & 13.195 & 32.877 & 6.266 & 1684.6 & 2285.1 \\
\hline 23.335 & 13.531 & 33.327 & 6.716 & 1685.4 & 2338.4 \\
\hline 22.623 & 13.693 & 33.659 & 7.048 & 1670.8 & 2363.2 \\
\hline 21.515 & 14.064 & 34.180 & 7.568 & 1664.5 & 2419.3 \\
\hline 21.015 & 14.237 & 34.535 & 7.924 & 1646.4 & 2444.5 \\
\hline 20.118 & 14.585 & 35.003 & 8.392 & 1640.2 & 2496.0 \\
\hline 19.195 & 14.945 & 35.644 & 9.032 & 1609.9 & 2545.9 \\
\hline 18.879 & 15.143 & 35.952 & 9.340 & 1599.6 & 2574.5 \\
\hline 17.903 & 15.527 & 36.540 & 9.928 & 1577.2 & 2627.7 \\
\hline 17.482 & 15.725 & 36.867 & 10.256 & 1562.3 & 2655.3 \\
\hline 17.007 & 15.913 & 37.179 & 10.567 & 1547.6 & 2681.4 \\
\hline 15.979 & 16.335 & 37.739 & 11.127 & 1530.1 & 2738.4 \\
\hline 15.478 & 16.533 & 38.046 & 11.434 & 1515.1 & 2765.0 \\
\hline 14.819 & 16.929 & 38.580 & 11.968 & 1493.3 & 2816.5 \\
\hline
\end{tabular}


Table A.3b

J-resistance test data for Compact Specimen A53W1-FL-3 tested at $288 \mathrm{C}$ (550 F); English units

\begin{tabular}{|c|c|c|c|c|c|}
\hline $\begin{array}{c}\text { Load, } \\
\text { lb }\end{array}$ & $\begin{array}{c}\text { Load-Line } \\
\text { Displacement, } \\
\text { inch }\end{array}$ & $\begin{array}{l}\text { Crack } \\
\text { Length, } \\
\text { inch }\end{array}$ & $\begin{array}{c}\text { Crack } \\
\text { Extension, } \\
\text { inch }\end{array}$ & $\frac{\begin{array}{c}J_{D}, \\
\text { inch-lb }\end{array}}{\text { inch }^{2}}$ & $\frac{\begin{array}{c}\mathbf{J}_{M}, \\
\text { inch-lb }\end{array}}{\text { inch }^{2}}$ \\
\hline 0 & 0.0000 & 1.0477 & 0.0000 & 0 & 0 \\
\hline 5578 & 0.0216 & 1.0477 & 0.0000 & 213 & 213 \\
\hline 6293 & 0.0419 & 1.0477 & 0.0000 & 636 & 636 \\
\hline 6633 & 0.0618 & 1.0477 & 0.0000 & 1087 & 1087 \\
\hline 6891 & 0.0818 & 1.0477 & 0.0000 & 1561 & 1561 \\
\hline 7107 & 0.1028 & 1.0477 & 0.0000 & 2076 & 2076 \\
\hline 7295 & 0.1228 & 1.0477 & 0.0000 & 2581 & 2581 \\
\hline 7453 & 0.1421 & 1.0477 & 0.0000 & 3079 & 3079 \\
\hline 7629 & 0.1641 & 1.0477 & 0.0000 & 3661 & 3661 \\
\hline 7752 & 0.1836 & 1.0477 & 0.0000 & 4187 & 4187 \\
\hline 7857 & 0.2034 & 1.0477 & 0.0000 & 4728 & 4728 \\
\hline 7934 & 0.2236 & 1.0477 & 0.0000 & 5287 & 5287 \\
\hline 8022 & 0.2468 & 1.0477 & 0.0000 & 5936 & 5936 \\
\hline 8068 & 0.2654 & 1.0477 & 0.0000 & 6460 & 6460 \\
\hline 8109 & 0.2874 & 1.0477 & 0.0000 & 7084 & 7084 \\
\hline 8068 & 0.3042 & 1.0477 & 0.0000 & 7560 & 7560 \\
\hline 8022 & 0.3083 & 1.0501 & 0.0024 & 7649 & 7675 \\
\hline 7770 & 0.3218 & 1.0642 & 0.0165 & 7864 & 8041 \\
\hline 7664 & 0.3313 & 1.0760 & 0.0283 & 7985 & 8295 \\
\hline 7477 & 0.3408 & 1.0886 & 0.0409 & 8093 & 8546 \\
\hline 7283 & 0.3547 & 1.1005 & 0.0528 & 8318 & 8913 \\
\hline 7219 & 0.3650 & 1.1124 & 0.0647 & 8441 & 9181 \\
\hline 7137 & 0.3765 & 1.1231 & 0.0754 & 8610 & 9483 \\
\hline 7049 & 0.3870 & 1.1331 & 0.0854 & 8756 & 9758 \\
\hline 6897 & 0.3992 & 1.1464 & 0.0987 & 8896 & 10073 \\
\hline 6779 & 0.4104 & 1.1583 & 0.1106 & 9022 & 10362 \\
\hline 6674 & 0.4216 & 1.1697 & 0.1220 & 9151 & 10649 \\
\hline 6539 & 0.4326 & 1.1822 & 0.1345 & 9252 & 10928 \\
\hline 6393 & 0.4446 & 1.1961 & 0.1484 & 9351 & 11230 \\
\hline 6299 & 0.4504 & 1.2072 & 0.1595 & 9328 & 11372 \\
\hline 6164 & 0.4619 & 1.2210 & 0.1733 & 9407 & 11657 \\
\hline 6029 & 0.4736 & 1.2348 & 0.1871 & 9483 & 11946 \\
\hline 5877 & 0.4863 & 1.2492 & 0.2015 & 9567 & 12257 \\
\hline 5760 & 0.4985 & 1.2642 & 0.2165 & 9622 & 12552 \\
\hline 5631 & 0.5059 & 1.2753 & 0.2276 & 9619 & 12730 \\
\hline 5420 & 0.5195 & 1.2944 & 0.2467 & 9619 & 13048 \\
\hline 5186 & 0.5327 & 1.3121 & 0.2644 & 9623 & 13352 \\
\hline 5027 & 0.5391 & 1.3252 & 0.2775 & 9540 & 13494 \\
\hline 4781 & 0.5537 & 1.3457 & 0.2980 & 9504 & 13814 \\
\hline 4670 & 0.5605 & 1.3597 & 0.3120 & 9401 & 13958 \\
\hline 4471 & 0.5742 & 1.3781 & 0.3304 & 9366 & 14252 \\
\hline 4266 & 0.5884 & 1.4033 & 0.3556 & 9192 & 14537 \\
\hline 4195 & 0.5962 & 1.4154 & 0.3677 & 9134 & 14700 \\
\hline 3979 & 0.6113 & 1.4386 & 0.3909 & 9006 & 15004 \\
\hline 3885 & 0.6191 & 1.4515 & 0.4038 & 8921 & 15162 \\
\hline 3779 & 0.6265 & 1.4637 & 0.4160 & 8837 & 15311 \\
\hline 3551 & 0.6431 & 1.4858 & 0.4381 & 8737 & 15636 \\
\hline 3440 & 0.6509 & 1.4979 & 0.4502 & 8651 & 15788 \\
\hline 3293 & 0.6665 & 1.5189 & 0.4712 & 8527 & 16082 \\
\hline
\end{tabular}


Table A.4a J-resistance test data for Compact Specimen A53W1-FL-4 tested at $288 \mathrm{C}(550 \mathrm{~F})$; SI units

\begin{tabular}{|c|c|c|c|c|c|}
\hline $\begin{array}{c}\text { Load, } \\
\text { kN }\end{array}$ & $\begin{array}{c}\text { Load-Line } \\
\text { Displacement, } \\
\text { mm }\end{array}$ & $\begin{array}{c}\text { Crack } \\
\text { Length, } \\
\text { mm }\end{array}$ & $\begin{array}{c}\text { Crack } \\
\text { Extension, } \\
\text { mm }\end{array}$ & $\underset{\mathbf{k J} / \mathbf{m}^{2}}{\mathbf{J}_{\mathbf{2}}}$ & $\begin{array}{c}\mathbf{J}_{\mathbf{M}} \\
\mathbf{k J} / \mathbf{m}^{2}\end{array}$ \\
\hline 0.000 & 0.000 & 26.825 & 0.000 & 0.0 & 0.0 \\
\hline 14.950 & 0.229 & 26.825 & 0.000 & 9.3 & 9.3 \\
\hline 23.256 & 0.462 & 26.825 & 0.000 & 33.4 & 33.4 \\
\hline 25.972 & 0.693 & 26.825 & 0.000 & 64.1 & 64.1 \\
\hline 27.527 & 0.927 & 26.825 & 0.000 & 97.8 & 97.8 \\
\hline 28.424 & 1.151 & 26.825 & 0.000 & 131.5 & 131.5 \\
\hline 29.215 & 1.377 & 26.825 & 0.000 & 166.7 & 166.7 \\
\hline 29.927 & 1.626 & 26.825 & 0.000 & 206.4 & 206.4 \\
\hline 30.428 & 1.836 & 26.825 & 0.000 & 240.7 & 240.7 \\
\hline 30.955 & 2.078 & 26.825 & 0.000 & 280.6 & 280.6 \\
\hline 31.351 & 2.301 & 26.825 & 0.000 & 318.2 & 318.2 \\
\hline 31.667 & 2.525 & 26.825 & 0.000 & 356.2 & 356.2 \\
\hline 31.983 & 2.753 & 26.825 & 0.000 & 395.4 & 395.4 \\
\hline 32.194 & 2.990 & 26.825 & 0.000 & 436.3 & 436.3 \\
\hline 32.353 & 3.193 & 26.825 & 0.000 & 471.7 & 471.7 \\
\hline 32.511 & 3.411 & 26.825 & 0.000 & 509.9 & 509.9 \\
\hline 32.590 & 3.566 & 26.906 & 0.081 & 534.7 & 536.9 \\
\hline 32.669 & 3.894 & 27.124 & 0.299 & 585.4 & 594.1 \\
\hline 32.669 & 4.247 & 27.380 & 0.555 & 639.2 & 656.3 \\
\hline 32.643 & 4.569 & 27.620 & 0.795 & 687.9 & 713.6 \\
\hline 32.142 & 4.917 & 27.893 & 1.068 & 739.0 & 775.4 \\
\hline 31.904 & 5.227 & 28.198 & 1.373 & 780.8 & 830.1 \\
\hline 31.509 & 5.502 & 28.486 & 1.661 & 816.4 & 878.5 \\
\hline 30.902 & 5.834 & 28.759 & 1.934 & 862.1 & 937.3 \\
\hline 30.111 & 6.190 & 29.174 & 2.349 & 902.5 & 998.8 \\
\hline 29.479 & 6.480 & 29.507 & 2.682 & 934.3 & 1048.6 \\
\hline 28.819 & 6.840 & 29.858 & 3.033 & 976.2 & 1110.3 \\
\hline 27.976 & 7.181 & 30.266 & 3.442 & 1008.9 & 1167.5 \\
\hline 27.396 & 7.447 & 30.581 & 3.756 & 1033.7 & 1212.0 \\
\hline 26.367 & 7.831 & 31.092 & 4.267 & 1062.9 & 1274.4 \\
\hline 25.524 & 8.131 & 31.465 & 4.640 & 1085.9 & 1322.8 \\
\hline 24.917 & 8.415 & 31.818 & 4.993 & 1106.4 & 1368.2 \\
\hline 24.416 & 8.793 & 32.218 & 5.393 & 1137.3 & 1428.5 \\
\hline 23.941 & 9.108 & 32.514 & 5.689 & 1165.1 & 1478.8 \\
\hline 23.414 & 9.408 & 32.822 & 5.997 & 1188.1 & 1526.2 \\
\hline 22.570 & 9.741 & 33.296 & 6.471 & 1200.2 & 1577.1 \\
\hline 21.911 & 10.058 & 33.669 & 6.844 & 1217.5 & 1625.7 \\
\hline 21.041 & 10.429 & 34.218 & 7.393 & 1224.4 & 1680.4 \\
\hline 20.329 & 10.772 & 34.573 & 7.748 & 1244.0 & 1731.8 \\
\hline 19.828 & 11.006 & 34.800 & 7.975 & 1257.8 & 1766.7 \\
\hline 19.063 & 11.397 & 35.512 & 8.688 & 1243.7 & 1819.9 \\
\hline 18.615 & 11.659 & 35.624 & 8.799 & 1272.4 & 1859.5 \\
\hline 17.798 & 12.055 & 36.235 & 9.410 & 1265.2 & 1913.3 \\
\hline 17.429 & 12.304 & 36.552 & 9.727 & 1267.8 & 1948.3 \\
\hline 16.848 & 12.614 & 36.923 & 10.098 & 1272.4 & 1991.6 \\
\hline 16.242 & 13.035 & 37.452 & 10.627 & 1272.7 & 2048.7 \\
\hline 15.688 & 13.332 & 37.820 & 10.995 & 1272.7 & 2089.2 \\
\hline 15.135 & 13.630 & 38.164 & 11.339 & 1274.2 & 2129.5 \\
\hline 14.396 & 14.077 & 38.641 & 11.816 & 1278.2 & 2188.8 \\
\hline
\end{tabular}


Table A.4b J-resistance test data for Compact Specimen A53W1-FL-4 tested at $288 \mathrm{C}$ (550 F); English units

\begin{tabular}{|c|c|c|c|c|c|}
\hline $\begin{array}{c}\text { Load, } \\
\text { lb }\end{array}$ & $\begin{array}{l}\text { Load-Line } \\
\text { Displacement, } \\
\text { inch }\end{array}$ & $\begin{array}{l}\text { Crack } \\
\text { Length, } \\
\text { inch }\end{array}$ & $\begin{array}{c}\text { Crack } \\
\text { Extension, } \\
\text { inch }\end{array}$ & $\frac{\begin{array}{c}\mathbf{J}_{\mathrm{D}} \\
\text { inch-lb }\end{array}}{\text { inch }^{2}}$ & $\begin{array}{c}\begin{array}{c}J_{M}, \\
\text { inch-lb }\end{array} \\
\text { inch }^{2}\end{array}$ \\
\hline 0 & 0.0000 & 1.0561 & 0.0000 & 0 & 0 \\
\hline 3322 & 0.0090 & 1.0561 & 0.0000 & 53 & 53 \\
\hline 5168 & 0.0182 & 1.0561 & 0.0000 & 191 & 191 \\
\hline 5772 & 0.0273 & 1.0561 & 0.0000 & 366 & 366 \\
\hline 6117 & 0.0365 & 1.0561 & 0.0000 & 558 & 558 \\
\hline 6316 & 0.0453 & 1.0561 & 0.0000 & 751 & 751 \\
\hline 6492 & 0.0542 & 1.0561 & 0.0000 & 952 & 952 \\
\hline 6650 & 0.0640 & 1.0561 & 0.0000 & 1178 & 1178 \\
\hline 6762 & 0.0723 & 1.0561 & 0.0000 & 1374 & 1374 \\
\hline 6879 & 0.0818 & 1.0561 & 0.0000 & 1602 & 1602 \\
\hline 6967 & 0.0906 & 1.0561 & 0.0000 & 1817 & 1817 \\
\hline 7037 & 0.0994 & 1.0561 & 0.0000 & 2034 & 2034 \\
\hline 7107 & 0.1084 & 1.0561 & 0.0000 & 2258 & 2258 \\
\hline 7154 & 0.1177 & 1.0561 & 0.0000 & 2491 & 2491 \\
\hline 7190 & 0.1257 & 1.0561 & 0.0000 & 2693 & 2693 \\
\hline 7225 & 0.1343 & 1.0561 & 0.0000 & 2912 & 2912 \\
\hline 7242 & 0.1404 & 1.0593 & 0.0032 & 3053 & 3066 \\
\hline 7260 & 0.1533 & 1.0679 & 0.0118 & 3343 & 3392 \\
\hline 7260 & 0.1672 & 1.0779 & 0.0218 & 3650 & 3748 \\
\hline 7254 & 0.1799 & 1.0874 & 0.0313 & 3928 & 4075 \\
\hline 7143 & 0.1936 & 1.0982 & 0.0421 & 4220 & 4427 \\
\hline 7090 & 0.2058 & 1.1101 & 0.0540 & 4459 & 4740 \\
\hline 7002 & 0.2166 & 1.1215 & 0.0654 & 4661 & 5016 \\
\hline 6867 & 0.2297 & 1.1322 & 0.0761 & 4923 & 5352 \\
\hline 6691 & 0.2437 & 1.1486 & 0.0925 & 5153 & 5703 \\
\hline 6551 & 0.2551 & 1.1617 & 0.1056 & 5335 & 5987 \\
\hline 6404 & 0.2693 & 1.1755 & 0.1194 & 5574 & 6340 \\
\hline 6217 & 0.2827 & 1.1916 & 0.1355 & 5761 & 6666 \\
\hline 6088 & 0.2932 & 1.2040 & 0.1479 & 5903 & 6920 \\
\hline 5859 & 0.3083 & 1.2241 & 0.1680 & 6069 & 7277 \\
\hline 5672 & 0.3201 & 1.2388 & 0.1827 & 6200 & 7553 \\
\hline 5537 & 0.3313 & 1.2527 & 0.1966 & 6317 & 7812 \\
\hline 5426 & 0.3462 & 1.2684 & 0.2123 & 6494 & 8156 \\
\hline 5320 & 0.3586 & 1.2801 & 0.2240 & 6653 & 8444 \\
\hline 5203 & 0.3704 & 1.2922 & 0.2361 & 6784 & 8715 \\
\hline 5016 & 0.3835 & 1.3109 & 0.2548 & 6853 & 9005 \\
\hline 4869 & 0.3960 & 1.3255 & 0.2694 & 6952 & 9283 \\
\hline 4676 & 0.4106 & 1.3472 & 0.2911 & 6991 & 9595 \\
\hline 4518 & 0.4241 & 1.3611 & 0.3050 & 7103 & 9889 \\
\hline 4406 & 0.4333 & 1.3701 & 0.3140 & 7182 & 10088 \\
\hline 4236 & 0.4487 & 1.3981 & 0.3420 & 7101 & 10392 \\
\hline 4137 & 0.4590 & 1.4025 & 0.3464 & 7265 & 10618 \\
\hline 3955 & 0.4746 & 1.4266 & 0.3705 & 7225 & 10925 \\
\hline 3873 & 0.4844 & 1.4391 & 0.3830 & 7239 & 11125 \\
\hline 3744 & 0.4966 & 1.4536 & 0.3975 & 7265 & 11372 \\
\hline 3609 & 0.5132 & 1.4745 & 0.4184 & 7267 & 11698 \\
\hline 3486 & 0.5249 & 1.4890 & 0.4329 & 7267 & 11929 \\
\hline 3363 & 0.5366 & 1.5025 & 0.4464 & 7276 & 12160 \\
\hline 3199 & 0.5542 & 1.5213 & 0.4652 & 7298 & 12498 \\
\hline
\end{tabular}


Table A.5a J-resistance test data for Compact Specimen A53W1-FL-5 tested at $288 \mathrm{C}$ (550 F); SI units

\begin{tabular}{|c|c|c|c|c|c|}
\hline $\begin{array}{c}\text { Load, } \\
\text { kN }\end{array}$ & $\begin{array}{c}\text { Load-Line } \\
\text { Displacement, } \\
\text { mm }\end{array}$ & $\begin{array}{c}\text { Crack } \\
\text { Length, } \\
\text { mm }\end{array}$ & $\begin{array}{c}\text { Crack } \\
\text { Extension, } \\
\text { mm }\end{array}$ & $\underset{\mathbf{k J} / \mathbf{m}^{2}}{\mathbf{J}_{\mathbf{D}}}$ & $\underset{\mathbf{k J} / \mathbf{m}^{2}}{\mathbf{J}_{\mathbf{2}}}$ \\
\hline 0.000 & 0.000 & 26.634 & 0.000 & 0.0 & 0.0 \\
\hline 24.996 & 0.594 & 26.634 & 0.000 & 40.5 & 40.5 \\
\hline 28.503 & 1.161 & 26.634 & 0.000 & 122.1 & 122.1 \\
\hline 30.348 & 1.768 & 26.634 & 0.000 & 218.2 & 218.2 \\
\hline 31.535 & 2.337 & 26.634 & 0.000 & 313.0 & 313.0 \\
\hline 32.484 & 2.926 & 26.634 & 0.000 & 414.5 & 414.5 \\
\hline 33.275 & 3.510 & 26.634 & 0.000 & 517.9 & 517.9 \\
\hline 33.803 & 4.079 & 26.634 & 0.000 & 620.6 & 620.6 \\
\hline 34.198 & 4.681 & 26.634 & 0.000 & 730.8 & 730.8 \\
\hline 34.620 & 5.258 & 26.634 & 0.000 & 837.6 & 837.6 \\
\hline 34.857 & 5.855 & 26.634 & 0.000 & 949.2 & 949.2 \\
\hline 35.121 & 6.449 & 26.634 & 0.000 & 1061.2 & 1061.2 \\
\hline 35.306 & 6.995 & 26.634 & 0.000 & 1164.7 & 1164.7 \\
\hline 35.490 & 7.577 & 26.634 & 0.000 & 1275.5 & 1275.5 \\
\hline 35.649 & 8.131 & 26.634 & 0.000 & 1381.5 & 1381.5 \\
\hline 35.226 & 8.700 & 26.634 & 0.000 & 1490.1 & 1490.1 \\
\hline 34.435 & 8.992 & 26.883 & 0.249 & 1523.3 & 1543.9 \\
\hline 33.829 & 9.197 & 27.157 & 0.523 & 1537.1 & 1581.0 \\
\hline 32.985 & 9.413 & 27.460 & 0.825 & 1549.3 & 1619.3 \\
\hline 32.194 & 9.649 & 27.964 & 1.330 & 1545.2 & 1659.5 \\
\hline 31.087 & 9.972 & 28.468 & 1.833 & 1555.5 & 1714.9 \\
\hline 30.533 & 10.208 & 28.741 & 2.107 & 1571.5 & 1755.8 \\
\hline 29.979 & 10.437 & 29.062 & 2.427 & 1580.6 & 1794.8 \\
\hline 29.320 & 10.673 & 29.470 & 2.836 & 1581.4 & 1834.2 \\
\hline 28.476 & 10.914 & 29.748 & 3.113 & 1595.5 & 1875.0 \\
\hline 27.712 & 11.143 & 30.127 & 3.492 & 1595.8 & 1912.3 \\
\hline 26.973 & 11.397 & 30.534 & 3.900 & 1596.3 & 1953.2 \\
\hline 26.288 & 11.547 & 30.777 & 4.143 & 1596.0 & 1977.3 \\
\hline 25.392 & 11.796 & 31.170 & 4.535 & 1595.1 & 2016.3 \\
\hline 24.944 & 12.042 & 31.605 & 4.971 & 1588.0 & 2054.1 \\
\hline 24.363 & 12.291 & 31.926 & 5.292 & 1593.5 & 2093.2 \\
\hline 23.810 & 12.576 & 32.360 & 5.725 & 1591.0 & 2136.7 \\
\hline 23.493 & 12.713 & 32.673 & 6.038 & 1578.0 & 2157.2 \\
\hline 22.992 & 13.010 & 33.091 & 6.457 & 1578.2 & 2202.9 \\
\hline 22.518 & 13.282 & 33.386 & 6.751 & 1588.1 & 2245.4 \\
\hline 22.307 & 13.419 & 33.695 & 7.060 & 1573.9 & 2265.7 \\
\hline 21.647 & 13.706 & 34.165 & 7.530 & 1563.9 & 2308.7 \\
\hline 21.067 & 14.003 & 34.579 & 7.944 & 1561.4 & 2353.7 \\
\hline 20.804 & 14.150 & 34.782 & 8.147 & 1560.4 & 2376.3 \\
\hline 20.277 & 14.448 & 35.197 & 8.562 & 1556.2 & 2420.8 \\
\hline 19.934 & 14.597 & 35.543 & 8.908 & 1536.4 & 2442.2 \\
\hline 19.301 & 14.907 & 36.081 & 9.446 & 1516.4 & 2486.8 \\
\hline 18.932 & 15.083 & 36.413 & 9.778 & 1501.6 & 2512.2 \\
\hline 18.404 & 15.403 & 36.883 & 10.249 & 1490.8 & 2559.2 \\
\hline 18.035 & 15.578 & 37.174 & 10.540 & 1480.3 & 2584.9 \\
\hline 17.191 & 15.926 & 37.705 & 11.070 & 1463.1 & 2634.5 \\
\hline 16.902 & 16.111 & 38.090 & 11.456 & 1439.2 & 2659.8 \\
\hline 16.691 & 16.284 & 38.403 & 11.768 & 1423.6 & 2684.3 \\
\hline 16.400 & 16.457 & 38.666 & 12.032 & 1414.8 & 2709.6 \\
\hline
\end{tabular}


Table A.5b J-resistance test data for Compact Specimen A53W1-FL-5 tested at $288 \mathrm{C}(550 \mathrm{~F})$; English units

\begin{tabular}{|c|c|c|c|c|c|}
\hline $\begin{array}{l}\text { Load, } \\
\text { lb }\end{array}$ & $\begin{array}{c}\text { Load-Line } \\
\text { Displacement, } \\
\text { inch }\end{array}$ & $\begin{array}{c}\text { Crack } \\
\text { Length, } \\
\text { inch }\end{array}$ & $\begin{array}{c}\text { Crack } \\
\text { Extension, } \\
\text { inch }\end{array}$ & $\frac{\begin{array}{c}\mathbf{J}_{\mathbf{D}} \\
\text { inch-lb }\end{array}}{\text { inch }^{2}}$ & $\frac{\begin{array}{c}\mathrm{J}_{\mathrm{M}}, \\
\text { inch-lb }\end{array}}{\text { inch }^{2}}$ \\
\hline 0 & 0.0000 & 1.0486 & 0.0000 & 0 & 0 \\
\hline 5555 & 0.0234 & 1.0486 & 0.0000 & 231 & 231 \\
\hline 6334 & 0.0457 & 1.0486 & 0.0000 & 697 & 697 \\
\hline 6744 & 0.0696 & 1.0486 & 0.0000 & 1246 & 1246 \\
\hline 7008 & 0.0920 & 1.0486 & 0.0000 & 1787 & 1787 \\
\hline 7219 & 0.1152 & 1.0486 & 0.0000 & 2367 & 2367 \\
\hline 7395 & 0.1382 & 1.0486 & 0.0000 & 2957 & 2957 \\
\hline 7512 & 0.1606 & 1.0486 & 0.0000 & 3544 & 3544 \\
\hline 7600 & 0.1843 & 1.0486 & 0.0000 & 4173 & 4173 \\
\hline 7693 & 0.2070 & 1.0486 & 0.0000 & 4783 & 4783 \\
\hline 7746 & 0.2305 & 1.0486 & 0.0000 & 5420 & 5420 \\
\hline 7805 & 0.2539 & 1.0486 & 0.0000 & 6059 & 6059 \\
\hline 7846 & 0.2754 & 1.0486 & 0.0000 & 6650 & 6650 \\
\hline 7887 & 0.2983 & 1.0486 & 0.0000 & 7283 & 7283 \\
\hline 7922 & 0.3201 & 1.0486 & 0.0000 & 7889 & 7889 \\
\hline 7828 & 0.3425 & 1.0486 & 0.0000 & 8508 & 8508 \\
\hline 7652 & 0.3540 & 1.0584 & 0.0098 & 8698 & 8816 \\
\hline 7518 & 0.3621 & 1.0692 & 0.0206 & 8777 & 9027 \\
\hline 7330 & 0.3706 & 1.0811 & 0.0325 & 8846 & 9246 \\
\hline 7154 & 0.3799 & 1.1009 & 0.0523 & 8823 & 9476 \\
\hline 6908 & 0.3926 & 1.1208 & 0.0722 & 8882 & 9792 \\
\hline 6785 & 0.4019 & 1.1315 & 0.0829 & 8973 & 10025 \\
\hline 6662 & 0.4109 & 1.1442 & 0.0956 & 9025 & 10248 \\
\hline 6516 & 0.4202 & 1.1602 & 0.1116 & 9030 & 10473 \\
\hline 6328 & 0.4297 & 1.1712 & 0.1226 & 9110 & 10706 \\
\hline 6158 & 0.4387 & 1.1861 & 0.1375 & 9112 & 10919 \\
\hline 5994 & 0.4487 & 1.2021 & 0.1535 & 9115 & 11153 \\
\hline 5842 & 0.4546 & 1.2117 & 0.1631 & 9113 & 11290 \\
\hline 5643 & 0.4644 & 1.2272 & 0.1786 & 9108 & 11513 \\
\hline 5543 & 0.4741 & 1.2443 & 0.1957 & 9067 & 11729 \\
\hline 5414 & 0.4839 & 1.2569 & 0.2083 & 9099 & 11952 \\
\hline 5291 & 0.4951 & 1.2740 & 0.2254 & 9085 & 12201 \\
\hline 5221 & 0.5005 & 1.2863 & 0.2377 & 9010 & 12318 \\
\hline 5109 & 0.5122 & 1.3028 & 0.2542 & 9012 & 12578 \\
\hline 5004 & 0.5229 & 1.3144 & 0.2658 & 9068 & 12821 \\
\hline 4957 & 0.5283 & 1.3266 & 0.2780 & 8987 & 12937 \\
\hline 4811 & 0.5396 & 1.3451 & 0.2965 & 8930 & 13183 \\
\hline 4682 & 0.5513 & 1.3614 & 0.3128 & 8916 & 13440 \\
\hline 4623 & 0.5571 & 1.3694 & 0.3208 & 8910 & 13569 \\
\hline 4506 & 0.5688 & 1.3857 & 0.3371 & 8886 & 13823 \\
\hline 4430 & 0.5747 & 1.3993 & 0.3507 & 8773 & 13945 \\
\hline 4289 & 0.5869 & 1.4205 & 0.3719 & 8659 & 14200 \\
\hline 4207 & 0.5938 & 1.4336 & 0.3850 & 8574 & 14345 \\
\hline 4090 & 0.6064 & 1.4521 & 0.4035 & 8512 & 14613 \\
\hline 4008 & 0.6133 & 1.4636 & 0.4150 & 8453 & 14760 \\
\hline 3820 & 0.6270 & 1.4844 & 0.4358 & 8354 & 15043 \\
\hline 3756 & 0.6343 & 1.4996 & 0.4510 & 8218 & 15188 \\
\hline 3709 & 0.6411 & 1.5119 & 0.4633 & 8129 & 15327 \\
\hline 3645 & 0.6479 & 1.5223 & 0.4737 & 8078 & 15472 \\
\hline
\end{tabular}


Table A.6a Test data from C(T) Specimen A8W4-FL-1

(Slant-notch with angle of 55 degrees from specimen face to follow fusion-line, test at $288 \mathrm{C}$; SI units)

\begin{tabular}{|c|c|c|c|c|c|c|c|c|}
\hline $\begin{array}{l}\text { Load, } \\
\text { kN }\end{array}$ & $\begin{array}{c}\text { Load-Line } \\
\text { Displacement, } \\
\text { mm }\end{array}$ & $\begin{array}{c}\text { Crack } \\
\text { Length, } \\
\text { mm }\end{array}$ & $\begin{array}{c}\text { Growth, } \\
\text { mm }\end{array}$ & $\mathbf{J}_{\mathbf{n o m}}^{(a)}$ & $\underset{\mathrm{k} J / \mathrm{m}^{2}}{\mathrm{~J}_{\mathbf{i}},}$ & $\underset{\mathrm{kJ} / \mathrm{m}^{2}}{\mathbf{J}_{\mathrm{iii}}}$ & $\begin{array}{l}J_{\text {tot }}^{(b)} \\
\mathbf{k J} / \mathrm{m}^{2}\end{array}$ & $\underset{\mathrm{kJ} / \mathrm{m}^{2}}{\mathrm{~J}_{\mathrm{m}}}$ \\
\hline 0.00 & 0.00 & 26.04 & 0.00 & 0.0 & 0.0 & 0.0 & 0.0 & 0.0 \\
\hline 15.56 & 0.26 & 26.04 & 0.00 & 10.3 & 5.7 & 2.8 & 8.4 & 10.3 \\
\hline 24.01 & 0.52 & 26.04 & 0.00 & 36.5 & 20.1 & 9.8 & 29.9 & 36.5 \\
\hline 29.10 & 0.82 & 26.04 & 0.00 & 76.5 & 42.1 & 20.6 & 62.7 & 76.5 \\
\hline 30.74 & 1.03 & 26.04 & 0.00 & 108.4 & 59.6 & 29.2 & 88.8 & 108.4 \\
\hline 32.06 & 1.30 & 26.04 & 0.00 & 151.8 & 83.5 & 40.8 & 124.3 & 151.8 \\
\hline 32.91 & 1.56 & 26.04 & 0.00 & 194.6 & 107.0 & 52.3 & 159.4 & 194.6 \\
\hline 33.63 & 1.80 & 26.04 & 0.00 & 234.2 & 128.8 & 63.0 & 191.8 & 234.2 \\
\hline 34.34 & 2.10 & 26.04 & 0.00 & 285.4 & 157.0 & 76.8 & 233.7 & 285.4 \\
\hline 34.79 & 2.29 & 26.04 & 0.00 & 320.1 & 176.1 & 86.1 & 262.2 & 320.1 \\
\hline 35.55 & 2.67 & 26.04 & 0.00 & 386.3 & 212.5 & 103.9 & 316.4 & 386.3 \\
\hline 35.88 & 2.84 & 26.04 & 0.00 & 417.7 & 229.7 & 112.4 & 342.1 & 417.7 \\
\hline 36.40 & 3.11 & 26.04 & 0.00 & 467.5 & 257.1 & 125.8 & 382.9 & 467.5 \\
\hline 36.74 & 3.32 & 26.04 & 0.00 & 506.5 & 278.6 & 136.2 & 414.8 & 506.5 \\
\hline 37.16 & 3.62 & 26.04 & 0.00 & 562.2 & 309.2 & 151.2 & 460.4 & 562.2 \\
\hline 37.43 & 3.82 & 26.04 & 0.00 & 599.6 & 329.8 & 161.3 & 491.1 & 599.6 \\
\hline 37.43 & 3.82 & 26.04 & 0.00 & 599.6 & 329.8 & 161.3 & 491.1 & 599.6 \\
\hline 37.54 & 3.91 & 26.08 & 0.05 & 614.5 & 338.0 & 165.3 & 503.3 & 615.9 \\
\hline 37.79 & 4.12 & 26.19 & 0.15 & 651.0 & 358.0 & 175.1 & 533.2 & 655.8 \\
\hline 38.07 & 4.45 & 26.34 & 0.30 & 709.7 & 390.3 & 190.9 & 581.2 & 719.9 \\
\hline 38.05 & 4.64 & 26.43 & 0.39 & 742.2 & 408.2 & 199.7 & 607.9 & 755.8 \\
\hline 37.96 & 4.91 & 26.55 & 0.51 & 790.2 & 434.6 & 212.6 & 647.2 & 808.6 \\
\hline 37.80 & 5.17 & 26.69 & 0.65 & 834.3 & 458.9 & 224.4 & 683.3 & 859.0 \\
\hline 37.54 & 5.39 & 26.84 & 0.80 & 870.7 & 478.9 & 234.2 & 713.1 & 902.0 \\
\hline 37.17 & 5.66 & 27.02 & 0.99 & 911.8 & 501.5 & 245.3 & 746.8 & 952.1 \\
\hline 36.53 & 5.99 & 27.32 & 1.28 & 960.3 & 528.2 & 258.3 & 786.5 & 1015.7 \\
\hline 35.86 & 6.20 & 27.58 & 1.54 & 985.9 & 542.2 & 265.2 & 807.5 & 1055.1 \\
\hline 34.82 & 6.42 & 27.94 & 1.90 & 1006.8 & 553.7 & 270.8 & 824.6 & 1095.9 \\
\hline 33.56 & 6.68 & 28.41 & 2.37 & 1026.2 & 564.4 & 276.0 & 840.5 & 1142.2 \\
\hline 32.72 & 6.95 & 28.82 & 2.78 & 1047.5 & 576.1 & 281.8 & 857.9 & 1188.2 \\
\hline 32.08 & 7.19 & 29.19 & 3.16 & 1068.0 & 587.4 & 287.3 & 874.7 & 1231.8 \\
\hline 31.24 & 7.48 & 29.60 & 3.56 & 1092.1 & 600.7 & 293.8 & 894.4 & 1281.6 \\
\hline 29.97 & 7.76 & 30.11 & 4.08 & 1106.2 & 608.4 & 297.6 & 906.0 & 1329.8 \\
\hline 28.64 & 7.97 & 30.56 & 4.52 & 1110.8 & 610.9 & 298.8 & 909.7 & 1364.4 \\
\hline 26.74 & 8.28 & 31.28 & 5.24 & 1108.5 & 609.7 & 298.2 & 907.9 & 1412.3 \\
\hline 25.90 & 8.47 & 31.74 & 5.71 & 1103.8 & 607.1 & 296.9 & 904.0 & 1440.6 \\
\hline 24.91 & 8.81 & 32.57 & 6.53 & 1093.1 & 601.2 & 294.0 & 895.2 & 1489.5 \\
\hline 24.36 & 9.02 & 33.07 & 7.04 & 1087.5 & 598.1 & 292.5 & 890.7 & 1521.1 \\
\hline 23.77 & 9.25 & 33.55 & 7.52 & 1087.4 & 598.1 & 292.5 & 890.6 & 1557.0 \\
\hline 23.16 & 9.54 & 34.01 & 7.98 & 1096.1 & 602.9 & 294.9 & 897.7 & 1601.1 \\
\hline 22.73 & 9.77 & 34.35 & 8.31 & 1107.1 & 608.9 & 297.8 & 906.7 & 1638.0 \\
\hline 22.09 & 10.07 & 34.74 & 8.71 & 1121.0 & 616.5 & 301.5 & 918.1 & 1684.3 \\
\hline 21.59 & 10.27 & 35.02 & 8.99 & 1128.5 & 620.7 & 303.6 & 924.2 & 1715.0 \\
\hline 20.99 & 10.53 & 35.36 & 9.33 & 1139.5 & 626.7 & 306.5 & 933.3 & 1755.0 \\
\hline 20.49 & 10.80 & 35.72 & 9.68 & 1149.8 & 632.4 & 309.3 & 941.7 & 1796.5 \\
\hline 20.03 & 11.04 & 36.03 & 10.00 & 1157.4 & 636.6 & 311.3 & 947.9 & 1832.2 \\
\hline 19.53 & 11.30 & 36.37 & 10.33 & 1165.9 & 641.2 & 313.6 & 954.9 & 1871.4 \\
\hline 18.91 & 11.67 & 36.77 & 10.73 & 1183.8 & 651.1 & 318.4 & 969.5 & 1927.4 \\
\hline 18.60 & 11.84 & 36.93 & 10.90 & 1194.2 & 656.8 & 321.2 & 978.0 & 1953.9 \\
\hline 18.19 & 12.07 & 37.14 & 11.10 & 1207.6 & 664.2 & 324.8 & 989.0 & 1987.7 \\
\hline 17.79 & 12.29 & 37.34 & 11.30 & 1220.5 & 671.3 & 328.3 & 999.6 & 2021.2 \\
\hline
\end{tabular}

(a) $\mathrm{J}_{\text {nom }}$ uses ASTM E1152 $\mathrm{J}_{\mathrm{D}}$ and ignores the fact that the notch is slanted.

(b) $\mathrm{J}_{\text {tot }}=\mathrm{J}_{\mathrm{i}}+\mathrm{J}_{\mathrm{iii}}$. 
Table A.6b Test data from C(T) Specimen A8W4-FL-1

(Slant-notch with angle of 55 degrees from specimen face to follow fusion-line, test at $288 \mathrm{C}$; English units)

\begin{tabular}{|c|c|c|c|c|c|c|c|c|}
\hline $\begin{array}{c}\text { Load, } \\
\text { lb }\end{array}$ & $\begin{array}{c}\text { Load-Line } \\
\text { Displacement, } \\
\text { inch }\end{array}$ & $\begin{array}{c}\text { Crack } \\
\text { Length, } \\
\text { inch }\end{array}$ & $\begin{array}{c}\text { Crack } \\
\text { Growth, } \\
\text { inch }\end{array}$ & $\begin{array}{l}\mathrm{J}_{\text {nom }}^{(a)} \\
\text { lb/inch }\end{array}$ & $\begin{array}{c}\mathbf{J}_{\mathbf{i}}, \\
\text { lb/inch }\end{array}$ & $\mathbf{J}_{\mathbf{D}} \frac{}{\begin{array}{c}\mathbf{J}_{\mathrm{iii}}, \\
\mathbf{l b} / \text { inch }\end{array}}$ & $\begin{array}{l}J_{\text {tot }}{ }^{(b)} \\
\text { lb/inch }\end{array}$ & $\underset{\mathbf{l b} / \text { inch }}{\mathbf{J}_{\mathbf{m}}}$ \\
\hline 0 & 0.0000 & 1.0251 & 0.0000 & 0 & 0 & 0 & 0 & 0 \\
\hline 3458 & 0.0103 & 1.0251 & 0.0000 & 59 & 32 & 16 & 48 & 59 \\
\hline 5335 & 0.0205 & 1.0251 & 0.0000 & 208 & 115 & 56 & 171 & 208 \\
\hline 6466 & 0.0322 & 1.0251 & 0.0000 & 437 & 240 & 118 & 358 & 437 \\
\hline 6832 & 0.0405 & 1.0251 & 0.0000 & 619 & 341 & 167 & 507 & 619 \\
\hline 7124 & 0.0513 & 1.0251 & 0.0000 & 867 & 477 & 233 & 710 & 867 \\
\hline 7313 & 0.0615 & 1.0251 & 0.0000 & 1111 & 612 & 299 & 911 & 1111 \\
\hline 7474 & 0.0708 & 1.0251 & 0.0000 & 1337 & 736 & 360 & 1096 & 1337 \\
\hline 7631 & 0.0825 & 1.0251 & 0.0000 & 1630 & 897 & 439 & 1336 & 1630 \\
\hline 7732 & 0.0903 & 1.0251 & 0.0000 & 1828 & 1006 & 492 & 1498 & 1828 \\
\hline 7900 & 0.1050 & 1.0251 & 0.0000 & 2206 & 1214 & 594 & 1808 & 2206 \\
\hline 7974 & 0.1118 & 1.0251 & 0.0000 & 2385 & 1313 & 642 & 1955 & 2385 \\
\hline 8089 & 0.1226 & 1.0251 & 0.0000 & 2670 & 1469 & 719 & 2188 & 2670 \\
\hline 8164 & 0.1309 & 1.0251 & 0.0000 & 2892 & 1592 & 779 & 2370 & 2892 \\
\hline 8258 & 0.1426 & 1.0251 & 0.0000 & 3210 & 1767 & 864 & 2631 & 3210 \\
\hline 8317 & 0.1504 & 1.0251 & 0.0000 & 3424 & 1884 & 922 & 2806 & 3424 \\
\hline 8317 & 0.1504 & 1.0251 & 0.0000 & 3424 & 1884 & 922 & 2806 & 3424 \\
\hline 8342 & 0.1538 & 1.0269 & 0.0018 & 3509 & 1931 & 945 & 2876 & 3517 \\
\hline 8397 & 0.1621 & 1.0310 & 0.0059 & 3717 & 2046 & 1001 & 3047 & 3745 \\
\hline 8459 & 0.1753 & 1.0370 & 0.0119 & 4052 & 2230 & 1091 & 3321 & 4111 \\
\hline 8456 & 0.1826 & 1.0406 & 0.0155 & 4238 & 2333 & 1141 & 3473 & 4316 \\
\hline 8435 & 0.1934 & 1.0452 & 0.0201 & 4512 & 2483 & 1215 & 3698 & 4617 \\
\hline 8401 & 0.2036 & 1.0509 & 0.0258 & 4764 & 2622 & 1282 & 3905 & 4905 \\
\hline 8343 & 0.2124 & 1.0566 & 0.0315 & 4972 & 2736 & 1338 & 4075 & 5151 \\
\hline 8260 & 0.2227 & 1.0640 & 0.0389 & 5206 & 2866 & 1402 & 4267 & 5436 \\
\hline 8118 & 0.2358 & 1.0756 & 0.0505 & 5483 & 3018 & 1476 & 4494 & 5799 \\
\hline 7969 & 0.2441 & 1.0858 & 0.0607 & 5629 & 3099 & 1515 & 4614 & 6025 \\
\hline 7738 & 0.2529 & 1.0999 & 0.0748 & 5749 & 3164 & 1548 & 4712 & 6258 \\
\hline 7458 & 0.2632 & 1.1183 & 0.0932 & 5859 & 3225 & 1577 & 4803 & 6522 \\
\hline 7270 & 0.2734 & 1.1347 & 0.1096 & 5981 & 3292 & 1610 & 4902 & 6785 \\
\hline 7129 & 0.2832 & 1.1494 & 0.1243 & 6098 & 3357 & 1642 & 4998 & 7033 \\
\hline 6943 & 0.2944 & 1.1653 & 0.1402 & 6236 & 3432 & 1679 & 5111 & 7318 \\
\hline 6661 & 0.3057 & 1.1856 & 0.1605 & 6316 & 3477 & 1700 & 5177 & 7593 \\
\hline 6365 & 0.3140 & 1.2030 & 0.1779 & 6343 & 3491 & 1707 & 5199 & 7791 \\
\hline 5943 & 0.3262 & 1.2314 & 0.2063 & 6330 & 3484 & 1704 & 5188 & 8064 \\
\hline 5755 & 0.3335 & 1.2497 & 0.2246 & 6303 & 3469 & 1697 & 5166 & 8226 \\
\hline 5535 & 0.3467 & 1.2822 & 0.2571 & 6241 & 3435 & 1680 & 5116 & 8505 \\
\hline 5413 & 0.3550 & 1.3021 & 0.2770 & 6210 & 3418 & 1672 & 5089 & 8686 \\
\hline 5282 & 0.3643 & 1.3210 & 0.2959 & 6209 & 3418 & 1671 & 5089 & 8890 \\
\hline 5148 & 0.3755 & 1.3392 & 0.3141 & 6259 & 3445 & 1685 & 5130 & 9142 \\
\hline 5051 & 0.3848 & 1.3522 & 0.3271 & 6321 & 3479 & 1702 & 5181 & 9353 \\
\hline 4908 & 0.3965 & 1.3679 & 0.3428 & 6401 & 3523 & 1723 & 5246 & 9617 \\
\hline 4797 & 0.4043 & 1.3789 & 0.3538 & 6444 & 3547 & 1735 & 5281 & 9793 \\
\hline 4664 & 0.4146 & 1.3923 & 0.3672 & 6507 & 3581 & 1752 & 5333 & 10021 \\
\hline 4553 & 0.4253 & 1.4063 & 0.3812 & 6566 & 3614 & 1767 & 5381 & 10258 \\
\hline 4452 & 0.4346 & 1.4187 & 0.3936 & 6609 & 3638 & 1779 & 5417 & 10462 \\
\hline 4341 & 0.4448 & 1.4318 & 0.4067 & 6657 & 3664 & 1792 & 5456 & 10686 \\
\hline 4202 & 0.4595 & 1.4476 & 0.4225 & 6760 & 3721 & 1820 & 5540 & 11005 \\
\hline 4133 & 0.4663 & 1.4541 & 0.4290 & 6819 & 3753 & 1836 & 5589 & 11157 \\
\hline 4042 & 0.4751 & 1.4621 & 0.4370 & 6895 & 3795 & 1856 & 5652 & 11350 \\
\hline 3953 & 0.4839 & 1.4701 & 0.4450 & 6969 & 3836 & 1876 & 5712 & 11541 \\
\hline
\end{tabular}

(a) $\mathrm{J}_{\text {nom }}$ uses ASTM E1152 $\mathrm{J}_{\mathrm{D}}$ and ignores the fact that the notch is slanted.

(b) $\mathrm{J}_{\mathrm{tat}}=\mathrm{J}_{\mathrm{i}}+\mathrm{J}_{\mathrm{iii}}$. 
Table A.7a Test data from C(T) Specimen A8W4-FL-2

(Slant-notch with angle of 55 degrees from specimen face to follow fusion-line, test at 288 C; SI units)

\begin{tabular}{|c|c|c|c|c|c|c|c|c|}
\hline $\begin{array}{l}\text { Load, } \\
\text { kN }\end{array}$ & $\begin{array}{c}\text { Load-Line } \\
\text { Displacement, } \\
\text { mm }\end{array}$ & $\begin{array}{c}\text { Crack } \\
\text { Length, } \\
\text { mm }\end{array}$ & $\begin{array}{c}\text { Growth, } \\
\text { mm }\end{array}$ & $\begin{array}{c}\mathrm{J}_{\text {nom }}^{(a)} \\
\mathbf{k J} / \mathrm{m}^{2}\end{array}$ & $\underset{\mathbf{k} J / \mathbf{m}^{2}}{\mathbf{J}_{\mathbf{i}}}$ & $\mathbf{J}_{\mathrm{D}} \frac{}{\mathbf{k J} / \mathrm{m}^{2}}$ & $\begin{array}{l}\mathrm{J}_{\mathrm{tot}}^{(\mathrm{b})} \\
\mathrm{kJ} / \mathrm{m}^{2}\end{array}$ & $\underset{\mathrm{kJ} / \mathbf{m}^{2}}{\mathbf{J}_{\mathrm{m}}}$ \\
\hline 0.00 & 0.00 & 26.03 & 0.00 & 0.0 & 0.0 & 0.0 & 0.0 & 0.0 \\
\hline 22.91 & 0.37 & 26.03 & 0.00 & 21.7 & 11.9 & 5.8 & 17.8 & 21.7 \\
\hline 28.32 & 0.74 & 26.03 & 0.00 & 70.0 & 38.5 & 18.8 & 57.3 & 70.0 \\
\hline 30.14 & 1.11 & 26.03 & 0.00 & 125.4 & 69.0 & 33.7 & 102.7 & 125.4 \\
\hline 31.46 & 1.51 & 26.03 & 0.00 & 186.9 & 102.8 & 50.3 & 153.1 & 186.9 \\
\hline 32.35 & 1.82 & 26.03 & 0.00 & 238.3 & 131.1 & 64.1 & 195.2 & 238.3 \\
\hline 33.17 & 2.20 & 26.03 & 0.00 & 301.2 & 165.7 & 81.0 & 246.7 & 301.2 \\
\hline 34.07 & 2.61 & 26.03 & 0.00 & 370.9 & 204.0 & 99.8 & 303.8 & 370.9 \\
\hline 34.75 & 2.98 & 26.03 & 0.00 & 434.8 & 239.1 & 117.0 & 356.1 & 434.8 \\
\hline 35.36 & 3.30 & 26.03 & 0.00 & 492.2 & 270.7 & 132.4 & 403.1 & 492.2 \\
\hline 35.91 & 3.65 & 26.03 & 0.00 & 556.0 & 305.8 & 149.6 & 455.4 & 556.0 \\
\hline 36.60 & 4.07 & 26.03 & 0.00 & 632.6 & 347.9 & 170.2 & 518.1 & 632.6 \\
\hline 37.18 & 4.44 & 26.03 & 0.00 & 702.0 & 386.1 & 188.8 & 574.9 & 702.0 \\
\hline 37.57 & 4.77 & 26.03 & 0.00 & 764.1 & 420.3 & 205.5 & 625.8 & 764.1 \\
\hline 37.92 & 5.13 & 26.03 & 0.00 & 833.2 & 458.3 & 224.1 & 682.4 & 833.2 \\
\hline 38.05 & 5.47 & 26.03 & 0.00 & 898.8 & 494.3 & 241.8 & 736.1 & 898.8 \\
\hline 37.99 & 5.56 & 26.07 & 0.04 & 914.0 & 502.7 & 245.9 & 748.6 & 915.8 \\
\hline 37.92 & 5.74 & 26.18 & 0.15 & 942.2 & 518.2 & 253.5 & 771.7 & 949.7 \\
\hline 37.36 & 5.92 & 26.36 & 0.33 & 968.6 & 532.7 & 260.6 & 793.3 & 985.2 \\
\hline 36.89 & 6.11 & 26.55 & 0.51 & 993.7 & 546.5 & 267.3 & 813.8 & 1019.9 \\
\hline 36.57 & 6.31 & 26.73 & 0.70 & 1020.7 & 561.4 & 274.6 & 836.0 & 1056.9 \\
\hline 35.70 & 6.60 & 27.10 & 1.08 & 1053.0 & 579.2 & 283.3 & 862.4 & 1110.3 \\
\hline 35.44 & 6.70 & 27.26 & 1.23 & 1062.1 & 584.2 & 285.7 & 869.9 & 1128.4 \\
\hline 34.65 & 6.93 & 27.51 & 1.48 & 1088.8 & 598.8 & 292.9 & 891.7 & 1170.0 \\
\hline 33.83 & 7.15 & 27.76 & 1.73 & 1113.2 & 612.3 & 299.5 & 911.7 & 1210.0 \\
\hline 32.59 & 7.37 & 28.10 & 2.07 & 1129.2 & 621.1 & 303.8 & 924.8 & 1247.5 \\
\hline 31.77 & 7.49 & 28.37 & 2.34 & 1132.0 & 622.6 & 304.5 & 927.1 & 1267.6 \\
\hline 29.80 & 7.74 & 28.89 & 2.86 & 1138.6 & 626.2 & 306.3 & 932.5 & 1308.7 \\
\hline 28.79 & 7.96 & 29.42 & 3.38 & 1138.3 & 626.1 & 306.2 & 932.3 & 1343.4 \\
\hline 28.16 & 8.10 & 29.87 & 3.84 & 1128.9 & 620.9 & 303.7 & 924.6 & 1364.9 \\
\hline 27.24 & 8.33 & 30.30 & 4.27 & 1133.6 & 623.5 & 304.9 & 928.4 & 1399.5 \\
\hline 26.02 & 8.56 & 30.75 & 4.72 & 1136.6 & 625.1 & 305.7 & 930.9 & 1434.1 \\
\hline 25.50 & 8.67 & 31.02 & 4.99 & 1134.3 & 623.9 & 305.1 & 929.0 & 1450.8 \\
\hline 24.42 & 8.92 & 31.48 & 5.45 & 1138.2 & 626.0 & 306.2 & 932.2 & 1488.1 \\
\hline 23.94 & 9.07 & 31.86 & 5.83 & 1131.0 & 622.0 & 304.2 & 926.3 & 1509.3 \\
\hline 22.60 & 9.31 & 32.48 & 6.45 & 1117.5 & 614.6 & 300.6 & 915.2 & 1541.5 \\
\hline 20.93 & 9.59 & 33.21 & 7.18 & 1098.7 & 604.3 & 295.6 & 899.8 & 1578.3 \\
\hline 20.38 & 9.75 & 33.92 & 7.89 & 1063.3 & 584.8 & 286.0 & 870.8 & 1596.5 \\
\hline 19.80 & 9.92 & 34.32 & 8.29 & 1053.8 & 579.6 & 283.5 & 863.1 & 1617.8 \\
\hline 19.46 & 10.06 & 35.03 & 8.99 & 1016.0 & 558.8 & 273.3 & 832.1 & 1633.7 \\
\hline 18.98 & 10.35 & 35.53 & 9.50 & 1016.0 & 558.8 & 273.3 & 832.1 & 1672.5 \\
\hline 18.75 & 10.49 & 35.71 & 9.68 & 1022.2 & 562.2 & 275.0 & 837.2 & 1692.7 \\
\hline 18.19 & 10.77 & 36.11 & 10.08 & 1029.0 & 566.0 & 276.8 & 842.8 & 1731.3 \\
\hline 17.98 & 10.92 & 36.41 & 10.38 & 1024.0 & 563.2 & 275.5 & 838.7 & 1751.0 \\
\hline 17.80 & 11.06 & 36.57 & 10.54 & 1029.9 & 566.4 & 277.0 & 843.5 & 1770.4 \\
\hline 17.35 & 11.35 & 36.96 & 10.93 & 1038.1 & 571.0 & 279.2 & 850.2 & 1811.5 \\
\hline 17.19 & 11.50 & 37.25 & 11.22 & 1032.7 & 568.0 & 277.8 & 845.8 & 1830.5 \\
\hline 16.85 & 11.66 & 37.42 & 11.39 & 1040.4 & 572.2 & 279.9 & 852.1 & 1853.6 \\
\hline 16.48 & 11.82 & 37.73 & 11.70 & 1034.5 & 569.0 & 278.3 & 847.3 & 1874.8 \\
\hline 16.22 & 11.97 & 37.89 & 11.86 & 1041.0 & 572.5 & 280.0 & 852.6 & 1896.0 \\
\hline
\end{tabular}

(a) $\mathrm{J}_{\text {nom }}$ uses ASTM E1152 $\mathrm{J}_{\mathrm{D}}$ and ignores the fact that the notch is slanted.

(b) $\mathbf{J}_{\mathrm{tot}}=\mathbf{J}_{\mathbf{i}}+\mathbf{J}_{\mathrm{iii}}$. 
Table A.7b Test data from C(T) Specimen A8W4-FL-2

(Slant-notch with angle of 55 degrees from specimen face to follow fusion-line, test at $288 \mathrm{C}$; English units)

\begin{tabular}{|c|c|c|c|c|c|c|c|c|}
\hline $\begin{array}{l}\text { Load, } \\
\text { lb }\end{array}$ & $\begin{array}{c}\text { Load-Line } \\
\text { Displacement, } \\
\text { inch }\end{array}$ & $\begin{array}{l}\text { Crack } \\
\text { Length, } \\
\text { inch }\end{array}$ & $\begin{array}{c}\text { Crack } \\
\text { Growth, } \\
\text { inch }\end{array}$ & $\begin{array}{l}\mathrm{J}_{\text {nom }}^{(a)} \\
\text { lb/inch }\end{array}$ & $\begin{array}{c}\mathbf{J}_{\mathbf{i}}, \\
\text { lb/inch }\end{array}$ & $\begin{array}{c}\mathrm{J}_{\mathrm{iii}} \\
\text { lb/inch }\end{array}$ & $\begin{array}{l}\mathrm{J}_{\text {tot }}^{(\mathbf{b})} \\
\mathrm{lb} / \text { inch }\end{array}$ & $\begin{array}{c}\mathrm{J}_{\mathbf{m}} \\
\text { lb/inch }\end{array}$ \\
\hline 0 & 0.0000 & 1.0248 & 0.0000 & 0 & 0 & 0 & 0 & 0 \\
\hline 5092 & 0.0145 & 1.0248 & 0.0000 & 124 & 68 & 33 & 102 & 124 \\
\hline 6293 & 0.0291 & 1.0248 & 0.0000 & 400 & 220 & 108 & 328 & 400 \\
\hline 6697 & 0.0438 & 1.0248 & 0.0000 & 716 & 394 & 193 & 587 & 716 \\
\hline 6990 & 0.0593 & 1.0248 & 0.0000 & 1067 & 587 & 287 & 875 & 1067 \\
\hline 7190 & 0.0718 & 1.0248 & 0.0000 & 1361 & 749 & 366 & 1115 & 1361 \\
\hline 7371 & 0.0867 & 1.0248 & 0.0000 & 1720 & 947 & 463 & 1410 & 1720 \\
\hline 7570 & 0.1028 & 1.0248 & 0.0000 & 2118 & 1166 & 570 & 1736 & 2118 \\
\hline 7723 & 0.1172 & 1.0248 & 0.0000 & 2483 & 1367 & 668 & 2035 & 2483 \\
\hline 7857 & 0.1299 & 1.0248 & 0.0000 & 2810 & 1547 & 757 & 2303 & 2810 \\
\hline 7981 & 0.1438 & 1.0248 & 0.0000 & 3175 & 1747 & 855 & 2602 & 3175 \\
\hline 8133 & 0.1602 & 1.0248 & 0.0000 & 3612 & 1988 & 972 & 2961 & 3612 \\
\hline 8262 & 0.1748 & 1.0248 & 0.0000 & 4009 & 2206 & 1079 & 3285 & 4009 \\
\hline 8350 & 0.1877 & 1.0248 & 0.0000 & 4363 & 2401 & 1175 & 3576 & 4363 \\
\hline 8426 & 0.2019 & 1.0248 & 0.0000 & 4758 & 2619 & 1281 & 3899 & 4758 \\
\hline 8455 & 0.2153 & 1.0248 & 0.0000 & 5132 & 2825 & 1382 & 4206 & 5132 \\
\hline 8443 & 0.2188 & 1.0263 & 0.0015 & 5219 & 2873 & 1405 & 4278 & 5229 \\
\hline 8426 & 0.2258 & 1.0308 & 0.0060 & 5380 & 2961 & 1448 & 4409 & 5423 \\
\hline 8303 & 0.2332 & 1.0379 & 0.0131 & 5531 & 3044 & 1489 & 4533 & 5625 \\
\hline 8197 & 0.2405 & 1.0451 & 0.0203 & 5674 & 3123 & 1527 & 4651 & 5823 \\
\hline 8127 & 0.2483 & 1.0523 & 0.0275 & 5828 & 3208 & 1569 & 4777 & 6035 \\
\hline 7934 & 0.2598 & 1.0671 & 0.0423 & 6013 & 3309 & 1619 & 4928 & 6340 \\
\hline 7875 & 0.2637 & 1.0732 & 0.0484 & 6064 & 3338 & 1633 & 4971 & 6443 \\
\hline 7699 & 0.2727 & 1.0830 & 0.0582 & 6217 & 3422 & 1674 & 5096 & 6681 \\
\hline 7518 & 0.2815 & 1.0931 & 0.0683 & 6356 & 3499 & 1711 & 5210 & 6909 \\
\hline 7242 & 0.2900 & 1.1064 & 0.0816 & 6448 & 3549 & 1736 & 5285 & 7123 \\
\hline 7061 & 0.2947 & 1.1169 & 0.0921 & 6464 & 3558 & 1740 & 5298 & 7238 \\
\hline 6621 & 0.3047 & 1.1376 & 0.1128 & 6501 & 3578 & 1750 & 5329 & 7472 \\
\hline 6398 & 0.3135 & 1.1581 & 0.1333 & 6500 & 3578 & 1750 & 5327 & 7671 \\
\hline 6258 & 0.3191 & 1.1759 & 0.1511 & 6446 & 3548 & 1735 & 5283 & 7793 \\
\hline 6053 & 0.3279 & 1.1930 & 0.1682 & 6473 & 3563 & 1743 & 5305 & 7991 \\
\hline 5783 & 0.3369 & 1.2107 & 0.1859 & 6490 & 3572 & 1747 & 5319 & 8189 \\
\hline 5666 & 0.3413 & 1.2211 & 0.1963 & 6477 & 3565 & 1744 & 5309 & 8284 \\
\hline 5426 & 0.3513 & 1.2392 & 0.2144 & 6499 & 3577 & 1750 & 5327 & 8497 \\
\hline 5320 & 0.3572 & 1.2544 & 0.2296 & 6458 & 3555 & 1739 & 5293 & 8618 \\
\hline 5022 & 0.3665 & 1.2786 & 0.2538 & 6381 & 3512 & 1718 & 5230 & 8802 \\
\hline 4652 & 0.3777 & 1.3075 & 0.2827 & 6273 & 3453 & 1689 & 5142 & 9012 \\
\hline 4529 & 0.3840 & 1.3353 & 0.3105 & 6072 & 3342 & 1634 & 4976 & 9116 \\
\hline 4400 & 0.3904 & 1.3512 & 0.3264 & 6017 & 3312 & 1620 & 4932 & 9237 \\
\hline 4324 & 0.3962 & 1.3789 & 0.3541 & 5802 & 3193 & 1562 & 4755 & 9328 \\
\hline 4219 & 0.4075 & 1.3988 & 0.3740 & 5801 & 3193 & 1562 & 4755 & 9550 \\
\hline 4166 & 0.4131 & 1.4059 & 0.3811 & 5837 & 3213 & 1571 & 4784 & 9665 \\
\hline 4043 & 0.4241 & 1.4215 & 0.3967 & 5875 & 3234 & 1582 & 4816 & 9885 \\
\hline 3996 & 0.4299 & 1.4334 & 0.4086 & 5847 & 3218 & 1574 & 4792 & 9998 \\
\hline 3955 & 0.4353 & 1.4398 & 0.4150 & 5881 & 3237 & 1583 & 4820 & 10109 \\
\hline 3856 & 0.4470 & 1.4552 & 0.4304 & 5928 & 3263 & 1596 & 4858 & 10343 \\
\hline 3820 & 0.4526 & 1.4664 & 0.4416 & 5897 & 3246 & 1587 & 4833 & 10452 \\
\hline 3744 & 0.4590 & 1.4733 & 0.4485 & 5941 & 3270 & 1599 & 4869 & 10584 \\
\hline 3662 & 0.4653 & 1.4854 & 0.4606 & 5907 & 3251 & 1590 & 4841 & 10705 \\
\hline 3604 & 0.4712 & 1.4918 & 0.4670 & 5944 & 3272 & 1600 & 4872 & 10826 \\
\hline
\end{tabular}

(a) $\mathrm{J}_{\text {nom }}$ uses ASTM E1152 $\mathrm{J}_{\mathrm{D}}$ and ignores the fact that the notch is slanted.

(b) $\mathrm{J}_{\mathrm{tot}}=\mathrm{J}_{\mathrm{i}}+\mathrm{J}_{\mathrm{iii}}$. 
Table A.8a Test data from C(T) Specimen A8W4-FL-3

(Slant-notch with angle of 55 degrees from specimen face to follow fusion-line, test at 288 C; SI units)

\begin{tabular}{|c|c|c|c|c|c|c|c|c|}
\hline $\begin{array}{c}\text { Load, } \\
\text { kN }\end{array}$ & $\begin{array}{c}\text { Load-Line } \\
\text { Displacement, } \\
\text { mm }\end{array}$ & $\begin{array}{c}\text { Crack } \\
\text { Length, } \\
\text { mm }\end{array}$ & $\begin{array}{c}\text { Growth, } \\
\text { mm }\end{array}$ & $\begin{array}{l}\mathbf{J}_{\text {nom }}^{(a)} \\
\mathbf{k J} / \mathbf{m}^{2}\end{array}$ & $\underset{\mathbf{k J} / \mathrm{m}^{2}}{\mathbf{J}_{\mathbf{i}},}$ & $\underset{\mathbf{k J} / \mathbf{m}^{2}}{\mathrm{~J}_{\mathrm{iii}}}$ & $\begin{array}{l}\mathbf{J}_{\text {tot }}^{(\mathbf{b})} \\
\mathbf{k J} / \mathbf{m}^{2}\end{array}$ & $\underset{\mathrm{kJ} / \mathrm{m}^{2}}{\mathbf{J}_{\mathrm{m}}}$ \\
\hline 0.00 & 0.00 & 26.74 & 0.00 & 0.0 & 0.0 & 0.0 & 0.0 & 0.0 \\
\hline 21.67 & 0.32 & 26.74 & 0.00 & 18.9 & 10.4 & 5.1 & 15.5 & 18.9 \\
\hline 28.21 & 0.65 & 26.74 & 0.00 & 61.4 & 33.8 & 16.5 & 50.3 & 61.4 \\
\hline 30.35 & 0.97 & 26.74 & 0.00 & 110.9 & 61.0 & 29.8 & 90.8 & 110.9 \\
\hline 31.69 & 1.31 & 26.74 & 0.00 & 165.4 & 91.0 & 44.5 & 135.5 & 165.4 \\
\hline 32.51 & 1.59 & 26.74 & 0.00 & 212.4 & 116.8 & 57.1 & 174.0 & 212.4 \\
\hline 33.28 & 1.88 & 26.74 & 0.00 & 262.7 & 144.5 & 70.7 & 215.2 & 262.7 \\
\hline 34.09 & 2.22 & 26.74 & 0.00 & 323.7 & 178.0 & 87.1 & 265.1 & 323.7 \\
\hline 34.70 & 2.53 & 26.74 & 0.00 & 378.6 & 208.2 & 101.8 & 310.1 & 378.6 \\
\hline 35.17 & 2.82 & 26.74 & 0.00 & 432.0 & 237.6 & 116.2 & 353.8 & 432.0 \\
\hline 35.62 & 3.14 & 26.74 & 0.00 & 490.4 & 269.7 & 131.9 & 401.6 & 490.4 \\
\hline 35.99 & 3.46 & 26.74 & 0.00 & 550.9 & 303.0 & 148.2 & 451.2 & 550.9 \\
\hline 36.31 & 3.79 & 26.74 & 0.00 & 613.5 & 337.4 & 165.0 & 502.5 & 613.5 \\
\hline 36.57 & 4.11 & 26.74 & 0.00 & 673.6 & 370.5 & 181.2 & 551.7 & 673.6 \\
\hline 36.78 & 4.44 & 26.74 & 0.00 & 738.0 & 405.9 & 198.5 & 604.4 & 738.0 \\
\hline 36.70 & 4.69 & 26.74 & 0.00 & 785.9 & 432.2 & 211.4 & 643.7 & 785.9 \\
\hline 36.26 & 4.78 & 26.74 & 0.00 & 803.4 & 441.9 & 216.1 & 658.0 & 803.4 \\
\hline 35.15 & 4.94 & 26.99 & 0.25 & 822.2 & 452.2 & 221.2 & 673.4 & 832.9 \\
\hline 34.41 & 5.13 & 27.22 & 0.47 & 845.3 & 464.9 & 227.4 & 692.3 & 866.3 \\
\hline 31.85 & 5.31 & 27.66 & 0.91 & 854.9 & 470.2 & 230.0 & 700.2 & 896.5 \\
\hline 30.77 & 5.48 & 28.02 & 1.27 & 864.8 & 475.6 & 232.6 & 708.3 & 923.7 \\
\hline 29.66 & 5.69 & 28.55 & 1.80 & 872.7 & 480.0 & 234.8 & 714.7 & 957.6 \\
\hline 29.32 & 5.79 & 28.80 & 2.06 & 875.2 & 481.4 & 235.4 & 716.8 & 973.1 \\
\hline 28.77 & 5.98 & 29.11 & 2.36 & 889.6 & 489.3 & 239.3 & 728.6 & 1003.1 \\
\hline 28.16 & 6.18 & 29.44 & 2.70 & 903.1 & 496.7 & 242.9 & 739.6 & 1034.3 \\
\hline 27.92 & 6.28 & 29.61 & 2.86 & 909.9 & 500.4 & 244.8 & 745.2 & 1049.9 \\
\hline 27.32 & 6.47 & 29.95 & 3.21 & 921.8 & 507.0 & 248.0 & 755.0 & 1080.8 \\
\hline 26.76 & 6.67 & 30.27 & 3.52 & 934.1 & 513.8 & 251.3 & 765.0 & 1110.7 \\
\hline 26.52 & 6.77 & 30.42 & 3.67 & 941.9 & 518.0 & 253.4 & 771.4 & 1127.0 \\
\hline 25.58 & 6.98 & 30.74 & 4.00 & 954.9 & 525.2 & 256.9 & 782.1 & 1159.2 \\
\hline 24.97 & 7.09 & 30.98 & 4.23 & 956.8 & 526.2 & 257.4 & 783.6 & 1175.0 \\
\hline 23.94 & 7.30 & 31.48 & 4.74 & 956.8 & 526.2 & 257.4 & 783.6 & 1205.7 \\
\hline 22.73 & 7.52 & 32.03 & 5.28 & 952.9 & 524.1 & 256.3 & 780.4 & 1235.4 \\
\hline 22.28 & 7.63 & 32.35 & 5.60 & 947.9 & 521.3 & 255.0 & 776.3 & 1250.6 \\
\hline 21.86 & 7.74 & 32.72 & 5.98 & 938.4 & 516.1 & 252.4 & 768.5 & 1264.6 \\
\hline 21.07 & 7.95 & 33.35 & 6.60 & 926.8 & 509.7 & 249.3 & 759.0 & 1292.6 \\
\hline 20.17 & 8.18 & 33.91 & 7.16 & 919.7 & 505.8 & 247.4 & 753.2 & 1321.9 \\
\hline 19.57 & 8.29 & 34.20 & 7.45 & 915.4 & 503.5 & 246.2 & 749.7 & 1336.6 \\
\hline 18.93 & 8.40 & 34.53 & 7.79 & 907.4 & 499.1 & 244.1 & 743.2 & 1350.8 \\
\hline 18.11 & 8.66 & 35.15 & 8.40 & 897.9 & 493.8 & 241.5 & 735.4 & 1382.3 \\
\hline 17.72 & 8.80 & 35.37 & 8.63 & 901.5 & 495.8 & 242.5 & 738.3 & 1401.0 \\
\hline 17.43 & 8.92 & 35.58 & 8.83 & 902.8 & 496.5 & 242.9 & 739.4 & 1416.5 \\
\hline 17.06 & 9.05 & 35.91 & 9.17 & 896.1 & 492.9 & 241.1 & 733.9 & 1433.1 \\
\hline 16.30 & 9.33 & 36.26 & 9.51 & 906.8 & 498.7 & 243.9 & 742.7 & 1468.4 \\
\hline 16.03 & 9.46 & 36.59 & 9.84 & 899.4 & 494.7 & 241.9 & 736.6 & 1484.8 \\
\hline 15.66 & 9.60 & 36.78 & 10.03 & 902.6 & 496.4 & 242.8 & 739.2 & 1501.9 \\
\hline 15.11 & 9.73 & 37.02 & 10.28 & 900.5 & 495.3 & 242.2 & 737.5 & 1518.0 \\
\hline 14.13 & 10.12 & 37.70 & 10.96 & 893.0 & 491.1 & 240.2 & 731.4 & 1562.3 \\
\hline
\end{tabular}

(a) $\mathrm{J}_{\text {nom }}$ uses ASTM E1152 $\mathrm{J}_{\mathrm{D}}$ and ignores the fact that the notch is slanted.

(b) $\mathrm{J}_{\text {Lot }}=\mathrm{J}_{\mathrm{i}}+\mathrm{J}_{\mathrm{iii}}$. 
Table A.8b Test data from C(T) Specimen A8W4-FL-3

(Slant-notch with angle of 55 degrees from specimen face to follow fusion-line, test at $288 \mathrm{C}$; English units)

\begin{tabular}{|c|c|c|c|c|c|c|c|c|}
\hline $\begin{array}{l}\text { Load, } \\
\text { lb }\end{array}$ & $\begin{array}{l}\text { Load-Line } \\
\text { Displacement, } \\
\text { inch }\end{array}$ & $\begin{array}{l}\text { Crack } \\
\text { Length, } \\
\text { inch }\end{array}$ & $\begin{array}{c}\text { Crack } \\
\text { Growth, } \\
\text { inch }\end{array}$ & $\begin{array}{l}\mathrm{J}_{\text {nom }}^{(\mathbf{a})} \\
\text { lb/inch }\end{array}$ & $\begin{array}{c}\mathbf{J}_{\mathbf{i}}, \\
\text { lb/inch }\end{array}$ & $\mathbf{J}_{\mathbf{D}} \frac{}{\begin{array}{c}\mathbf{J}_{\mathrm{iii}}, \\
\mathrm{lb} / \mathrm{inch}\end{array}}$ & $\begin{array}{l}\mathrm{J}_{\text {tot }}^{(b)} \\
\text { lb/inch }\end{array}$ & $\underset{\text { lb/inch }}{\mathbf{J}_{\mathbf{m}}}$ \\
\hline 0 & 0.0000 & 1.0529 & 0.0000 & 0 & 0 & 0 & 0 & 0 \\
\hline 4816 & 0.0128 & 1.0529 & 0.0000 & 108 & 59 & 29 & 88 & 108 \\
\hline 6270 & 0.0256 & 1.0529 & 0.0000 & 351 & 193 & 94 & 287 & 351 \\
\hline 6744 & 0.0383 & 1.0529 & 0.0000 & 633 & 349 & 170 & 519 & 633 \\
\hline 7043 & 0.0515 & 1.0529 & 0.0000 & 944 & 520 & 254 & 774 & 944 \\
\hline 7225 & 0.0625 & 1.0529 & 0.0000 & 1213 & 668 & 326 & 994 & 1213 \\
\hline 7395 & 0.0740 & 1.0529 & 0.0000 & 1500 & 826 & 404 & 1229 & 1500 \\
\hline 7576 & 0.0876 & 1.0529 & 0.0000 & 1848 & 1017 & 498 & 1515 & 1848 \\
\hline 7711 & 0.0996 & 1.0529 & 0.0000 & 2162 & 1190 & 582 & 1772 & 2162 \\
\hline 7816 & 0.1111 & 1.0529 & 0.0000 & 2467 & 1358 & 664 & 2022 & 2467 \\
\hline 7916 & 0.1235 & 1.0529 & 0.0000 & 2800 & 1541 & 754 & 2295 & 2800 \\
\hline 7998 & 0.1362 & 1.0529 & 0.0000 & 3146 & 1731 & 847 & 2578 & 3146 \\
\hline 8068 & 0.1492 & 1.0529 & 0.0000 & 3503 & 1928 & 943 & 2871 & 3503 \\
\hline 8127 & 0.1616 & 1.0529 & 0.0000 & 3846 & 2117 & 1035 & 3152 & 3846 \\
\hline 8174 & 0.1748 & 1.0529 & 0.0000 & 4214 & 2319 & 1134 & 3454 & 4214 \\
\hline 8156 & 0.1846 & 1.0529 & 0.0000 & 4488 & 2470 & 1208 & 3678 & 4488 \\
\hline 8057 & 0.1882 & 1.0529 & 0.0000 & 4587 & 2525 & 1235 & 3760 & 4587 \\
\hline 7811 & 0.1946 & 1.0626 & 0.0097 & 4694 & 2584 & 1264 & 3848 & 4756 \\
\hline 7647 & 0.2019 & 1.0715 & 0.0186 & 4827 & 2657 & 1299 & 3956 & 4946 \\
\hline 7078 & 0.2090 & 1.0888 & 0.0359 & 4882 & 2687 & 1314 & 4001 & 5119 \\
\hline 6838 & 0.2156 & 1.1030 & 0.0501 & 4938 & 2718 & 1329 & 4047 & 5274 \\
\hline 6592 & 0.2241 & 1.1238 & 0.0709 & 4983 & 2743 & 1341 & 4084 & 5468 \\
\hline 6516 & 0.2280 & 1.1340 & 0.0811 & 4997 & 2751 & 1345 & 4096 & 5557 \\
\hline 6393 & 0.2354 & 1.1459 & 0.0930 & 5080 & 2796 & 1367 & 4163 & 5728 \\
\hline 6258 & 0.2432 & 1.1592 & 0.1063 & 5157 & 2838 & 1388 & 4227 & 5906 \\
\hline 6205 & 0.2471 & 1.1656 & 0.1127 & 5196 & 2860 & 1399 & 4258 & 5995 \\
\hline 6070 & 0.2549 & 1.1793 & 0.1264 & 5264 & 2897 & 1417 & 4314 & 6171 \\
\hline 5947 & 0.2625 & 1.1916 & 0.1387 & 5334 & 2936 & 1436 & 4372 & 6342 \\
\hline 5895 & 0.2666 & 1.1975 & 0.1446 & 5378 & 2960 & 1448 & 4408 & 6435 \\
\hline 5684 & 0.2749 & 1.2103 & 0.1574 & 5453 & 3001 & 1468 & 4469 & 6619 \\
\hline 5549 & 0.2791 & 1.2195 & 0.1666 & 5464 & 3007 & 1471 & 4478 & 6709 \\
\hline 5320 & 0.2876 & 1.2395 & 0.1866 & 5463 & 3007 & 1471 & 4478 & 6885 \\
\hline 5051 & 0.2961 & 1.2608 & 0.2079 & 5441 & 2995 & 1465 & 4460 & 7054 \\
\hline 4951 & 0.3005 & 1.2735 & 0.2206 & 5413 & 2979 & 1457 & 4436 & 7141 \\
\hline 4857 & 0.3047 & 1.2882 & 0.2353 & 5358 & 2949 & 1442 & 4392 & 7221 \\
\hline 4682 & 0.3132 & 1.3128 & 0.2599 & 5292 & 2913 & 1425 & 4337 & 7381 \\
\hline 4482 & 0.3220 & 1.3350 & 0.2821 & 5251 & 2890 & 1414 & 4304 & 7548 \\
\hline 4348 & 0.3264 & 1.3464 & 0.2935 & 5227 & 2877 & 1407 & 4284 & 7632 \\
\hline 4207 & 0.3308 & 1.3596 & 0.3067 & 5181 & 2852 & 1395 & 4247 & 7713 \\
\hline 4025 & 0.3408 & 1.3838 & 0.3309 & 5127 & 2822 & 1380 & 4202 & 7893 \\
\hline 3938 & 0.3464 & 1.3926 & 0.3397 & 5147 & 2833 & 1386 & 4219 & 8000 \\
\hline 3873 & 0.3511 & 1.4007 & 0.3478 & 5155 & 2837 & 1388 & 4225 & 8088 \\
\hline 3791 & 0.3564 & 1.4138 & 0.3609 & 5117 & 2816 & 1377 & 4194 & 8183 \\
\hline 3621 & 0.3672 & 1.4275 & 0.3746 & 5178 & 2850 & 1394 & 4244 & 8384 \\
\hline 3563 & 0.3726 & 1.4404 & 0.3875 & 5136 & 2827 & 1383 & 4209 & 8478 \\
\hline 3481 & 0.3779 & 1.4479 & 0.3950 & 5154 & 2837 & 1387 & 4224 & 8576 \\
\hline 3357 & 0.3831 & 1.4575 & 0.4046 & 5142 & 2830 & 1384 & 4214 & 8668 \\
\hline 3141 & 0.3984 & 1.4843 & 0.4314 & 5099 & 2807 & 1373 & 4179 & 8921 \\
\hline
\end{tabular}

(a) $\mathrm{J}_{\text {nom }}$ uses ASTM E1152 $\mathrm{J}_{\mathrm{D}}$ and ignores the fact that the notch is slanted.

(b) $\mathrm{J}_{\text {tod }}=\mathrm{J}_{\mathrm{i}}+\mathrm{J}_{\mathrm{iij}}$. 
Table A.9a Test data from C(T) Specimen A8W4-FL-5

(Slant-notch with angle of 55 degrees from specimen face to follow fusion-line, test at $288 \mathrm{C}$; SI units)

\begin{tabular}{|c|c|c|c|c|c|c|c|c|}
\hline $\begin{array}{l}\text { Load, } \\
\text { kN }\end{array}$ & $\begin{array}{c}\text { Load-Line } \\
\text { Displacement, } \\
\text { mm }\end{array}$ & $\begin{array}{c}\text { Crack } \\
\text { Length, } \\
\text { mm }\end{array}$ & $\begin{array}{c}\text { Growth, } \\
\text { mm }\end{array}$ & $\begin{array}{c}\mathrm{J}_{\mathrm{nom}}^{(\mathrm{a})} \\
\mathrm{kJ} / \mathrm{m}^{2}\end{array}$ & $\underset{\mathbf{k J} / \mathbf{m}^{2}}{\mathbf{J}_{\mathbf{3}}}$ & $\underset{\mathbf{k J} / \mathbf{m}^{2}}{\mathbf{J}_{i i i}}$ & $\begin{array}{l}\mathrm{J}_{\mathrm{tot}}^{(\mathrm{b})} \\
\mathrm{kJ} / \mathrm{m}^{2}\end{array}$ & $\underset{\mathrm{kJ} / \mathrm{m}^{2}}{\mathbf{J}_{\mathrm{m}}}$ \\
\hline 0.00 & 0.00 & 25.84 & 0.00 & 0.0 & 0.0 & 0.0 & 0.0 & 0.0 \\
\hline 21.96 & 0.29 & 25.84 & 0.00 & 16.6 & 9.1 & 4.5 & 13.6 & 16.6 \\
\hline 29.87 & 0.58 & 25.84 & 0.00 & 54.7 & 30.1 & 14.7 & 44.8 & 54.7 \\
\hline 32.72 & 0.86 & 25.84 & 0.00 & 98.6 & 54.2 & 26.5 & 80.8 & 98.6 \\
\hline 34.17 & 1.15 & 25.84 & 0.00 & 147.2 & 81.0 & 39.6 & 120.6 & 147.2 \\
\hline 35.41 & 1.45 & 25.84 & 0.00 & 200.4 & 110.2 & 53.9 & 164.1 & 200.4 \\
\hline 36.44 & 1.74 & 25.84 & 0.00 & 252.6 & 138.9 & 67.9 & 206.9 & 252.6 \\
\hline 37.34 & 2.03 & 25.84 & 0.00 & 306.7 & 168.7 & 82.5 & 251.2 & 306.7 \\
\hline 38.10 & 2.30 & 25.84 & 0.00 & 359.0 & 197.4 & 96.6 & 294.0 & 359.0 \\
\hline 38.65 & 2.59 & 25.84 & 0.00 & 415.8 & 228.7 & 111.9 & 340.5 & 415.8 \\
\hline 39.21 & 2.88 & 25.84 & 0.00 & 471.8 & 259.5 & 126.9 & 386.4 & 471.8 \\
\hline 39.71 & 3.17 & 25.84 & 0.00 & 530.1 & 291.6 & 142.6 & 434.2 & 530.1 \\
\hline 40.21 & 3.50 & 25.84 & 0.00 & 596.4 & 328.0 & 160.4 & 488.5 & 596.4 \\
\hline 40.58 & 3.76 & 25.84 & 0.00 & 649.4 & 357.2 & 174.7 & 531.9 & 649.4 \\
\hline 40.90 & 4.03 & 25.84 & 0.00 & 705.9 & 388.2 & 189.9 & 578.1 & 705.9 \\
\hline 41.05 & 4.30 & 25.84 & 0.00 & 762.3 & 419.3 & 205.1 & 624.3 & 762.3 \\
\hline 41.00 & 4.41 & 25.89 & 0.06 & 782.0 & 430.1 & 210.4 & 640.5 & 784.2 \\
\hline 40.69 & 4.62 & 26.06 & 0.23 & 817.8 & 449.8 & 220.0 & 669.8 & 827.2 \\
\hline 40.53 & 4.81 & 26.20 & 0.36 & 851.5 & 468.3 & 229.1 & 697.4 & 866.7 \\
\hline 40.42 & 5.00 & 26.31 & 0.48 & 884.3 & 486.4 & 237.9 & 724.2 & 904.7 \\
\hline 40.10 & 5.19 & 26.49 & 0.65 & 914.8 & 503.1 & 246.1 & 749.2 & 943.5 \\
\hline 39.95 & 5.39 & 26.67 & 0.84 & 946.3 & 520.5 & 254.6 & 775.0 & 984.3 \\
\hline 39.81 & 5.59 & 26.82 & 0.98 & 979.6 & 538.8 & 263.5 & 802.3 & 1025.0 \\
\hline 39.71 & 5.73 & 26.89 & 1.06 & 1005.0 & 552.7 & 270.3 & 823.1 & 1054.3 \\
\hline 39.13 & 5.96 & 27.14 & 1.31 & 1037.5 & 570.6 & 279.1 & 849.7 & 1100.6 \\
\hline 34.36 & 6.18 & 29.19 & 3.35 & 947.2 & 521.0 & 254.8 & 775.8 & 1124.4 \\
\hline 33.25 & 6.36 & 29.49 & 3.65 & 962.7 & 529.5 & 259.0 & 788.5 & 1156.6 \\
\hline 32.22 & 6.52 & 30.00 & 4.16 & 962.4 & 529.3 & 258.9 & 788.2 & 1184.9 \\
\hline 31.01 & 6.77 & 30.46 & 4.62 & 979.7 & 538.8 & 263.5 & 802.4 & 1229.4 \\
\hline 30.16 & 6.93 & 30.90 & 5.07 & 981.5 & 539.8 & 264.0 & 803.8 & 1257.8 \\
\hline 29.14 & 7.09 & 31.19 & 5.35 & 991.5 & 545.3 & 266.7 & 812.0 & 1285.4 \\
\hline 28.19 & 7.34 & 31.87 & 6.03 & 988.7 & 543.8 & 266.0 & 809.7 & 1325.4 \\
\hline 27.66 & 7.52 & 32.35 & 6.51 & 989.0 & 544.0 & 266.0 & 810.0 & 1356.1 \\
\hline 27.05 & 7.71 & 32.65 & 6.81 & 1002.0 & 551.1 & 269.5 & 820.6 & 1388.6 \\
\hline 26.39 & 7.89 & 32.86 & 7.02 & 1020.2 & 561.1 & 274.4 & 835.5 & 1421.0 \\
\hline 25.79 & 8.07 & 33.15 & 7.31 & 1029.2 & 566.1 & 276.9 & 842.9 & 1450.1 \\
\hline 25.29 & 8.27 & 33.47 & 7.63 & 1039.4 & 571.7 & 279.6 & 851.3 & 1483.1 \\
\hline 24.65 & 8.47 & 33.77 & 7.93 & 1051.2 & 578.2 & 282.8 & 860.9 & 1516.6 \\
\hline 24.13 & 8.66 & 34.04 & 8.21 & 1062.5 & 584.4 & 285.8 & 870.2 & 1548.2 \\
\hline 23.20 & 8.87 & 34.42 & 8.58 & 1067.8 & 587.3 & 287.2 & 874.5 & 1582.0 \\
\hline 22.70 & 8.98 & 34.63 & 8.79 & 1069.1 & 588.0 & 287.6 & 875.6 & 1599.8 \\
\hline 21.91 & 9.19 & 35.04 & 9.20 & 1069.8 & 588.4 & 287.8 & 876.2 & 1632.3 \\
\hline 21.44 & 9.39 & 35.34 & 9.50 & 1076.5 & 592.1 & 289.6 & 881.7 & 1663.2 \\
\hline 20.51 & 9.61 & 35.69 & 9.86 & 1080.6 & 594.3 & 290.7 & 885.0 & 1696.6 \\
\hline 19.96 & 9.82 & 36.05 & 10.21 & 1082.6 & 595.4 & 291.2 & 886.6 & 1728.1 \\
\hline 19.49 & 10.05 & 36.44 & 10.60 & 1082.7 & 595.5 & 291.2 & 886.7 & 1761.8 \\
\hline 19.25 & 10.15 & 36.62 & 10.78 & 1083.2 & 595.8 & 291.4 & 887.1 & 1777.8 \\
\hline 18.77 & 10.36 & 36.94 & 11.10 & 1086.4 & 597.5 & 292.2 & 889.8 & 1809.2 \\
\hline 18.19 & 10.60 & 37.25 & 11.42 & 1093.6 & 601.5 & 294.2 & 895.7 & 1845.3 \\
\hline
\end{tabular}

(a) $\mathrm{J}_{\text {nom }}$ uses ASTM E1152 $\mathrm{J}_{\mathrm{D}}$ and ignores the fact that the notch is slanted.

(b) $\mathrm{J}_{\mathrm{tot}}=\mathrm{J}_{\mathbf{i}}+\mathrm{J}_{\mathrm{iii}}$. 
Table A.9b Test data from C(T) Specimen A8W4-FL-5

(Slant-notch with angle of 55 degrees from specimen face to follow fusion-line, test at $288 \mathrm{C}$; English units)

\begin{tabular}{|c|c|c|c|c|c|c|c|c|}
\hline $\begin{array}{l}\text { Load, } \\
\text { lb }\end{array}$ & $\begin{array}{c}\text { Load-Line } \\
\text { Displacement, } \\
\text { inch }\end{array}$ & $\begin{array}{c}\text { Crack } \\
\text { Length, } \\
\text { inch }\end{array}$ & $\begin{array}{c}\text { Crack } \\
\text { Growth, } \\
\text { inch }\end{array}$ & $\begin{array}{l}\mathbf{J}_{\text {nom }}^{(a)} \\
\text { lb/inch }\end{array}$ & $\begin{array}{c}\mathbf{J}_{\mathbf{i}}, \\
\text { lb/inch }\end{array}$ & $\begin{array}{c}\mathbf{J}_{\mathrm{iii}} \\
\text { lb/inch }\end{array}$ & $\begin{array}{l}\mathrm{J}_{\text {tot }}^{(b)} \\
\text { lb/inch }\end{array}$ & $\underset{\text { lb/inch }}{\mathbf{J}_{\mathbf{m}}}$ \\
\hline 0 & 0.0000 & 1.0172 & 0.0000 & 0 & 0 & 0 & 0 & 0 \\
\hline 4881 & 0.0116 & 1.0172 & 0.0000 & 95 & 52 & 26 & 78 & 95 \\
\hline 6639 & 0.0230 & 1.0172 & 0.0000 & 312 & 172 & 84 & 256 & 312 \\
\hline 7272 & 0.0339 & 1.0172 & 0.0000 & 563 & 310 & 152 & 461 & 563 \\
\hline 7594 & 0.0452 & 1.0172 & 0.0000 & 841 & 463 & 226 & 689 & 841 \\
\hline 7869 & 0.0571 & 1.0172 & 0.0000 & 1144 & 630 & 308 & 938 & 1144 \\
\hline 8098 & 0.0684 & 1.0172 & 0.0000 & 1442 & 794 & 388 & 1182 & 1442 \\
\hline 8297 & 0.0798 & 1.0172 & 0.0000 & 1751 & 964 & 471 & 1435 & 1751 \\
\hline 8467 & 0.0906 & 1.0172 & 0.0000 & 2050 & 1128 & 552 & 1680 & 2050 \\
\hline 8590 & 0.1021 & 1.0172 & 0.0000 & 2374 & 1307 & 639 & 1946 & 2374 \\
\hline 8713 & 0.1133 & 1.0172 & 0.0000 & 2694 & 1483 & 725 & 2208 & 2694 \\
\hline 8824 & 0.1248 & 1.0172 & 0.0000 & 3027 & 1666 & 815 & 2481 & 3027 \\
\hline 8936 & 0.1377 & 1.0172 & 0.0000 & 3405 & 1874 & 917 & 2791 & 3405 \\
\hline 9018 & 0.1479 & 1.0172 & 0.0000 & 3708 & 2041 & 998 & 3039 & 3708 \\
\hline 9088 & 0.1587 & 1.0172 & 0.0000 & 4031 & 2219 & 1085 & 3304 & 4031 \\
\hline 9123 & 0.1694 & 1.0172 & 0.0000 & 4352 & 2396 & 1172 & 3568 & 4352 \\
\hline 9111 & 0.1736 & 1.0194 & 0.0022 & 4465 & 2458 & 1202 & 3660 & 4478 \\
\hline 9041 & 0.1819 & 1.0262 & 0.0090 & 4670 & 2570 & 1257 & 3827 & 4723 \\
\hline 9006 & 0.1895 & 1.0314 & 0.0142 & 4862 & 2676 & 1309 & 3985 & 4949 \\
\hline 8982 & 0.1968 & 1.0360 & 0.0188 & 5049 & 2779 & 1359 & 4139 & 5166 \\
\hline 8912 & 0.2043 & 1.0428 & 0.0256 & 5223 & 2875 & 1406 & 4281 & 5387 \\
\hline 8877 & 0.2122 & 1.0502 & 0.0330 & 5404 & 2974 & 1455 & 4429 & 5621 \\
\hline 8848 & 0.2200 & 1.0558 & 0.0386 & 5593 & 3079 & 1506 & 4585 & 5853 \\
\hline 8824 & 0.2256 & 1.0588 & 0.0416 & 5738 & 3159 & 1545 & 4703 & 6020 \\
\hline 8695 & 0.2346 & 1.0686 & 0.0514 & 5924 & 3261 & 1595 & 4855 & 6285 \\
\hline 7635 & 0.2434 & 1.1493 & 0.1321 & 5409 & 2977 & 1456 & 4433 & 6420 \\
\hline 7389 & 0.2502 & 1.1611 & 0.1439 & 5497 & 3026 & 1480 & 4505 & 6604 \\
\hline 7160 & 0.2566 & 1.1809 & 0.1637 & 5495 & 3025 & 1479 & 4504 & 6766 \\
\hline 6891 & 0.2664 & 1.1992 & 0.1820 & 5594 & 3079 & 1506 & 4585 & 7020 \\
\hline 6703 & 0.2729 & 1.2166 & 0.1994 & 5604 & 3085 & 1509 & 4593 & 7182 \\
\hline 6475 & 0.2791 & 1.2279 & 0.2107 & 5662 & 3116 & 1524 & 4640 & 7339 \\
\hline 6264 & 0.2888 & 1.2548 & 0.2376 & 5646 & 3107 & 1520 & 4627 & 7568 \\
\hline 6147 & 0.2961 & 1.2735 & 0.2563 & 5647 & 3108 & 1520 & 4629 & 7743 \\
\hline 6012 & 0.3035 & 1.2852 & 0.2680 & 5721 & 3149 & 1540 & 4689 & 7929 \\
\hline 5865 & 0.3108 & 1.2935 & 0.2763 & 5825 & 3206 & 1568 & 4775 & 8114 \\
\hline 5731 & 0.3176 & 1.3050 & 0.2878 & 5877 & 3235 & 1582 & 4817 & 8280 \\
\hline 5619 & 0.3254 & 1.3177 & 0.3005 & 5935 & 3267 & 1598 & 4864 & 8469 \\
\hline 5479 & 0.3333 & 1.3295 & 0.3123 & 6003 & 3304 & 1616 & 4920 & 8660 \\
\hline 5361 & 0.3408 & 1.3403 & 0.3231 & 6067 & 3339 & 1633 & 4972 & 8840 \\
\hline 5156 & 0.3491 & 1.3551 & 0.3379 & 6097 & 3356 & 1641 & 4997 & 9033 \\
\hline 5045 & 0.3535 & 1.3634 & 0.3462 & 6105 & 3360 & 1643 & 5003 & 9135 \\
\hline 4869 & 0.3618 & 1.3794 & 0.3622 & 6108 & 3362 & 1644 & 5007 & 9320 \\
\hline 4764 & 0.3696 & 1.3913 & 0.3741 & 6147 & 3383 & 1655 & 5038 & 9497 \\
\hline 4559 & 0.3782 & 1.4053 & 0.3881 & 6170 & 3396 & 1661 & 5057 & 9688 \\
\hline 4436 & 0.3865 & 1.4191 & 0.4019 & 6182 & 3402 & 1664 & 5067 & 9868 \\
\hline 4330 & 0.3955 & 1.4346 & 0.4174 & 6182 & 3403 & 1664 & 5067 & 10060 \\
\hline 4277 & 0.3997 & 1.4416 & 0.4244 & 6185 & 3404 & 1665 & 5069 & 10151 \\
\hline 4172 & 0.4080 & 1.4542 & 0.4370 & 6203 & 3414 & 1670 & 5084 & 10331 \\
\hline 4043 & 0.4175 & 1.4667 & 0.4495 & 6245 & 3437 & 1681 & 5118 & 10536 \\
\hline
\end{tabular}

(a) $\mathrm{J}_{\text {nom }}$ uses ASTM E1 $152 \mathrm{~J}_{\mathrm{D}}$ and ignores the fact that the notch is slanted.

(b) $\mathrm{J}_{\text {tor }}=\mathrm{J}_{\mathrm{i}}+\mathrm{J}_{\mathrm{iii}}$. 
Table A.10a J-resistance test data for Compact Specimen F33-4-SS-1 tested at 288 C (550 F); SI units

\begin{tabular}{|c|c|c|c|c|c|}
\hline $\begin{array}{c}\text { Load, } \\
\text { kN }\end{array}$ & $\begin{array}{c}\text { Load-Line } \\
\text { Displacement, } \\
\text { mm }\end{array}$ & $\begin{array}{c}\text { Crack } \\
\text { Length, } \\
\text { mm }\end{array}$ & $\begin{array}{c}\text { Crack } \\
\text { Extension, } \\
\text { mm }\end{array}$ & $\begin{array}{c}\mathrm{J} \\
\mathrm{kJ} / \mathrm{m}^{2}\end{array}$ & $\begin{array}{c}J_{M}, \\
k J / m^{2}\end{array}$ \\
\hline 4.72 & 0.01 & 28.77 & 0.00 & 0.1 & 0.1 \\
\hline 6.25 & 0.10 & 28.77 & 0.00 & 2.0 & 2.0 \\
\hline 12.46 & 0.43 & 28.77 & 0.00 & 13.9 & 13.9 \\
\hline 18.62 & 0.94 & 28.77 & 0.00 & 44.9 & 44.9 \\
\hline 24.82 & 3.41 & 28.77 & 0.00 & 252.9 & 252.9 \\
\hline 31.01 & 6.67 & 28.77 & 0.00 & 606.3 & 606.3 \\
\hline 37.22 & 11.10 & 28.77 & 0.00 & 1192.1 & 1192.1 \\
\hline 43.34 & 17.52 & 28.77 & 0.00 & 2197.7 & 2197.7 \\
\hline 43.37 & 17.56 & 28.77 & 0.00 & 2204.1 & 2204.1 \\
\hline 43.48 & 17.73 & 28.83 & 0.06 & 2225.7 & 2233.0 \\
\hline 43.61 & 17.94 & 28.92 & 0.15 & 2249.1 & 2268.4 \\
\hline 43.71 & 18.31 & 29.05 & 0.28 & 2292.3 & 2329.5 \\
\hline 43.83 & 19.24 & 29.38 & 0.61 & 2404.9 & 2488.0 \\
\hline 43.96 & 19.88 & 29.61 & 0.84 & 2481.9 & 2599.8 \\
\hline 43.91 & 20.65 & 29.91 & 1.14 & 2570.8 & 2734.5 \\
\hline 43.80 & 20.76 & 29.96 & 1.19 & 2582.9 & 2754.2 \\
\hline 43.69 & 20.87 & 30.01 & 1.24 & 2595.0 & 2774.0 \\
\hline 43.58 & 21.10 & 30.10 & 1.33 & 2619.0 & 2813.5 \\
\hline 43.33 & 21.65 & 30.36 & 1.59 & 2675.1 & 2911.5 \\
\hline 43.18 & 21.99 & 30.52 & 1.75 & 2706.9 & 2970.9 \\
\hline 43.08 & 22.21 & 30.64 & 1.87 & 2727.7 & 3010.7 \\
\hline 42.92 & 22.56 & 30.81 & 2.04 & 2759.0 & 3072.7 \\
\hline 42.81 & 22.80 & 30.94 & 2.16 & 2779.9 & 3115.0 \\
\hline 42.71 & 23.02 & 31.06 & 2.28 & 2798.9 & 3155.1 \\
\hline 42.42 & 23.60 & 31.38 & 2.61 & 2844.4 & 3259.1 \\
\hline 42.29 & 23.79 & 31.49 & 2.71 & 2858.1 & 3292.7 \\
\hline 42.15 & 23.95 & 31.58 & 2.81 & 2870.6 & 3322.2 \\
\hline 42.06 & 24.06 & 31.64 & 2.87 & 2878.9 & 3342.5 \\
\hline 41.75 & 24.39 & 31.83 & 3.06 & 2904.2 & 3402.8 \\
\hline 41.63 & 24.51 & 31.89 & 3.12 & 2912.7 & 3423.2 \\
\hline 41.53 & 24.61 & 31.94 & 3.17 & 2920.5 & 3441.7 \\
\hline 41.41 & 24.73 & 32.01 & 3.24 & 2929.7 & 3463.9 \\
\hline 41.27 & 24.87 & 32.08 & 3.31 & 2940.2 & 3488.9 \\
\hline 41.15 & 24.99 & 32.15 & 3.38 & 2949.7 & 3511.6 \\
\hline 40.75 & 25.39 & 32.37 & 3.60 & 2979.2 & 3583.4 \\
\hline 40.09 & 26.03 & 32.71 & 3.93 & 3026.8 & 3700.1 \\
\hline 39.44 & 26.67 & 33.03 & 4.26 & 3074.1 & 3814.7 \\
\hline 38.79 & 27.31 & 33.34 & 4.57 & 3120.4 & 3929.2 \\
\hline
\end{tabular}


Table A.10b J-resistance test data for Compact Specimen F33-4-SS-1 tested at $288 \mathrm{C}$ (550 F); English units

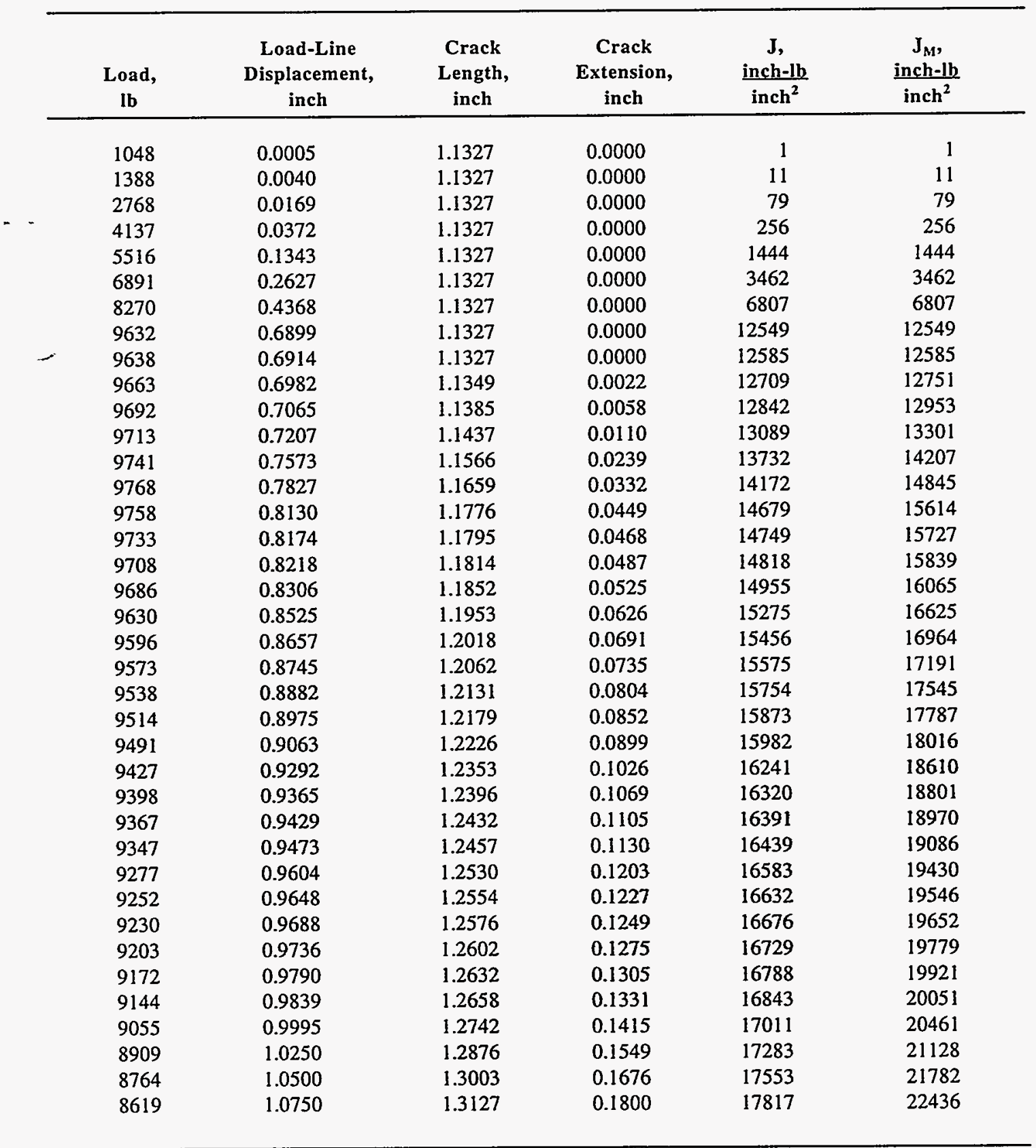


Table A.11a J-resistance test data for Compact Specimen F33-4-SS-2 tested at $288 \mathrm{C}(550 \mathrm{~F})$; SI units

\begin{tabular}{|c|c|c|c|c|c|}
\hline $\begin{array}{c}\text { Load, } \\
\text { kN }\end{array}$ & $\begin{array}{c}\text { Load-Line } \\
\text { Displacement, } \\
\text { mm }\end{array}$ & $\begin{array}{c}\text { Crack } \\
\text { Length, } \\
\text { mm }\end{array}$ & $\begin{array}{c}\text { Crack } \\
\text { Extension, } \\
\text { mm }\end{array}$ & $\underset{k J / m^{2}}{J}$ & $\begin{array}{c}\mathrm{J}_{\mathrm{M}}, \\
\mathrm{kJ} / \mathrm{m}^{2}\end{array}$ \\
\hline 0.89 & 0.04 & 28.53 & 0.0000 & 0. & 0. \\
\hline 8.27 & 0.17 & 28.53 & 0.0000 & 2 & 2 \\
\hline 13.05 & 0.25 & 28.53 & 0.0000 & 6 & 6 \\
\hline 19.29 & 0.81 & 28.53 & 0.0000 & 40 & 40 \\
\hline 25.33 & 3.01 & 28.53 & 0.0000 & 230 & 230 \\
\hline 31.75 & 6.16 & 28.53 & 0.0000 & 578 & 578 \\
\hline 38.00 & 10.33 & 28.53 & 0.0000 & 1140 & 1140 \\
\hline 44.22 & 17.45 & 28.53 & 0.0000 & 2272 & 2272 \\
\hline 44.38 & 18.00 & 28.79 & 0.2580 & 2330 & 2364 \\
\hline 44.40 & 18.09 & 28.85 & 0.3140 & 2339 & 2381 \\
\hline 44.48 & 19.52 & 29.42 & 0.8830 & 2502 & 2627 \\
\hline 44.31 & 19.95 & 29.64 & 1.1100 & 2544 & 2703 \\
\hline 44.15 & 20.41 & 29.93 & 1.3930 & 2580 & 2783 \\
\hline 43.97 & 20.87 & 30.16 & 1.6210 & 2626 & 2865 \\
\hline 43.77 & 21.30 & 30.38 & 1.8480 & 2664 & 2941 \\
\hline 43.56 & 21.65 & 30.61 & 2.0740 & 2690 & 3005 \\
\hline 43.37 & 21.86 & 30.72 & 2.1880 & 2709 & 3043 \\
\hline 43.24 & 21.99 & 30.83 & 2.2990 & 2712 & 3065 \\
\hline 42.99 & 22.21 & 30.95 & 2.4130 & 2733 & 3106 \\
\hline 42.85 & 22.45 & 31.06 & 2.5270 & 2756 & 3149 \\
\hline 42.67 & 22.68 & 31.18 & 2.6420 & 2779 & 3191 \\
\hline 42.46 & 22.92 & 31.34 & 2.8090 & 2791 & 3234 \\
\hline 42.35 & 23.02 & 31.40 & 2.8650 & 2799 & 3252 \\
\hline 42.09 & 23.25 & 31.51 & 2.9790 & 2821 & 3295 \\
\hline 41.96 & 23.36 & 31.57 & 3.0360 & 2831 & 3315 \\
\hline 41.82 & 23.49 & 31.63 & 3.0940 & 2843 & 3338 \\
\hline 41.55 & 23.73 & 31.74 & 3.2080 & 2864 & 3381 \\
\hline 41.42 & 23.84 & 31.80 & 3.2650 & 2874 & 3401 \\
\hline 40.22 & 24.89 & 32.47 & 3.9320 & 2930 & 3586 \\
\hline 40.08 & 25.02 & 32.52 & 3.9890 & 2942 & 3609 \\
\hline 39.95 & 25.13 & 32.58 & 4.0460 & 2951 & 3629 \\
\hline 39.85 & 25.24 & 32.64 & 4.1020 & 2960 & 3649 \\
\hline 39.54 & 25.65 & 32.86 & 4.3260 & 2989 & 3724 \\
\hline 39.33 & 25.91 & 32.97 & 4.4410 & 3012 & 3770 \\
\hline 39.11 & 26.16 & 33.14 & 4.6050 & 3023 & 3816 \\
\hline 38.90 & 26.42 & 33.25 & 4.7190 & 3046 & 3863 \\
\hline 38.68 & 26.67 & 33.37 & 4.8330 & 3068 & 3909 \\
\hline 38.01 & 27.43 & 33.76 & 5.2240 & 3119 & 4047 \\
\hline 37.34 & 28.19 & 34.15 & 5.6130 & 3169 & 4184 \\
\hline 36.44 & 29.21 & 34.65 & 6.1110 & 3234 & 4367 \\
\hline
\end{tabular}


Table A.11b J-resistance test data for Compact Specimen F33-4-SS-2 tested at $288 \mathrm{C}(550 \mathrm{~F})$; English units

\begin{tabular}{|c|c|c|c|c|c|}
\hline $\begin{array}{c}\text { Load, } \\
\text { lb }\end{array}$ & $\begin{array}{c}\text { Load-Line } \\
\text { Displacement, } \\
\text { inch }\end{array}$ & $\begin{array}{l}\text { Crack } \\
\text { Length, } \\
\text { inch }\end{array}$ & $\begin{array}{c}\text { Crack } \\
\text { Extension, } \\
\text { inch }\end{array}$ & $\begin{array}{c}\mathrm{J}, \\
\frac{\text { inch-lb }}{\text { inch }^{2}}\end{array}$ & $\begin{array}{c}\mathbf{J}_{\mathbf{M}}, \\
\text { inch-lb } \\
\text { inch }^{2}\end{array}$ \\
\hline 198 & 0.0015 & 1.1234 & 0.0000 & 0 & 0 \\
\hline 1838 & 0.0066 & 1.1234 & 0.0000 & 13 & 13 \\
\hline 2899 & 0.0099 & 1.1234 & 0.0000 & 33 & 33 \\
\hline 4286 & 0.0317 & 1.1234 & 0.0000 & 230 & 230 \\
\hline 5630 & 0.1184 & 1.1234 & 0.0000 & 1314 & 1314 \\
\hline 7055 & 0.2424 & 1.1234 & 0.0000 & 3298 & 3298 \\
\hline 8444 & 0.4067 & 1.1234 & 0.0000 & 6511 & 6511 \\
\hline 9828 & 0.6870 & 1.1234 & 0.0000 & 12972 & 12972 \\
\hline 9862 & 0.7085 & 1.1336 & 0.0102 & 13301 & 13500 \\
\hline 9867 & 0.7124 & 1.1358 & 0.0124 & 13354 & 13597 \\
\hline 9884 & 0.7686 & 1.1581 & 0.0347 & 14288 & 14999 \\
\hline 9846 & 0.7856 & 1.1671 & 0.0437 & 14523 & 15432 \\
\hline 9811 & 0.8037 & 1.1782 & 0.0548 & 14733 & 15893 \\
\hline 9772 & 0.8218 & 1.1872 & 0.0638 & 14992 & 16361 \\
\hline 9726 & 0.8384 & 1.1962 & 0.0728 & 15209 & 16791 \\
\hline 9681 & 0.8525 & 1.2051 & 0.0817 & 15360 & 17157 \\
\hline 9637 & 0.8608 & 1.2095 & 0.0861 & 15467 & 17375 \\
\hline 9609 & 0.8657 & 1.2139 & 0.0905 & 15486 & 17502 \\
\hline 9554 & 0.8745 & 1.2184 & 0.0950 & 15605 & 17733 \\
\hline 9521 & 0.8838 & 1.2229 & 0.0995 & 15736 & 17978 \\
\hline 9481 & 0.8931 & 1.2274 & 0.1040 & 15865 & 18223 \\
\hline 9436 & 0.9023 & 1.2340 & 0.1106 & 15935 & 18463 \\
\hline 9411 & 0.9063 & 1.2362 & 0.1128 & 15982 & 18569 \\
\hline 9354 & 0.9155 & 1.2407 & 0.1173 & 16106 & 18812 \\
\hline 9325 & 0.9199 & 1.2429 & 0.1195 & 16163 & 18928 \\
\hline 9294 & 0.9248 & 1.2452 & 0.1218 & 16232 & 19058 \\
\hline 9233 & 0.9341 & 1.2497 & 0.1263 & 16355 & 19303 \\
\hline 9204 & 0.9385 & 1.2520 & 0.1286 & 16410 & 19419 \\
\hline 8938 & 0.9800 & 1.2782 & 0.1548 & 16732 & 20477 \\
\hline 8906 & 0.9849 & 1.2805 & 0.1571 & 16797 & 20606 \\
\hline 8878 & 0.9893 & 1.2827 & 0.1593 & 16848 & 20722 \\
\hline 8857 & 0.9937 & 1.2849 & 0.1615 & 16900 & 20838 \\
\hline 8786 & 1.0100 & 1.2937 & 0.1703 & 17067 & 21265 \\
\hline 8739 & 1.0200 & 1.2982 & 0.1748 & 17196 & 21530 \\
\hline 8692 & 1.0300 & 1.3047 & 0.1813 & 17263 & 21792 \\
\hline 8645 & 1.0400 & 1.3092 & 0.1858 & 17390 & 220.57 \\
\hline 8596 & 1.0500 & 1.3137 & 0.1903 & 17516 & 22322 \\
\hline 8446 & 1.0800 & 1.3291 & 0.2057 & 17812 & 23106 \\
\hline 8298 & 1.1100 & 1.3444 & 0.2210 & 18095 & 23891 \\
\hline 8099 & 1.1500 & 1.3640 & 0.2406 & 18468 & 24935 \\
\hline
\end{tabular}


Table A.12a Test data from C(T) Specimen F33-4-SSS-1

(Slant-notch with angle of 55 degrees from specimen face, test at 288 C; SI units)

\begin{tabular}{|c|c|c|c|c|c|c|c|c|}
\hline $\begin{array}{l}\text { Load, } \\
\text { kN }\end{array}$ & $\begin{array}{c}\text { Load-Line } \\
\text { Displacement, } \\
\text { mm }\end{array}$ & $\begin{array}{c}\text { Crack } \\
\text { Length, } \\
\text { mm }\end{array}$ & $\begin{array}{c}\text { Growth, } \\
\text { mm }\end{array}$ & $\begin{array}{l}\mathrm{J}_{\mathrm{nom}}^{(\mathrm{a})} \\
\mathrm{kJ} / \mathrm{m}^{2}\end{array}$ & $\underset{\mathrm{kJ} / \mathrm{m}^{2}}{\mathrm{~J}_{\mathrm{i}}}$ & $\underset{\mathrm{kJ} / \mathrm{m}^{2}}{\mathrm{~J}_{\mathrm{iii}}}$ & $\begin{array}{l}\mathrm{J}_{\left(\alpha^{(b)}\right.}, \\
\mathrm{kJ} / \mathrm{m}^{2}\end{array}$ & $\underset{\mathrm{kJ} / \mathrm{m}^{2}}{\mathbf{J}_{\mathrm{m}}}$ \\
\hline 12.15 & 0.13 & 26.67 & 0.00 & 3.3 & 1.8 & 0.9 & 2.7 & 3.3 \\
\hline 18.90 & 0.38 & 26.67 & 0.00 & 20.0 & 11.0 & 5.4 & 16.4 & 20.0 \\
\hline 23.15 & 1.27 & 26.67 & 0.00 & 99.3 & 54.6 & 26.7 & 81.3 & 99.3 \\
\hline 28.82 & 3.30 & 26.67 & 0.00 & 323.1 & 177.7 & 86.9 & 264.6 & 323.1 \\
\hline 34.49 & 6.10 & 26.67 & 0.00 & 698.1 & 384.0 & 187.8 & 571.7 & 698.1 \\
\hline 39.89 & 10.16 & 26.67 & 0.00 & 1338.8 & 736.3 & 360.1 & 1096.5 & 1338.8 \\
\hline 40.30 & 10.67 & 26.76 & 0.09 & 1417.9 & 779.8 & 381.4 & 1161.3 & 1424.9 \\
\hline 40.50 & 11.18 & 27.01 & 0.34 & 1484.7 & 816.6 & 399.4 & 1216.0 & 1511.4 \\
\hline 40.03 & 12.19 & 27.61 & 0.94 & 1606.7 & 883.7 & 432.2 & 1315.9 & 1684.7 \\
\hline 39.49 & 12.70 & 27.98 & 1.31 & 1660.7 & 913.4 & 446.7 & 1360.1 & 1772.0 \\
\hline 39.01 & 13.21 & 28.34 & 1.67 & 1713.2 & 942.3 & 460.9 & 1403.1 & 1859.3 \\
\hline 38.68 & 14.22 & 29.05 & 2.38 & 1815.0 & 998.3 & 488.2 & 1486.5 & 2033.7 \\
\hline 37.80 & 15.24 & 29.78 & 3.11 & 1910.7 & 1050.9 & 514.0 & 1564.9 & 2209.9 \\
\hline 37.33 & 16.51 & 30.69 & 4.02 & 2024.1 & 1113.3 & 544.5 & 1657.7 & 2431.5 \\
\hline 36.99 & 17.15 & 31.13 & 4.46 & 2082.1 & 1145.2 & 560.1 & 1705.2 & 2546.2 \\
\hline 36.45 & 17.78 & 31.56 & 4.89 & 2139.9 & 1176.9 & 575.6 & 1752.6 & 2661.8 \\
\hline 35.91 & 18.67 & 32.15 & 5.48 & 2218.8 & 1220.3 & 596.9 & 1817.2 & 2823.8 \\
\hline 35.17 & 19.05 & 32.40 & 5.73 & 2252.6 & 1238.9 & 605.9 & 1844.9 & 2894.4 \\
\hline 34.76 & 19.68 & 32.82 & 6.15 & 2304.6 & 1267.5 & 619.9 & 1887.5 & 3010.7 \\
\hline 34.09 & 20.32 & 33.25 & 6.58 & 2354.5 & 1295.0 & 633.4 & 1928.3 & 3127.6 \\
\hline 33.41 & 20.95 & 33.67 & 7.00 & 2402.7 & 1321.5 & 646.3 & 1967.8 & 3244.5 \\
\hline 33.01 & 21.59 & 34.07 & 7.40 & 2450.4 & 1347.7 & 659.2 & 2006.9 & 3361.9 \\
\hline 32.33 & 22.23 & 34.49 & 7.82 & 2495.1 & 1372.3 & 671.2 & 2043.5 & 3479.7 \\
\hline 31.39 & 22.86 & 34.91 & 8.24 & 2533.9 & 1393.6 & 681.6 & 2075.3 & 3596.9 \\
\hline 30.38 & 23.50 & 35.34 & 8.67 & 2568.3 & 1412.6 & 690.9 & 2103.4 & 3712.8 \\
\hline 29.70 & 24.13 & 35.77 & 9.10 & 2599.1 & 1429.5 & 699.2 & 2128.7 & 3828.1 \\
\hline 29.02 & 24.76 & 36.20 & 9.53 & 2627.2 & 1445.0 & 706.7 & 2151.7 & 3943.3 \\
\hline 28.35 & 25.40 & 36.63 & 9.96 & 2651.8 & 1458.5 & 713.3 & 2171.8 & 4058.5 \\
\hline 27.67 & 26.03 & 37.11 & 10.44 & 2662.2 & 1464.2 & 716.1 & 2180.3 & 4172.6 \\
\hline 27.00 & 26.67 & 37.56 & 10.89 & 2676.0 & 1471.8 & 719.8 & 2191.6 & 4287.5 \\
\hline 26.12 & 27.31 & 38.02 & 11.35 & 2684.8 & 1476.6 & 722.2 & 2198.9 & 4402.0 \\
\hline 25.45 & 27.94 & 38.41 & 11.74 & 2708.2 & 1489.5 & 728.5 & 2218.0 & 4518.0 \\
\hline 24.91 & 28.58 & 38.79 & 12.12 & 2732.0 & 1502.6 & 734.9 & 2237.5 & 4634.4 \\
\hline 24.30 & 29.21 & 39.16 & 12.49 & 2755.8 & 1515.7 & 741.3 & 2257.0 & 4751.1 \\
\hline 23.83 & 29.84 & 39.52 & 12.85 & 2778.4 & 1528.1 & 747.4 & 2275.5 & 4868.2 \\
\hline 23.22 & 30.48 & 39.87 & 13.20 & 2800.2 & 1540.1 & 753.3 & 2293.4 & 4985.7 \\
\hline
\end{tabular}

(a) $\mathrm{J}_{\text {nom }}$ uses ASTM E1152 $\mathrm{J}_{\mathrm{D}}$ and ignores the fact that the notch is slanted.

(b) $\mathrm{J}_{\mathrm{tat}}=\mathrm{J}_{\mathrm{i}}+\mathrm{J}_{\mathrm{iij}}$. 
Table A.12b Test data from C(T) Specimen F33-4-SSS-1

(Slant-notch with angle of 55 degrees from specimen face, test at $288 \mathrm{C}$; English units)

\begin{tabular}{|c|c|c|c|c|c|c|c|c|}
\hline $\begin{array}{l}\text { Load, } \\
\text { lb }\end{array}$ & $\begin{array}{c}\text { Load-Line } \\
\text { Displacement, } \\
\text { inch }\end{array}$ & $\begin{array}{c}\text { Crack } \\
\text { Length, } \\
\text { inch }\end{array}$ & $\begin{array}{c}\text { Crack } \\
\text { Growth, } \\
\text { inch }\end{array}$ & $\begin{array}{l}J_{\text {nom }}^{(a)}, \\
\text { lb/inch }\end{array}$ & $\begin{array}{c}\mathrm{J}_{\mathbf{i}}, \\
\mathrm{lb} / \text { inch }\end{array}$ & $\begin{array}{c}\mathrm{J}_{\mathrm{iii}}, \\
\text { lb/inch }\end{array}$ & $\begin{array}{l}\mathrm{J}_{\text {tat }}^{(b)} \\
\mathrm{lb} / \text { inch }\end{array}$ & $\underset{\text { lb/inch }}{\mathbf{J}_{\mathbf{m}}}$ \\
\hline 3792 & 0.0010 & 1.0438 & 0.0000 & 5 & 3 & 1 & 4 & 5 \\
\hline 3971 & 0.0112 & 1.0438 & 0.0000 & 116 & 64 & 31 & 95 & 116 \\
\hline 5309 & 0.0913 & 1.0438 & 0.0000 & 1150 & 633 & 309 & 942 & 1150 \\
\hline 6650 & 0.1987 & 1.0438 & 0.0000 & 2938 & 1616 & 790 & 2406 & 2938 \\
\hline 7946 & 0.3455 & 1.0438 & 0.0000 & 5921 & 3257 & 1593 & 4849 & 5921 \\
\hline 9261 & 0.5713 & 1.0458 & 0.0020 & 11306 & 6218 & 3041 & 9260 & 11330 \\
\hline 9302 & 0.5864 & 1.0513 & 0.0075 & 11606 & 6383 & 3122 & 9505 & 11719 \\
\hline 9312 & 0.5913 & 1.0533 & 0.0095 & 11701 & 6436 & 3148 & 9583 & 11846 \\
\hline 9296 & 0.6587 & 1.0815 & 0.0377 & 12952 & 7124 & 3484 & 10608 & 13588 \\
\hline 9226 & 0.6851 & 1.0951 & 0.0513 & 13388 & 7363 & 3601 & 10965 & 14284 \\
\hline 9075 & 0.7251 & 1.1179 & 0.0741 & 13985 & 7692 & 3762 & 11454 & 15336 \\
\hline 9016 & 0.7388 & 1.1259 & 0.0821 & 14183 & 7801 & 3815 & 11616 & 15701 \\
\hline 8957 & 0.7510 & 1.1335 & 0.0897 & 14347 & 7891 & 3859 & 11750 & 16027 \\
\hline 8883 & 0.7642 & 1.1418 & 0.0980 & 14519 & 7985 & 3906 & 11891 & 16379 \\
\hline 8788 & 0.7783 & 1.1506 & 0.1068 & 14698 & 8084 & 3954 & 12038 & 16754 \\
\hline 8734 & 0.7866 & 1.1557 & 0.1119 & 14808 & 8144 & 3983 & 12128 & 16976 \\
\hline 8673 & 0.7959 & 1.1612 & 0.1174 & 14930 & 8211 & 4016 & 12228 & 17224 \\
\hline 8346 & 0.8462 & 1.1927 & 0.1489 & 15486 & 8517 & 4166 & 12683 & 18524 \\
\hline 8316 & 0.8506 & 1.1957 & 0.1519 & 15529 & 8541 & 4177 & 12718 & 18641 \\
\hline 8254 & 0.8599 & 1.2021 & 0.1583 & 15614 & 8588 & 4200 & 12788 & 18886 \\
\hline 8197 & 0.8687 & 1.2085 & 0.1647 & 15686 & 8627 & 4220 & 12847 & 19118 \\
\hline 8121 & 0.8818 & 1.2183 & 0.1745 & 15782 & 8680 & 4245 & 12925 & 19462 \\
\hline 8055 & 0.8955 & 1.2281 & 0.1843 & 15890 & 8740 & 4274 & 13014 & 19822 \\
\hline 7988 & 0.9097 & 1.2377 & 0.1939 & 16015 & 8808 & 4308 & 13116 & 20197 \\
\hline 7906 & 0.9263 & 1.2469 & 0.2031 & 16212 & 8917 & 4361 & 13278 & 20639 \\
\hline 7784 & 0.9497 & 1.2601 & 0.2163 & 16469 & 9058 & 4430 & 13488 & 21258 \\
\hline 7714 & 0.9629 & 1.2674 & 0.2236 & 16616 & 9139 & 4470 & 13609 & 21609 \\
\hline 7644 & 0.9761 & 1.2747 & 0.2309 & 16760 & 9218 & 4508 & 13726 & 21961 \\
\hline 7573 & 0.9897 & 1.2823 & 0.2385 & 16902 & 9296 & 4547 & 13843 & 22322 \\
\hline 7389 & 1.0250 & 1.3031 & 0.2593 & 17207 & 9464 & 4629 & 14093 & 23244 \\
\hline 7249 & 1.0500 & 1.3178 & 0.2740 & 17412 & 9577 & 4684 & 14260 & 23902 \\
\hline 7104 & 1.0750 & 1.3324 & 0.2886 & 17606 & 9683 & 4736 & 14419 & 24559 \\
\hline 6959 & 1.1000 & 1.3470 & 0.3032 & 17787 & 9783 & 4785 & 14568 & 25214 \\
\hline 6814 & 1.1250 & 1.3614 & 0.3176 & 17959 & 9877 & 4831 & 14708 & 25869 \\
\hline 6669 & 1.1500 & 1.3757 & 0.3319 & 18120 & 9966 & 4874 & 14840 & 26522 \\
\hline 6523 & 1.1750 & 1.3899 & 0.3461 & 18272 & 10050 & 4915 & 14965 & 27173 \\
\hline 6378 & 1.2000 & 1.4040 & 0.3602 & 18412 & 10127 & 4953 & 15079 & 27823 \\
\hline 6173 & 1.2350 & 1.4235 & 0.3797 & 18584 & 10221 & 4999 & 15220 & 28722 \\
\hline
\end{tabular}

(a) $\mathrm{J}_{\text {nom }}$ uses ASTM E1152 $\mathrm{J}_{\mathrm{D}}$ and ignores the fact that the notch is slanted.

(b) $\mathrm{J}_{\mathrm{t \alpha}}=\mathrm{J}_{\mathrm{i}}+\mathrm{J}_{\mathrm{iii}}$. 
Table A.13a Test data from C(T) Specimen F33-4-SSS-2

(Slant-notch with angle of 55 degrees from specimen face, test at 288 C; SI units)

\begin{tabular}{|c|c|c|c|c|c|c|c|c|}
\hline $\begin{array}{c}\text { Load, } \\
\text { kN }\end{array}$ & $\begin{array}{c}\text { Load-Line } \\
\text { Displacement, } \\
\text { mm }\end{array}$ & $\begin{array}{c}\text { Crack } \\
\text { Length, } \\
\text { mm }\end{array}$ & $\begin{array}{c}\text { Growth, } \\
\text { mm }\end{array}$ & $\begin{array}{l}\mathrm{J}_{\mathrm{nom}}^{(2)} \\
\mathrm{kJ} / \mathrm{m}^{2}\end{array}$ & $\underset{\mathrm{kJ} / \mathrm{m}^{2}}{\mathrm{~J}_{\mathrm{j}}}$ & $\begin{array}{c}\mathbf{J}_{\mathrm{iii}}, \\
\mathbf{k} \mathbf{J} / \mathbf{m}^{2}\end{array}$ & $\begin{array}{l}\mathrm{J}_{\mathrm{tok}}^{(\mathrm{b})} \\
\mathrm{kJ} / \mathrm{m}^{2}\end{array}$ & $\underset{\mathrm{kJ} / \mathrm{m}^{2}}{\mathbf{J}_{\mathrm{m}}}$ \\
\hline 17.07 & 0.03 & 26.51 & 0.00 & 0.9 & 0.5 & 0.2 & 0.7 & 0.9 \\
\hline 17.87 & 0.28 & 26.51 & 0.00 & 20.3 & 11.2 & 5.5 & 16.6 & 20.3 \\
\hline 23.89 & 2.32 & 26.51 & 0.00 & 201.5 & 110.8 & 54.2 & 165.0 & 201.5 \\
\hline 29.92 & 5.05 & 26.51 & 0.00 & 514.6 & 283.0 & 138.4 & 421.5 & 514.6 \\
\hline 35.76 & 8.78 & 26.51 & 0.00 & 1036.9 & 570.3 & 278.9 & 849.2 & 1036.9 \\
\hline 41.67 & 14.51 & 26.56 & 0.05 & 1980.0 & 1089.0 & 532.6 & 1621.6 & 1984.3 \\
\hline 41.86 & 14.90 & 26.70 & 0.19 & 2032.7 & 1118.0 & 546.8 & 1664.8 & 2052.3 \\
\hline 41.90 & 15.02 & 26.75 & 0.24 & 2049.1 & 1127.0 & 551.2 & 1678.2 & 2074.5 \\
\hline 41.83 & 16.73 & 27.47 & 0.96 & 2268.3 & 1247.6 & 610.2 & 1857.7 & 2379.7 \\
\hline 41.52 & 17.40 & 27.82 & 1.30 & 2344.7 & 1289.6 & 630.7 & 1920.3 & 2501.7 \\
\hline 40.84 & 18.42 & 28.39 & 1.88 & 2449.2 & 1347.1 & 658.8 & 2005.9 & 2685.8 \\
\hline 40.57 & 18.77 & 28.60 & 2.09 & 2483.9 & 1366.1 & 668.2 & 2034.3 & 2749.8 \\
\hline 40.31 & 19.08 & 28.79 & 2.28 & 2512.6 & 1381.9 & 675.9 & 2057.8 & 2806.8 \\
\hline 39.97 & 19.41 & 29.00 & 2.49 & 2542.8 & 1398.5 & 684.0 & 2082.6 & 2868.4 \\
\hline 39.55 & 19.77 & 29.23 & 2.71 & 2574.2 & 1415.8 & 692.5 & 2108.3 & 2934.2 \\
\hline 39.30 & 19.98 & 29.35 & 2.84 & 2593.3 & 1426.3 & 697.6 & 2123.9 & 2973.0 \\
\hline 39.03 & 20.22 & 29.49 & 2.98 & 2614.6 & 1438.0 & 703.3 & 2141.4 & 3016.4 \\
\hline 37.56 & 21.49 & 30.29 & 3.78 & 2712.0 & 1491.6 & 729.5 & 2221.1 & 3244.2 \\
\hline 37.42 & 21.60 & 30.37 & 3.86 & 2719.6 & 1495.8 & 731.6 & 2227.4 & 3264.6 \\
\hline 37.14 & 21.84 & 30.53 & 4.02 & 2734.6 & 1504.0 & 735.6 & 2239.6 & 3307.6 \\
\hline 36.88 & 22.07 & 30.70 & 4.18 & 2747.1 & 1510.9 & 739.0 & 2249.9 & 3348.2 \\
\hline 36.55 & 22.40 & 30.94 & 4.43 & 2764.0 & 1520.2 & 743.5 & 2263.7 & 3408.3 \\
\hline 36.25 & 22.75 & 31.19 & 4.68 & 2782.8 & 1530.5 & 748.6 & 2279.1 & 3471.5 \\
\hline 35.94 & 23.11 & 31.44 & 4.93 & 2804.8 & 1542.6 & 754.5 & 2297.1 & 3537.2 \\
\hline 35.58 & 23.53 & 31.67 & 5.16 & 2839.2 & 1561.6 & 763.7 & 2325.3 & 3614.5 \\
\hline 35.03 & 24.12 & 32.01 & 5.49 & 2884.3 & 1586.4 & 775.9 & 2362.2 & 3722.9 \\
\hline 34.71 & 24.46 & 32.19 & 5.68 & 2910.0 & 1600.5 & 782.8 & 2383.3 & 3784.5 \\
\hline 34.40 & 24.79 & 32.38 & 5.86 & 2935.3 & 1614.4 & 789.6 & 2404.0 & 3846.0 \\
\hline 34.08 & 25.14 & 32.57 & 6.06 & 2960.1 & 1628.1 & 796.3 & 2424.3 & 3909.3 \\
\hline 33.25 & 26.03 & 33.10 & 6.59 & 3013.5 & 1657.4 & 810.6 & 2468.1 & 4070.8 \\
\hline 32.62 & 26.67 & 33.47 & 6.96 & 3049.3 & 1677.1 & 820.3 & 2497.4 & 4186.0 \\
\hline 31.97 & 27.31 & 33.84 & 7.33 & 3083.3 & 1695.8 & 829.4 & 2525.2 & 4301.0 \\
\hline 31.31 & 27.94 & 34.21 & 7.70 & 3115.0 & 1713.3 & 837.9 & 2551.2 & 4415.8 \\
\hline 30.66 & 28.58 & 34.58 & 8.07 & 3145.1 & 1729.8 & 846.0 & 2575.8 & 4530.4 \\
\hline 30.01 & 29.21 & 34.94 & 8.43 & 3173.4 & 1745.4 & 853.6 & 2599.0 & 4644.8 \\
\hline 29.35 & 29.84 & 35.30 & 8.79 & 3200.0 & 1760.0 & 860.8 & 2620.8 & 4758.9 \\
\hline 28.70 & 30.48 & 35.66 & 9.15 & 3224.6 & 1773.5 & 867.4 & 2640.9 & 4872.8 \\
\hline 27.78 & 31.37 & 36.16 & 9.64 & 3254.6 & 1790.0 & 875.5 & 2665.5 & 5030.1 \\
\hline
\end{tabular}

(a) $J_{\text {nom }}$ uses ASTM E1152 $J_{D}$ and ignores the fact that the notch is slanted.

(b) $\mathrm{J}_{\text {Lot }}=\mathrm{J}_{\mathrm{i}}+\mathrm{J}_{\mathrm{iii}}$. 
Table A.13b Test data from C(T) Specimen F33-4-SSS-2

(Slant-notch with angle of 55 degrees from specimen face, test at 288 C; English units)

\begin{tabular}{|c|c|c|c|c|c|c|c|c|}
\hline $\begin{array}{c}\text { Load, } \\
\text { lb }\end{array}$ & $\begin{array}{c}\text { Load-Line } \\
\text { Displacement, } \\
\text { inch }\end{array}$ & $\begin{array}{c}\text { Crack } \\
\text { Length, } \\
\text { inch }\end{array}$ & $\begin{array}{c}\text { Crack } \\
\text { Growth, } \\
\text { inch }\end{array}$ & $\begin{array}{l}\mathrm{J}_{\text {nom }}^{(2)} \\
\text { lb/inch }\end{array}$ & $\begin{array}{c}\mathbf{J}_{\mathbf{i}}, \\
\text { lb/inch }\end{array}$ & $\begin{array}{c}\mathbf{J}_{\mathrm{iji}}, \\
\mathrm{lb} / \text { inch }\end{array}$ & $\begin{array}{c}\mathrm{J}_{\left(\alpha^{(b)}\right.} \\
\text { lb/inch }\end{array}$ & $\underset{\text { lb/inch }}{\mathbf{J}_{\mathbf{m}}}$ \\
\hline 2700 & 0.0050 & 1.0500 & 0.0000 & 19 & 10 & 5 & 16 & 19 \\
\hline 4200 & 0.0150 & 1.0500 & 0.0000 & 114 & 63 & 31 & 93 & 114 \\
\hline 5145 & 0.0500 & 1.0500 & 0.0000 & 567 & 312 & 153 & 464 & 567 \\
\hline 6405 & 0.1300 & 1.0500 & 0.0000 & 1845 & 1015 & 496 & 1511 & 1845 \\
\hline 7665 & 0.2400 & 1.0500 & 0.0000 & 3986 & 2192 & 1072 & 3265 & 3986 \\
\hline 8865 & 0.4000 & 1.0500 & 0.0000 & 7644 & 4204 & 2056 & 6260 & 7644 \\
\hline 8955 & 0.4200 & 1.0537 & 0.0037 & 8096 & 4453 & 2178 & 6631 & 8136 \\
\hline 9000 & 0.4400 & 1.0635 & 0.0135 & 8478 & 4663 & 2281 & 6943 & 8630 \\
\hline 8895 & 0.4800 & 1.0871 & 0.0371 & 9174 & 5046 & 2468 & 7514 & 9620 \\
\hline 8775 & 0.5000 & 1.1014 & 0.0514 & 9483 & 5216 & 2551 & 7767 & 10118 \\
\hline 8670 & 0.5200 & 1.1158 & 0.0658 & 9782 & 5380 & 2631 & 8011 & 10617 \\
\hline 8595 & 0.5600 & 1.1438 & 0.0938 & 10363 & 5700 & 2788 & 8487 & 11613 \\
\hline 8400 & 0.6000 & 1.1725 & 0.1225 & 10910 & 6000 & 2935 & 8935 & 12618 \\
\hline 8295 & 0.6500 & 1.2081 & 0.1581 & 11557 & 6356 & 3109 & 9465 & 13884 \\
\hline 8220 & 0.6750 & 1.2255 & 0.1755 & 11889 & 6539 & 3198 & 9737 & 14539 \\
\hline 8100 & 0.7000 & 1.2425 & 0.1925 & 12219 & 6720 & 3287 & 10007 & 15199 \\
\hline 7980 & 0.7350 & 1.2658 & 0.2158 & 12669 & 6968 & 3408 & 10376 & 16124 \\
\hline 7815 & 0.7500 & 1.2756 & 0.2256 & 12862 & 7074 & 3460 & 10534 & 16527 \\
\hline 7725 & 0.7750 & 1.2923 & 0.2423 & 13159 & 7237 & 3540 & 10777 & 17191 \\
\hline 7575 & 0.8000 & 1.3090 & 0.2590 & 13444 & 7394 & 3616 & 11011 & 17859 \\
\hline 7425 & 0.8250 & 1.3254 & 0.2754 & 13720 & 7546 & 3691 & 11237 & 18526 \\
\hline 7335 & 0.8500 & 1.3415 & 0.2915 & 13992 & 7696 & 3764 & 11459 & 19197 \\
\hline 7185 & 0.8750 & 1.3578 & 0.3078 & 14247 & 7836 & 3832 & 11668 & 19869 \\
\hline 6975 & 0.9000 & 1.3746 & 0.3246 & 14468 & 7957 & 3892 & 11849 & 20538 \\
\hline 6750 & 0.9250 & 1.3914 & 0.3414 & 14665 & 8066 & 3945 & 12011 & 21200 \\
\hline 6600 & 0.9500 & 1.4083 & 0.3583 & 14841 & 8163 & 3992 & 12155 & 21858 \\
\hline 6450 & 0.9750 & 1.4252 & 0.3752 & 15002 & 8251 & 4036 & 12287 & 22516 \\
\hline 6300 & 1.0000 & 1.4422 & 0.3922 & 15142 & 8328 & 4073 & 12401 & 23174 \\
\hline 6150 & 1.0250 & 1.4610 & 0.4110 & 15201 & 8361 & 4089 & 12450 & 23825 \\
\hline 6000 & 1.0500 & 1.4789 & 0.4289 & 15280 & 8404 & 4110 & 12514 & 24482 \\
\hline 5805 & 1.0750 & 1.4970 & 0.4470 & 15330 & 8432 & 4124 & 12555 & 25136 \\
\hline 5655 & 1.1000 & 1.5123 & 0.4623 & 15464 & 8505 & 4160 & 12665 & 25798 \\
\hline 5535 & 1.1250 & 1.5272 & 0.4772 & 15600 & 8580 & 4196 & 12776 & 26462 \\
\hline 5400 & 1.1500 & 1.5416 & 0.4916 & 15736 & 8655 & 4233 & 12888 & 27129 \\
\hline 5295 & 1.1750 & 1.5559 & 0.5059 & 15865 & 8726 & 4268 & 12993 & 27797 \\
\hline 5160 & 1.2000 & 1.5698 & 0.5198 & 15989 & 8794 & 4301 & 13095 & 28468 \\
\hline
\end{tabular}

(a) $\mathrm{J}_{\text {nom }}$ uses ASTM E1152 $\mathrm{J}_{\mathrm{D}}$ and ignores the fact that the notch is slanted.

(b) $J_{\text {tox }}=J_{i}+J_{i i i}$. 
STAINLESS STEEL SUBMERGED ARC WELD FUSION LINE TOUGHNESS

\section{Battelle}

505 King Avenue

Columbus, Ohio 43201

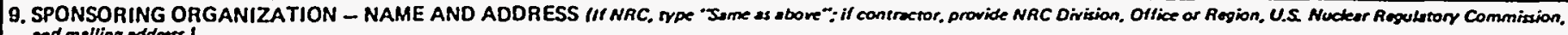
and molling addrexs)

Division of Engineering Technology

Office of Nuclear Regulatory Research

U.S. Nuclear Regulatory Commission

Washington, DC $20555-0001$

10. SUPPLEMENTARY NOTES

11. ABSTRACT $(200$ mants or was)

This effort evaluated the fracture toughness of austenitic steel submerged-arc weld (SAW) fusion lines. The incentive was to explain why cracks grow into the fusion line in many pipe tests conducted with cracks initially centered in SAWs. The concern was that the fusion line may have a lower toughness than the SAW.

It was found that the fusion line, $\mathrm{J}_{\mathrm{Ic}}$ was greater than the SAW toughness but much less than the base metal. Of greater importance may be that the crack growth resistance $\left(J_{D}-R\right)$ of the fusion line appeared to reach a steady-state value, while the SAW had a continually increasing $J_{D}-R$ curve. This explains why the cracks eventually turn to the fusion line in the pipe experiments. A method of incorporating these results would be to use the weld metal $\mathrm{J}-\mathrm{R}$ curve up to the fusion-line steady-state $\mathrm{J}$ value. These results may be more important to LBB analyses than the ASME flaw evaluation procedures, since there is more crack growth with through-wall cracks in LBB analyses than for surface cracks in pipe flaw evaluations.

Fracture, welds, fusion-line, toughness, stainless steel, leakbefore-break, cracks, pipe

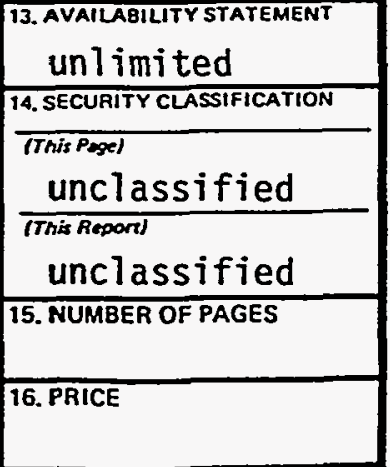

